\title{
Patient characterization protocols for psychophysiological studies of traumatic brain injury and post-TBI psychiatric disorders
}

\section{Paul E. Rapp ${ }^{1}$, Brenna M. Rosenberg ${ }^{1}$, David O. Keyser ${ }^{1}{ }^{*}$, Dominic Nathan ${ }^{1}$, Kevin M. Toruno ${ }^{1}$, Christopher J. Cellucci ${ }^{2}$, Alfonso M. Albano ${ }^{3}$, Scott A. Wylie ${ }^{4}$, Douglas Gibson ${ }^{5}$, Adele M. K. Gilpin ${ }^{6,7}$ and Theodore R. Bashore ${ }^{8}$}

${ }^{1}$ Department of Military and Emergency Medicine, Uniformed Services University, Bethesda, MD, USA

${ }^{2}$ Aquinas, LLC, Berwyn, IL, USA

${ }^{3}$ Physics Department, Bryn Mawr College, Bryn Mawr, PA, USA

${ }^{4}$ Neurology Department, Vanderbilt University, Nashville, TN, USA

${ }^{5}$ Combat Casualty Care Directorate, Army Medical Research and Materiel Command, Fort Detrick, MD, USA

${ }^{6}$ Arnold and Porter, LLP, Washington, DC, USA

7 Department of Epidemiology and Preventive Medicine, University of Maryland, College Park, MD, USA

${ }^{8}$ Psychology Department, University of Northern Colorado, Greeley, CO, USA

\section{Edited by:}

Yun Chen, US Army Medical Research Institute of Chemical Defense, USA

\section{Reviewed by:}

Charles W. Wilkinson, University of

Washington, USA

Firas H. Kobeissy, University of

Florida, USA

Jinhui Chen, Indiana University, USA

*Correspondence:

David O. Keyser, Department of Military and Emergency Medicine,

Uniformed Services University, 4301

Jones Bridge Road, Bethesda, MD

20814, USA

e-mail: david.keyser@usuhs.edu
Psychophysiological investigations of traumatic brain injury (TBI) are being conducted for several reasons, including the objective of learning more about the underlying physiological mechanisms of the pathological processes that can be initiated by a head injury. Additional goals include the development of objective physiologically based measures that can be used to monitor the response to treatment and to identify minimally symptomatic individuals who are at risk of delayed-onset neuropsychiatric disorders following injury. Research programs studying TBI search for relationships between psychophysiological measures, particularly ERP (event-related potential) component properties (e.g., timing, amplitude, scalp distribution), and a participant's clinical condition. Moreover, the complex relationships between brain injury and psychiatric disorders are receiving increased research attention, and ERP technologies are making contributions to this effort. This review has two objectives supporting such research efforts. The first is to review evidence indicating that TBI is a significant risk factor for post-injury neuropsychiatric disorders. The second objective is to introduce ERP researchers who are not familiar with neuropsychiatric assessment to the instruments that are available for characterizing TBI, post-concussion syndrome, and psychiatric disorders. Specific recommendations within this very large literature are made. We have proceeded on the assumption that, as is typically the case in an ERP laboratory, the investigators are not clinically qualified and that they will not have access to participant medical records.

Keywords: cognitive assessment, neuropsychiatric assessment, resilience, sociological assessment

\section{INTRODUCTION}

The assessment of mild TBI presents significant challenges. This is particularly true in those cases where the patient is asymptomatic or minimally symptomatic in the immediate post-injury period and subsequently presents a serious neuropsychiatric disorder. This has motivated the search for physiological variables, including alterations in the properties of ERPs (event-related potentials), which can identify individuals at risk of illness while in the premorbid state.

We wish to outline the specific aims of this contribution. It is not our present purpose to identify a comprehensive assessment procedure for traumatic brain injury (TBI). Such an assessment would include elements of the pre-injury medical history, laboratory results (biomarkers, genomics, neuroendocrine evaluation, markers of inflammation), quantitative electroencephalography, evoked potentials, event-related potentials, electromyography, eye tracking, balance assessments, a neurological examination, a psychiatric interview, and the results of imaging studies. Our purpose is far more limited. Hundreds, if not thousands, of standardized patient self-report instruments have been used in TBI studies. The diversity of instruments used has made it impossible to compare the results of different studies in a statistically meaningful way. Our object was to review the instruments that have been used and evaluate the clinical and statistical evidence that supported their use. Our recommendations, which are principally directed to psychophysiologists who are not necessarily familiar with this material, are based on this review. While this paper is primarily directed to the psychophysiological community, the recommendations may be useful in other types of TBI research such as imaging or biomarker studies. We explicitly recognize that no set of recommendations will be applicable to all studies. Investigators must make choices that will be informed by the study's objects and 
clinical population. It is hoped that these recommendations may be helpful when making study-specific choices.

As part of the effort to construct psychophysiological characterization of TBI, it is necessary to identify relations between experimentally induced factor effects on candidate assessment measures like ERPs and clinically observable manifestations of injury. This is particularly important in longitudinal studies where the ability of ERPs to provide indices of the responses to treatment or the progression of disease is being investigated. Variations in the levels of experimental factors (i.e., independent variables) can produce different effects on two or more dependent measures. A classic example is provided in the McCarthy and Donchin (1) matrix task in which both stimulus discriminability and stimulusresponse compatibility are varied. In the matrix task visual stimuli are presented on a computer. A single trial has two components, a cue word (SAME or OPPOSITE) followed by a matrix containing the word LEFT or RIGHT. Example matrices, Noise or No-Noise, are shown in Figure 1. If the cue word is SAME and the matrix contains the word LEFT, then a left button press is the correct response. If the cue word is OPPOSITE and the word LEFT appears, a right button press is the correct response. Two factors are therefore manipulated, stimulus identification and response selection. The dependent measures were reaction time (RT) and P300 latency. McCarthy and Donchin found that variations in both stimulus discriminability and S-R compatibility influenced RT; RT was prolonged by the appearance of the target word in the noise $(\mathrm{A}-\mathrm{Z})$ matrix and by the need to make an incompatible response. In contrast, P300 latency was influenced only by variations in stimulus discriminability; it was increased when the target word appeared in a noise matrix. However, P300 latency was not altered by variations in compatibility. Thus, the factor effects on RT and P300 latency were dissociated; they were not the same. Dissociations of this type provide the rationale for using a demanding technology like ERPs. They yield information not evident in RT and allow us to fractionate the stimulus input-response output process with greater precision than is afforded by reliance exclusively on response latency.

In the ideal case, the identification of systematic relations between well-delineated clinical symptoms and precisely controlled experimental factor effects would be accomplished by a review of the patient's clinical history in which all medical records obtained in the post-injury period including neuroradiological studies are obtained. In many cases, these records are not available to researchers. In the extreme case, clinical characterization of participants published in some ERP studies of TBI is limited to the simple statement that "participants have a documented history of TBI." The objective of this contribution is to construct a middle path between the ideal case of access to all pertinent medical records on one hand, and the absence of any patient characterization on the other hand. The construction proceeds with two assumptions. First, it is assumed that medical records will not be available to investigators. The only data they will have is what they measure themselves. Second, the assessment will be limited to standardized clinical inventories that can be administered by ERP investigators who are not physicians or licensed psychologists. The selection of neuropsychological tests to be incorporated into a battery for TBI patients

\section{NO NOISE}

\begin{tabular}{|c|c|}
\hline \# \# \# \# \# \# & \# \# \# \# \# \# \\
\hline \# R I GH T & \# \# \# \# \# \# \\
\hline \# \# \# \# \# \# & \# \# L E F T \\
\hline \# \# \# \# \# \# & \# \# \# \# \# \# \\
\hline \multicolumn{2}{|c|}{ NOISE } \\
\hline N R I G H T & Z F G W I \\
\hline K Q P Z M & O R U S N \\
\hline Q C X T K & L E F T P \\
\hline M F G H P & I A L C V \\
\hline
\end{tabular}

FIGURE 1 | Examples of high discriminability (NO NOISE) and low discriminability (NOISE) stimulus matrices used in the McCarthy-Donchin matrix task [modified from McCarthy and Donchin (1)].

is not discussed in this paper. This issue has been addressed by Bagiella et al. (2).

A head injury is an event that may lead to a disease process or processes; it is not a disease (3). Given the lack of diagnostic precision, we propose a purely operational response by recommending that all studies of TBI/PCS [post-concussion syndrome (PCS)] have four participant groups: head injury negative/head injury positive crossed against symptom negative/symptom-positive where, if possible, symptoms are assessed on the day of the ERP study. Even this seemingly robust operationalization will introduce sources of ambiguity because a participant is symptom-positive or asymptomatic depending on the symptoms assessed and on the threshold criteria used to determine symptom presence or absence. Additionally, the symptoms presented following a brain injury are not unique to head injury patients. It is therefore essential to recognize that a Head Injury Negative-Symptom-Positive group should be incorporated into the study. In studies with sufficiently large participant populations, nature of injury (for example, blast versus non-blast injury) and time after injury can also be considered in-group partitioning.

The administration of any inventory requires time. It is impractical to administer all of the inventories and tests that come to mind. We have constructed a prioritized list for studies that reflect an interest in mild TBI that may progress to the presentation of a major psychiatric disorder or clinically significant psychiatric symptoms. Studies with a particular emphasis investigating a specific hypothesis will need to include assessment instruments that speak most directly to the hypothesis. A structured evaluation is therefore suggested. If a brief instrument for a given presentation meets diagnostic threshold, it can be followed with a more detailed examination in that area if this is a focus of the investigation. In cases where we have to make a choice between equivalent or nearly equivalent instruments, we have chosen the assessment instrument 
that has the longest application history and the largest validating population.

\section{ASSESSMENTS RECOMMENDED FOR ALL ERP STUDIES OF TRAUMATIC BRAIN INJURY DEMOGRAPHIC INFORMATION}

It is essential that the demographic characteristics of the participant population be described thoroughly. Demographic information should include conventional elements: age, gender, education, ethnic/racial identification, employment status, family/household status (marriage/partnership/living alone), number of children (in home/not in home), and handedness since there are important relations between handedness and cerebral laterality which may have important implications for the effects of TBI. For participants who are present or prior serving members of the armed forces, we recommend recording duty status (active duty/separated), years in military, service branch/component, highest grade/rank attained, deployments (locations and dates), and duration since separation from service. Because it is well documented that medications can affect quantitative EEGs $(4,5)$, EEG topography and Loreta computations (6) and event-related potentials $(7,8)$, a record of current medications (name of medication, dose, and date initiated) should, therefore, be included in the patient characterization. Some medications used in the past, but not currently used may have prolonged effects on cognition, affect, and EEGs/ERPs. An effort should be made to obtain a record of past medications and the date of medication termination.

\section{COMBAT EXPOSURE}

In studies with active duty military personnel and veterans, an assessment of combat exposure can inform the interpretation of other measures. Keane et al. (9) (Table 10.1) have identified 11 standardized measures of combat exposure. The most commonly used is the seven item Combat Exposure Scale $(10,11)$. For this reason, this instrument is recommended for use in studies where combat exposure is not a central focus of the investigation. For studies where adverse military experiences are a critical interest, the more detailed Deployment Risk and Resilience Inventory should be used (12-15) (additional information can be found at the Department of Veterans Affairs, National Center for PTSD website).

The Deployment Risk and Resilience Inventory uses 104 items to construct 14 scales, two predeployment/prewar scales, 10 deployment/Warzone scales, and two postdeployment/postwar scales. The deployment/Warzone scales are Combat Experiences, Concerns about Life and Family Disruption, Deployment Social Support, Difficulty Living and Working Environment, Exposure to the Aftermath of Battle, General Harassment, Perceived Threat, Self-Report of Nuclear/Biological/Chemical (NBC) Exposures, Sense of Preparedness, and Sexual Harassment.

\section{CATEGORIZATION OF SEVERITY AT THE TIME OF INJURY}

A categorization of severity at the time of injury can be attempted, but as noted above the uncertainties associated with long delayed assessments indicate that these classifications are only an approximation. A search for relations between changes in the characteristics of EEGs/ERPs and post-concussion symptoms determined at the time of testing (described in the next section) is more likely to be scientifically fruitful. Arlinghaus et al. (16) presented a classification of TBI based on the clinical presentation at the time of injury using either the Glasgow Coma Scale (GCS), or the duration of loss of consciousness (LOC) or the duration of post-traumatic amnesia. The VA/DoD TBI Severity Classification (17) is similar to, but not identical to, the Arlinghaus et al. classification. The two classifications differ in the LOC criterion separating moderate and severe injury and in the introduction of an additional criterion (alteration of consciousness/mental state) in the DoD classification (see Table 1).

There is a lack of consensus in the literature. Greenwald et al. (18) and Rao and Lyketsos (19) have the same classification based on the GCS, but have different criteria when classification is based on LOC (see Table 2).

This is not an exhaustive account of TBI/concussion classification systems. Cantu (20) has summarized grading systems by Nelson et al. (21), Ommaya (22), Cantu (23, 24), Colorado Medical Society (25), Jordan et al. (26), Torg (27), Roberts (28), and Kelly and Rosenberg (29). Anderson et al. (30) report that there

Table 1 | Classification of traumatic brain injury severity.

\begin{tabular}{|c|c|c|c|}
\hline Criteria & Mild & Moderate & Severe \\
\hline \multicolumn{4}{|c|}{ ARLINGHAUS ET AL. (16) } \\
\hline Glasgow coma scale & $13-15$ & $9-12$ & $\leq 8$ \\
\hline $\begin{array}{l}\text { Loss of } \\
\text { consciousness }\end{array}$ & $\begin{array}{l}30 \text { min or less } \\
\text { or none }\end{array}$ & $\begin{array}{l}30 \text { min to } \\
1 \text { week }\end{array}$ & $\begin{array}{l}\text { More than } \\
1 \text { week }\end{array}$ \\
\hline $\begin{array}{l}\text { Post-traumatic } \\
\text { amnesia }\end{array}$ & Less than $24 \mathrm{~h}$ & $\begin{array}{l}\text { More than } \\
24 \mathrm{~h} \text { less than } \\
1 \text { week }\end{array}$ & $\begin{array}{l}\text { More than } \\
1 \text { week }\end{array}$ \\
\hline \multicolumn{4}{|l|}{ VA/DoD } \\
\hline Glasgow coma scale & $13-15$ & $9-12$ & $\leq 8$ \\
\hline $\begin{array}{l}\text { Loss of } \\
\text { consciousness }\end{array}$ & $0-30 \mathrm{~min}$ & $30 \mathrm{~min}$ to $24 \mathrm{~h}$ & More than $24 \mathrm{~h}$ \\
\hline $\begin{array}{l}\text { Post-traumatic } \\
\text { amnesia }\end{array}$ & $\begin{array}{l}\text { Less than } 24 \mathrm{~h} \\
\text { or none }\end{array}$ & $\begin{array}{l}\text { More than } \\
24 \mathrm{~h} \text { less than } \\
1 \text { week }\end{array}$ & $\begin{array}{l}\text { More than } \\
1 \text { week }\end{array}$ \\
\hline $\begin{array}{l}\text { Alteration of con- } \\
\text { sciousness/mental } \\
\text { state }\end{array}$ & $\begin{array}{l}\text { A moment up } \\
\text { to } 24 \mathrm{~h}\end{array}$ & $\begin{array}{l}>24 \mathrm{~h} \text {, severity } \\
\text { based on other } \\
\text { criteria }\end{array}$ & $\begin{array}{l}>24 \mathrm{~h} \text {, severity } \\
\text { based on other } \\
\text { criteria }\end{array}$ \\
\hline
\end{tabular}

Table 2 | Comparison of TBI classification criteria.

\begin{tabular}{lll}
\hline Class of injury & Greenwald et al. (18) & Rao and Lyketsos (19) \\
\hline Mild & $\begin{array}{l}\text { Cognitively altered or loss of } \\
\text { consciousness less than } 30 \mathrm{~min}\end{array}$ & $\begin{array}{l}\text { Loss of consciousness } \\
\text { less than } 30 \mathrm{~min}\end{array}$ \\
Moderate & Cognitively altered or loss of & Loss of consciousness \\
& consciousness 30 min to $6 \mathrm{~h}$ & $1-24 \mathrm{~h}$ \\
Severe & Loss of consciousness greater & Loss of consciousness \\
& than $6 \mathrm{~h}$ & more than 24 h
\end{tabular}


are at least 41 different guidelines for grading mild head injury. The Mayo Classification for Traumatic Brain Injury Severity (31) establishes criteria for the categories Symptomatic (Possible), Mild (Probable), and Moderate-Severe. The strength of the Mayo classification lies in its use of multiple indicators. It can be used when a specific single indicator is not available to investigators. In their study sample ( $N=1501$ participants) at least one single measure was not available for a large number of injury events. For example, GCS scores were not available in 74\% of the injury events, loss consciousness data were not available in $70 \%$, post-traumatic amnesia was absent in 58\%, and head CT was not performed in $49 \%$ of the incidents. Using available information, however, all injury events could be classified using this procedure. This system of classification is therefore particularly well suited for retrospective studies. We recommend use of the Mayo Classification for psychophysiological research in non-clinical, civilian research environments. For research with military populations, however, it may be important to relate psychophysiological variables to pre-existing military medical histories. The VA/DoD classification is warranted in these instances. We recommend using either the Mayo or the VA/DoD classification or recording both. We again note that classifications long after the time of injury based on patient report are potentially unreliable and that these assessments should be the last elements in the battery.

\section{CURRENT POST-CONCUSSION SYMPTOMS}

Care should be exercised in the interpretation of symptoms identified using checklists of PCS. For example, Gunstad and Suhr (32) investigated the non-specificity of PCS symptom expectation and concluded that "symptom checklists for 'PCS' may not be useful for diagnosis." Two sets of diagnostic criteria for PCS are available, the ICD-10 criteria for PCS (33), and the DSM-IV criteria for post-concussional disorder (PCD) (34). The ICD-10 criteria require a LOC to meet diagnostic threshold, whereas the DSM-IV criteria require "significant cerebral concussion" as evidenced by LOC, post-traumatic amnesia, or post-traumatic onset of seizures. As McCrea (35) observes, given the restrictiveness of both sets of criteria, most mild TBI patients would be excluded from diagnosis even in the presence of significant post-traumatic symptoms. The problem of selecting which of the two criteria should be used to determine the presence or absence of post-concussion symptoms is revealed by Boake et al. (36). They compared agreement observed against agreement expected by chance between the two diagnoses using the Kappa statistic and found that it was low, a value of 0.13 .

Assessment is obscured further by the fact that post-concussion symptoms are not specific to head injury. Boake et al. (37) found that among patients presenting extracranial trauma, $40 \%$ met the PCS diagnostic criterion and 7\% met the PCD diagnosis criterion, whereas patients with TBI had rates of 64 and $11 \%$ (see Table 3). However, Iverson (38) found that $80 \%$ of non-head injury patients reported three or more post-concussion symptoms while Gouvier et al. (39) found "no significant differences between the brain-damaged individuals and normals on items assessing self-reported memory problems, problems becoming interested in things, frequent loss of temper, irritability fatigue, or impatience."
Table 3 | Comparison of post-concussion symptoms following TBI and extracranial injury Boake et al. (37).

\begin{tabular}{lcc}
\hline & $\begin{array}{c}\text { Meet DSM-IV PCD } \\
\text { symptom criterion }\end{array}$ & $\begin{array}{c}\text { Meet ICD-10 PCS } \\
\text { symptom criterion }\end{array}$ \\
\hline Traumatic brain injury, $N=178$ & $19(11 \%)$ & $114(64 \%)$ \\
Extracranial trauma, $N=104$ & $7(7 \%)$ & $42(40 \%)$ \\
\hline
\end{tabular}

The non-specificity of PCS/PCD symptoms has caused some investigators to question the utility of the diagnosis (3). In a review of the studies cited here and additional work, Smith (40) concluded: "In summary, the so-called symptoms of postconcussional syndrome are notable in that: (1) they are present in a significant number of the normal population, and (2) they are present in very significant numbers of patients who have suffered trauma not involving concussion or brain injury. Therefore, I conclude there is inadequate evidence that these symptoms meet the definition of a 'syndrome'." Professor Smith entitled his letter "Post-concussional symptoms, not a syndrome." We agree. While the validity of the diagnosis is in doubt, the characterization of symptoms remains important in the search for relationships between clinical presentation and CNS electrophysiology. Precisely articulating extant symptoms at the time of testing is important irrespective of their meeting any particular diagnostic criteria.

Our review of the literature suggests that the most viable instrument for assessing current post-concussive symptom is the Rivermead Post-Concussion Symptom Questionnaire [RPQ16, (41)], a 16 item questionnaire that can be self-administered or clinician administered. It assesses the degree of symptom severity on a scale from 0 to $4(0=$ not experienced at all; $1=$ no more of a problem than before injury; $2=$ a mild problem; $3=$ a moderate problem; $4=$ a severe problem). The RPQ16 yields an aggregate score by summing all scores of two or more. The King et al. (41) test-retest reliability study of self administration of the questionnaire resulted in a Spearman correlation coefficient of 0.90 . The inter-rater (inter-clinical) scoring gave a Spearman correlation of 0.87 . Their study also indicated that some symptoms (namely, headaches, dizziness, noise sensitivity, forgetfulness, and poor concentration) were experienced consistently. In contrast, other symptoms were more difficult to identify and had variable expressions. These symptoms included feeling frustrated, feeling depressed, taking longer to think, and restlessness. The authors reasoned that the reliability of the aggregate score indicates that "individual symptoms may substitute for each other over time, but leave the general level of subjective experience unchanged."

In addition to the test-retest reliability of the summed RPQ16, Eyres et al. (42) assessed its internal and external construct validity. They estimated its internal construct validity using the Rasch model (43) and its external construct validity by comparing the summed RPQ16 score with the score on the Rivermead Head Injury Follow-Up Questionnaire (44). Their results indicated that the original 16 item summed RPQ16 score did not meet Rasch internal construct validity criteria, meaning that summing individual responses into a single aggregate score could not be justified. Their analysis did reveal, however, that if three (headache, dizziness, and nausea) of the 16 elements were summed separately, 
then the two resulting scales did meet internal construct validity, the RPQ3 and the RPQ13. Importantly, using the Spearman rank correlation, they estimated the external construct validity of the RPQ13 to be 0.82 , with individual item correlations between 0.52 and 0.71 , and of the RPQ3 to be 0.62 with individual item correlations between 0.40 and 0.60 . The overall test-retest reliability of the RPQ13 was 0.89 with individual item correlations between 0.59 and 0.69 . The overall test-retest reliability of the RPQ3 was 0.72 with individual item correlations between 0.59 and 0.69 . This pattern of results supported their recommendation that the RPQ16 be used as two distinct scales, the RPQ3 and the RPQ13. It is interesting to note the division into two independent scales resulting from statistical analysis conducted by Eyres et al. is consistent with Ryan and Warden's classification of symptom clusters based on clinical observation (45). Ryan and Warden identified two symptom clusters, "early" symptoms that are present immediately after injury and "late" symptoms that appear days and weeks after injury. Early symptoms include drowsiness, headaches, dizziness, and nausea. The late symptoms in the Ryan-Warden classification include irritability, concentration difficulties, memory problems, headaches, fatigue, dizziness, visual disturbances, noise sensitivity, judgment problems, depression, and anxiety.

An alternative subscale structure (somatic, cognitive, emotional) using the 16 elements of the Rivermead Post-Concussion symptom scale has been proposed by Smith-Seemiller et al. (46) (see Table 4). The utility of this set of subscores was indicated by their results which showed that chronic pain patients and mild TBI patients were indistinguishable when characterized using the single summed RPQ16; however, significant between-group differences were observed when the subscales were compared. Mild TBI patient had higher scores on the cognitive subscale than did patients with chronic pain (at $p=0.0005$ ), indicating greater cognitive symptoms in the mild TBI group; whereas patients with chronic pain had higher scores on the affective subscale than did patients with mild TBI (at $p=0.05$ ), indicating greater affective symptoms in the chronic pain group. In contrast, the scores on the somatic subscale for the two groups were indistinguishable. It should be stressed that, as Smith-Seemiller

Table 4 | Rivermead subscales.

\begin{tabular}{ll}
\hline Subscale & Content \\
\hline RPQ3 & Headaches, feelings of dizziness, nausea, and/or vomiting \\
RPQ13 & $\begin{array}{l}\text { Noise sensitivity, sleep disturbance, fatigue, irritability, } \\
\text { depressed affect, feeling of frustration, forgetfulness, } \\
\text { poor concentration, taking longer to think, blurred vision, } \\
\text { light sensitivity, double vision, restlessness }\end{array}$
\end{tabular}

RPQ (cognitive) Forgetfulness, poor concentration, taking longer to think

RPQ Irritability, depressed affect, feeling of frustration,

(emotional) restlessness

RPQ (somatic) Fatigue, headache, dizziness, nausea, and/or vomiting, noise sensitivity, sleep disturbance, blurred vision, double vision, sensitivity to light et al. noted, these between-group differences were found in two patient populations whose subscale scores overlapped considerably. These scores cannot, therefore, accurately classify individual chronic pain and mild TBI patients, a serious deficiency when the goal is diagnostic specificity that guides therapeutic decisions for individual patients. Potter et al. (47) performed a structural equation modeling analysis of the Smith-Seemiller three-factor results. They concluded, as did Eyres et al. that PCS is not a unitary single factor syndrome, but their analysis did support the identification of separate cognitive, emotional, and somatic subscales.

Based on the results of Eyres et al. (42), Potter et al. (47) and more recently Ettenhofer and Barry (48), we conclude that PCS is not a unitary syndrome. This being the case, we recommend administering the Rivermead Post-concussion Questionnaire and reporting both the RP3/RP13 identified by Eyres et al. (42) and the RPQ (Cognitive), RPQ (Emotional), and RPQ (Somatic) identified by Smith-Seemiller et al. (46). The components assigned to each factor are identified in Table 4.

\section{CURRENT POST-CONCUSSION SEVERITY CLASSIFICATION}

It is helpful to characterize a clinical condition in broad categories of minimal, mild, moderate, and severe. The previously described analysis of the Rivermead Post-Concussion Questionnaire indicates that PCS is not a unitary disorder. This suggests that when a severity classification is made by summing 16 individual scores, it must be interpreted with care. It would, at best, be a broad indication of clinical status. Explicitly recognizing this, Potter et al. (47) computed the cumulative frequencies of summed RPQ16 scores from their clinical sample (168 head injury patients where posttraumatic amnesia was less than $24 \mathrm{~h}$, assessed 6 months after sustaining a closed skull head injury). They considered taking 75, 90, 95 limits as cut-off bands to produce the following classification.

Minimal $(<75 \%$ of sample) RPQ $\in 0-12$

Mild (75-90\% of sample) RPQ $\in 13-24$

Moderate (90-95\% of sample) RPQ $\in 25-32$

Severe ( $95 \%$ of sample) RPQ $>33$

A limited qualitative understanding of classification based on these cut scores can be obtained by noting that the RPQ16 score for a non-clinical sample of adults in the general population is 5.8 (49). Potter et al. state that "these bands are provisional and await further research to examine their sensitivity and specificity against general clinical populations, as well as their correspondence to quality of life and general functioning."

\section{ASSESSMENT OF GENERAL HEALTH AT THE TIME OF THE ERP STUDY}

Event-related potentials are a sensitive but non-specific indication of CNS function. They can be altered by a wide variety of medical conditions. The interpretation of ERPs should, therefore, incorporate at least a cursory assessment of the participant's state of health at the time of recording. Health assessments fall into two general categories, disease-specific assessments and generic assessments of health. Consideration here is limited to generic assessments. Of the generic instruments now available, the SF36 (Short Form Health Survey) is the most commonly used and systematically validated $(50,51)$ and is recommended for ERP studies 
of TBI. A qualifying observation should be made. The use of the SF36, or indeed any outcome measure, in a randomized clinical trial raises additional issues (52). The selection of instruments used in randomized clinical trials should follow the COSMIN standards (53). The SF36, a generic measure of perceived health (54-56), yields an eight scale profile of functional health and well-being: physical functioning, role-physical (problems with work or daily activities as a result of physical health), bodily pain, general health, vitality, social functioning, role-emotional (problems with work or daily activities as a result of emotional problems), and mental health. Estimates of internal consistency ( $\alpha$ coefficients) range from 0.62 to 0.94 , with majority of scores equaling or exceeding 0.80 . Test-retest coefficients ranged from 0.43 to 0.90 for a 6 -month interval and from 0.60 to 0.81 for a 2 -week interval.

\section{ASSESSMENT OF PSYCHIATRIC SYMPTOMS AT TIME OF THE ERP STUDY}

The symptom checklist-90-revised $(57,58)$ is a psychiatric instrument which is not specific to a single disorder. The 90 item instrument is self-administered and consists of questions of the form "How much were you disturbed by ....?" The participant responds on a scale of $0=$ Not at All to $4=$ Extremely. The Checklist provides scores on nine dimensions and three global indices (see Table 5).

An extensive literature reporting on the instrument's reliability and validity is summarized in Derogatis (59). Reliability studies resulted in Cronbach $\alpha$ scores for the subscales and global indices between 0.77 and 0.90 . The 1 week test-retest correlations ranged from $r=0.78$ to 0.90 , and the 10 week test-retest correlations ranged from 0.68 to 0.80 . Validity was established by comparisons with the Minnesota Multiphasic Personality Inventory, the Beck Depression Inventory, the Beck Anxiety Inventory, the Montgomery-Asberg Depression Rating Scale, and the Maudsley Obessional Compulsive inventory. Separate norms are available for adolescents as young as 13 years. A sixth grade reading competency is required.

\section{ESTIMATION OF PREMORBID INTELLIGENCE}

It has been argued that an estimate of premorbid intellectual functioning is critical to the interpretation of any post-injury assessment $(60,61)$. This is a matter of particular interest for ERP researchers since there is a prior literature suggesting that there are ERP correlates with intelligence [for example (62-64)]. As summarized by Franzen et al. (65) [see also (66)] there are, broadly speaking, five approaches to estimating premorbid intelligence: (1) historical data, (2) "hold-don't hold" estimates, (3) "best performance" estimates, (4) demographic estimation, and (5) combined methods (demographic and "hold-don't hold" or

Table 5 | Symptom checklist-90-R subscales and global indices.

SCL-90-R Somatization, obsessive-compulsive, interpersonal-

subscales sensitivity, depression, anxiety, hostility, phobic anxiety, paranoid ideation, psychoticism

SCL-90-R Global severity index, positive symptom total, positive global indices symptom distress index "best performance"). Franzen et al. noted that, "Although none of the methods reviewed in this paper are optimal in all situations, any one of them is probably preferable to none at all."

\section{Historical data}

Historical data include information about educational and employment history obtained in clinical interviews with the patient and family members can be used to provide an approximate estimate of premorbid intelligence. Kareken and Williams (67) conducted experiments comparing clinical judgment against a quantitative procedure for estimating an IQ. Clinicians were given demographic information about hypothetical patients and asked to estimate the corresponding IQs. The same information was used in an actuarial equation to compute an IQ estimate. The clinician's estimates were close to the computed estimates. Nonetheless, on reviewing systematic biases that lead to inaccurate clinician estimates of intellectual function, Kareken (68) recommended using quantitative methods. This is especially appropriate for ERP researchers since the clinicians participating in the Kareken and Williams study were highly experienced neuropsychologists.

\section{Hold-don't hold methods}

"Hold-don't hold" methods estimate premorbid functioning by measuring variables that are believed to be spared by the injury or disease, that is a "hold" variable is a component of intellectual functioning that is assumed to retain its premorbid value. The validity of the procedure therefore turns on the validity of this assumption. Word reading tests are a specific implementation a of "hold" estimation procedure. They estimate premorbid intelligence by determining the participant's ability to pronounce words from a standardized reading list. The test is constructed on the assumption that reading is highly correlated with intelligence and that reading ability is resilient against disease and injury (a "hold" variable). It is further assumed that the reading of irregular words is more robust against CNS insult than the reading of regular words (69). Evidence supporting this assumption is summarized presently. Ciplotti and Warrington (70) have noted that the method can be inaccurate if the patient had a specific learning disability prior to injury or if the injury damaged areas specifically important to the process tested, for example left temporal lobe injury. Several variants have been introduced. The National Adult Reading Test [NART, (71)] is appropriate for British participants. The North American Adult Reading Test [NAART, (72)] and the American National Adult Reading Test [AMNART, (73)] were designed for use with North American participants.

\section{Best performance methods}

As typically implemented in a best performance estimation, several tests are administered post-injury and the highest score is used as the estimate of pre-injury ability (61). Scores on other tests are assumed to reflect post-injury deficits if they are $1.5 \mathrm{SD}$ below the highest score. This procedure assumes that there is a single performance level that characterizes an individual's competence across many areas and that the highest score on a given test reflects this overall level (the existence of a general ability factor). This assumption has, however, been challenged (74). Their results indicate that 
the "best performance" method can result in an overestimate of premorbid functioning. In reviewing the Mortensen et al. results, Lezak et al. (61) noted that the Mortensen results were in most instances based on the single highest score obtained by healthy control subjects in the WAIS-A (Wechsler Adult Intelligence Scale) battery of tests. Since the overall score is a weighted average of individual test scores, the highest single score will be expected to give an overestimate of the overall score. Lezak et al. recommended using a cluster of highest scores, though the criterion for selecting that score cluster is not specified.

\section{Demographic methods}

The demographic method can be viewed as a quantitative version of the historical method in which a regression equation uses demographic variables to compute the premorbid IQ $(75,76)$. The best known example is the Barona equation (76) that predicts the WAIS-R IQ using age, sex, race, education, occupation, urban/rural residence, and geographical region. However, there is controversy over the accuracy of the estimate it provides. For example, whereas, Eppinger et al. (77), using the 1984 Barona et al. equation found that the equation overestimates the IQ of normal individuals, Ryan and Prifitera (78) found that the equation under-estimated IQ when IQ was greater than 110, but it was generally reliable in the 90-109 range. A revised formula (79) has improved accuracy for populations composed primarily of Caucasians and African Americans but also shows regression to the mean $[(80,81)$, where Grove's response to Veiel and Koopman, Grove (82), and the counter-response, Veiel and Koopman (83), should also be noted].

\section{Combined methods}

Combined methods use both demographic and current test scores to estimate premorbid IQ. Strictly speaking, the most commonly used implementation of AMNART in IQ estimation is a combined method since it includes one demographic variable (years of education) in its regression equation (73). A more systematic approach was published by Crawford et al. $(84,85)$ who used NART with five demographic variables (age, sex, race, education, occupation). They found that the combined method outperformed NART alone in predicting IQ. Vanderploeg and Schinka (86) used WAIS-R subtests as measures of current ability. No single subtest was specified as the "hold" measure. Rather, 33 regression formulas were constructed using the 11 WAIS-R subtests to estimate Full Scale, Verbal and Performance IQs. Because Vanderploeg and Schinka anticipated using the procedure to estimate premorbid IQ in a TBI population, they did not make a recommendation as to which of the 33 equations should be used with a specific patient. Rather, they indicated that the choice of WAIS-R subtest should be based on the patient's injury. For example, they suggested that the WAIS$\mathrm{R}$ picture completion subtest be used following left hemisphere damage, while the comprehension, information, and vocabulary subtests be considered following right hemisphere damage. In the Oklahoma Premorbid Intelligence estimation (OPIE) procedure, another combined method, Scott et al. (87) used four demographic variables (age, race, education, and occupation). Four predictions of Full Scale IQ were computed for each participant. Three were produced using the WAIS-R Vocabulary score only, the Picture Completion score only, and both the Vocabulary and Picture Completion scores along with the demographic variables. The fourth prediction used the highest WAIS-R. The OPIE procedure was tested with several clinical populations (dementia, TBI, cerebral vascular accident, neoplasm, epilepsy, and chronic pain). Estimates of premorbid IQ did not show systematic under- or over-estimation in any of these populations.

In a comparison study, Axelrod et al. $(88,89)$ computed predicted FSIQ (Full Scale Intelligence Quotient) scores obtained using five methods from a population of 104 neurological patients. The five methods used were:

1. The Barona equation that uses demographic data only (76).

2. BEST-3 (90) that uses demographic information and the best age-scaled score of the WAIS-R Information, Vocabulary, and Picture Completion subtests with the corresponding regression equation of Vanderploeg and Schinka (86).

3. OPIE (91), that uses raw scores from the WAIS-R Vocabulary and Picture Completion subtests and demographic information as did Vanderploeg and Schinka (86).

4. OPIE-2 (91) a variant of the OPIE method that uses the better of the two scores on Vocabulary or Picture Completion subtests if one is specifically impaired along with demographic information.

5. OPIE-R ((92), as described in (88)) provides a quantitatively based criterion for implementing OPIE-2. The Vocabulary score and demographic information are used if the age-scaled Vocabulary score is more than four points greater than the Picture Completion score, and if the picture Completion score is four points greater than the Vocabulary score, it is used with demographic information. If the point spread between the two scores is less than four, both scores and demographic information are used in the Krull et al. (91) equation.

Results obtained with the five methods were compared to the actual FSIQ. Axelrod et al. concluded that BEST-3, OPIE, OPIE2 , and OPIE-R are "equally effective approaches for premorbid estimation.”

Riley and Simmonds (93) studied 26 patients who sustained a severe TBI. They were given the NART within 12 months of injury and again at least 12 months later. If the NART score is acceptable as a "hold" variable in this population, it should be approximately constant with time. Eleven participants (4\% of sample) showed an improvement of more than five IQ points. Three participants showed an improvement of 20 points. This argues against accepting NART as a "hold" variable in the severe TBI population.

Further evidence against a "hold-don't hold" procedure in a TBI population was published by Hoofien et al. (94). They began their investigation by noting that most of the studies used to validate predictions of premorbid intelligence are studies of concurrent validity in which a predictor based on demographic variables and/or current performance is used to estimate current performance in the WAIS-R. They also note that the studies are usually performed with a healthy control population. Hoofien et al. provide a direct test of predictive validity in which current performance and demographic information was used to estimate a premorbid intelligence score in a TBI population. The premorbid 
measure was the Israeli military's Primary Psychometric Rating which is administered at age 18 . This score is highly correlated with WAIS and was used to compute a premorbid IQ. The population $(N=54)$ had sustained a TBI subsequent to this initial testing. Hoofien et al. used two methods to estimate premorbid IQ. The first method, denoted BEST-10, used the best score of 10 of the 11 WAIS subtests and demographic variables with the regression equations published by Vanderploeg and Schinka (86) (10 scales are used because the Hebrew version of WAIS does not include a Vocabulary subtest.). The second method, denoted BEST-2, used the best score of either the Information subtest or the Picture Completion subtest and the same Vanderploeg and Schinka regression equations. BEST-2 therefore differs from BEST-10 in implementing an a priori identification of two "hold" variables. Both procedures used the same demographic variables: age, gender, premorbid occupation, and premorbid education. Following Vanderploeg and Schinka, the premorbid education and premorbid occupation scores were combined to form a single socio-economic status score. The correlations between the estimates of premorbid IQs were 0.583 for BEST-2 and 0.622 for BEST-10. The difference was not statistically significant. The BEST-10 under-estimated IQ by 2.07 points (not significant) and the BEST-2 under-estimated IQ by 5.39 points (statistically significant). In the case of BEST2, 26\% of the participants had an estimated IQ more than 1 SD from the premorbid score. While with BEST-10, $6 \%$ of the patients had an estimated score more than 1 SD from the premorbid score. Hoofien et al. conclude that for this population, a best performance procedure is better than a "hold-don't hold" method.

In contrast, positive evidence for using a "hold-don't hold" procedure to estimate premorbid intelligence in a TBI population has been published by Green et al. (95). In the Green et al. study, 24 participants who had experienced a severe TBI were assessed 2 and 5 months post-injury. Three tests were used to measure premorbid intelligence, the Wechsler Adult Reading Test [WTAR, (96)], the Vocabulary subtest of WAIS-III, and the Matrix Reasoning subtest of WAIS-III. As in the case of AMNART, the WTAR (Wide Range Achievement Test) uses words that have an atypical grapheme to phoneme translation. Three subtest of current ability from the WAIS-III were also administered: symbol digit modalities, similarities, and block design. The scores obtained with tests of current ability improved in a manner consistent with recovery from the TBI. Performance on WTAR was stable and the WTARderived estimate of IQ was similar to the estimate obtained with the 1997 Crawford and Allan demographic equation (460). Green et al. concluded "Thus, converging evidence - high stability during recovery from TBI and similar IQ estimates to those of a demographic equation suggests - that the WTAR is a valid measure of premorbid IQ for TBI. Where word pronunciation tests are indicated (i.e., in patients for whom English is spoken and read fluently), these results endorse the use of WTAR for patients with TBI."

This review of the literature supports the conclusion that the observation of Franzen et al. (65) that no method for estimating premorbid intelligence is optimal in all situations is particularly true in the case of TBI populations. The situation is further complicated by the evolution of intelligence testing. WAIS-III was released in 1997, and WAIS-IV was released in 2008. The scores obtained on these tests are highly correlated with each other and with WAIS-R. This indicates that previous studies of the comparative value of different methods for estimating premorbid intelligence are still valid, but it is necessary to use recomputed regression equations if WAIS-III or WAIS-IV scores are to be used.

For ERP researchers premorbid intelligence estimates based on WAIS-IV and WRAT-4 raise practical difficulties. Administration of these tests requires considerable time. Administration of the complete WAIS battery requires $75 \mathrm{~min}$ (range 60-90 min). In a research study where premorbid intelligence is not a critical measure, this may be an unacceptable participant burden. The WTAR requires $10 \mathrm{~min}$. However, access to the WAIS battery and to WTAR requires clinical licensure, and most ERP researchers are not clinically qualified. Though it is normalized for WAIS-R, AMNART with the Grober and Sliwinski formula continues to be used (97). For ERP studies where assessment of injury-induced cognitive decline is not a primary focus, and in the absence of collaborators with appropriate licensure, we recommend using AMNART with the Grober and Sliwinski formula (73) and both Barona formulas $(76,79)$. Caution must be exercised in the interpretation of the results particularly when the three methods give divergent values. If a licensed collaborator is available, the choice between WAIS and WTAR should be based on an overall assessment of participant burden, with WTAR being the choice that minimizes that burden.

\section{ADDITIONAL ASSESSMENTS RECOMMENDED FOR STUDIES INVESTIGATING TRAUMATIC BRAIN INJURY AND SPECIFIC NEUROPSYCHIATRIC DISORDERS}

The relationships between TBI and neuropsychiatric disorders are receiving increased attention. In those studies where these relationships are a primary focus, it is recommended that the assessment provided by the Symptom Checklist-90-R be confirmed by additional instruments. This concurs with the recommendation of Homaifar et al. (98), who writing specifically about depression following TBI, recommended that multiple means of assessment should be used when diagnosing neuropsychiatric disorders following TBI. Here we consider eight disorders where a substantial body of evidence indicates that a TBI is a significant risk factor for their presentation: depressive illness, post-traumatic stress disorder (PTSD), anxiety, psychotic disorders, sleep disorders, suicidal ideation, alcohol abuse, and substance abuse.

The recommendations presented here follow the diagnostic classifications of the DSM-IV. At present, these diagnostic groups define the assessment criteria that must be satisfied in studies of post-TBI psychopathology. It should be noted, however, that a significant revision of assessment practices may soon be required. The classical discrete disease conceptualization of psychopathology that was modeled on physical medicine is being challenged. As summarized by Smith and Oltmanns (99), "the syndromal approach may need to be jettisoned due to lack of validity." Among others, Smith and Oltmanns have argued for an emerging consensus in which psychopathology is described along continuous, homogeneous dimensions of functioning instead of in discrete categories. This type of dimensional approach has been taken, for example, by Widiger et al. (100) who described a fourdimensional continuum for describing personality disorders and 
by Brown and Barlow (101) who published a dimensional model for describing anxiety and mood disorders. Therefore while the current classifications are observed here, investigators who are looking for changes in the properties of ERPs that may be associated with different types of psychopathology should recognize that the diagnostic structure on which their investigations are based is being challenged and may be discarded. Indeed, if it is found that different alterations in the morphology and timing of ERP components are associated with the different functional dimensions now being proposed $(100,101)$ and not with DSM-IV categories, then ERP evidence may be important in facilitating this transition.

Further cautionary observations should be made. Association, even temporally sequenced association, does not establish causation. The results summarized here indicating that TBI can lead to psychiatric disorders require further development and should be considered suggestive, certainly important, but not definitive. The identification of causal associations between TBI and psychiatric disorders is complicated by case histories that include multiple injury events, which is particularly true in military populations, and in some instances by the delayed onset of psychiatric symptoms. This time delay can be highly variable from patient to patient. Delayed-onset presentations following TBI include depression (102-106, 463), PTSD (106-110), PCS (111-113), and psychosis (114-116).

\section{ASSESSMENT OF DEPRESSION}

In addition to the general considerations concerning psychiatric diagnosis outlined above, problems are encountered when assessing post-injury depression that are specific to depressive illness. Differences in the etiology of post-injury depression can be a significant complication. Depression following TBI can be a psychological response to deficits (117) or a neurologically derived consequence of failures in CNS networks (118). This complex multifactor etiology has resulted in large variation in the reported incidence of depression following TBI. Some of the reasons for which have been summarized by Kim et al. (119). Part of the variability is due to differences in the patient populations being examined. Some studies consider only mild TBI while some include patients with moderate and severe injuries. All too often the criteria for subtyping the severity of a TBI between mild, moderate and severe are not reported explicitly. Moreover, the time interval between injury and assessment can also be a critical factor and goes unreported. It is also important to recognize that acute, transient depression can be an appropriate situational reaction to the injury. However, if the depression persists for several months following the injury then the concern is that it reflects a symptomatic expression of underlying neuropathophysiology. Between-study variability in reported incidence is also due to differences in diagnostic criteria used to diagnose depression. For example, Seel and Kreutzer (120) found a diagnosis of depression in 38\% of their sample with the Beck Depression Inventory and a rate of $30 \%$ in the same sample with the Neurobehavioral Functioning Inventory Depression Scale. The concerns raised by Kim et al. (119) were echoed by Iverson (121) who argued that PCS is often misdiagnosed as depression.

In Table 6 we have listed the incidence of depressive illness following TBI as reported over the past 25 years. Arguably the most
Table 6 | Depressive illness following traumatic brain injury.

\begin{tabular}{ll}
\hline Source & $\begin{array}{l}\text { Reported incidence of depression in } \\
\text { a post-TBI population }\end{array}$ \\
\hline Brooks et al. (372) & $51 \% N=42$ \\
Varney et al. (373) & $77 \% N=120$ \\
Schoenhuber and Gentilini (374) & $39 \% N=35$ \\
Alexander (375) & $25 \% N=36$ \\
Ettlin et al. (376) & $42 \% N=26$ \\
Jorge et al. (103) & $42 \% N=66$ \\
Fann et al. (377) & $26 \% N=50$ \\
Parker and Rosenblum (378) & $36 \% N=33$ \\
Hibbard (124) & $61 \% N=100$ \\
Sliwinski et al. (146) & $25 \% N=100$ \\
Salazar et al. (379) & $34 \% N=120$ \\
Kreutzer et al. (380) & $42 \% N=722$ \\
Silver et al. (237) & $11 \% N=361$ \\
Koponen et al. (266) & $26.7 \% N=60$ \\
Jorge and Robinson (381) & $51.6 \% N=91$ \\
Seel and Kreutzer (120) & $38 \%$ (Beck Depression Index), 30\% \\
& $N F I D e p r e s s i o n$ Scale, $N=172$ \\
Seel et al. (382) & $27 \% N=666$ \\
Rapoport et al. (383) & $15.3 \% N=170$ \\
Ashman et al. (384) & $18.6 \% N=188$ \\
Dikmen et al. (385) & $31 \%$ at 1 month, 17\% 3 to 5years, \\
O'Donnell et al. (386) & $N=283$ \\
Rapoport et al. (387) & $10 \% N=363$ \\
Fann et al. (132) & $15.3 \% N=74$ \\
Rowland et al. (152) & $22.5 \% N=135$ \\
deGuise et al. (123) & $25 \% N=51$ \\
Homaifar et al. (98) & $52 \% N=46$ \\
Wilk et al. (126) & $26.7 \%, 30$ years post-injury, $N=52$ \\
& $53.1 \% N=559$ \\
\hline & $15 \% N=3952$ \\
&
\end{tabular}

interesting aspect of the numbers in the table is their diversity. The patient inclusion criteria of the studies listed in the table differed from study to study. For example, the highest incidences were reported by Bombardier et al. (122) who excluded uncomplicated mild TBI (GCS score from 13 to 15 with no radiological abnormalities) and by deGuise et al. (123), whose patients all presented with severe TBI. Hibbard (124) who found a depression incidence of $61 \%$ did not report injury severity. The post-TBI depression population is very heterogeneous clinically. This point in emphasized by Moldover et al. (125). These authors reviewed the multiple etiological pathways that can result in post-injury depression and emphasized the need for similarly diverse clinical responses. An especially instructive example of the etiological heterogeneity of depression in TBI patients was given by Wilk et al. (126). They compared rates observed in four groups (concussions with/without LOC crossed against blast-induced versus non-blast injury). The following rates of major depression were observed: concussion with LOC following blast $(21.2 \%)$, concussion with LOC following non-blast injury (15.8\%), concussion without LOC following blast-induced injury $(10.2 \%)$, and concussion without LOC following non-blast injury (16.0\%). 
An alternative assessment of the relationship between TBI and depression can be obtained from a lifetime prevalence study. Holsinger et al. (105) found that the lifetime prevalence of major depression among men who had suffered a head injury in World War II was $18.5 \%$ as compared to a rate of $13.4 \%$ for a matched comparison group. However, this is probably an underestimate. Using recently developed epidemiological methods, Kruijshaar et al. (127) controlled for the influence of recall bias when responding to survey questions. They obtained an estimate of a lifetime prevalence of major depression in the general population of $20 \%$ in men and $30 \%$ in women. Though the absolute values obtained by Holsinger et al. may be underestimates, the important observation in the present context is obtained by comparing the results from the two populations.

In summary, although the reported incidence of depressive illness after suffering a head injury varies across a reasonably wide range, the overall pattern points clearly to an increase in the probability of a depressive illness emerging following such an event. Therefore, assessment of depression in the TBI-positive population is of critical importance. Based on an assessment of diagnostic sensitivity and specificity (128), Robinson and Jorge (129) concluded that "the standard DSM-IV-TR criteria are the most logical criteria to use for the diagnosis of major depression in the TBI population." Several standardized self-report inventories for depression that are consistent with DSM-IV criteria are available. We reviewed the Patient Health Questionnaire 9, the Neurobehavioral Functioning Inventory, and the Beck Depression Inventory.

The Patient Health Questionnaire [PHQ, (130)] screens for several common mental disorders and was originally designed for use in primary care. Included within the PHQ is a nine item depression subscale, the PHQ-9, based directly on the diagnostic criteria for major depressive disorder in the DSM-IV. The nine items are presented as a series of questions. For example, "over the past 2 weeks have you been bothered by any of the following problems: little or no interest or pleasure in doing things?" Items are scored by the assignments $0=$ not at all, $1=$ several days, $2=$ more than half the days, $3=$ nearly every day. A global score is computed by summing all individual items scores. In a general medical practice population, the PHQ- 9 was found to have a sensitivity of $88 \%$ and a specificity of $88 \%$ for major depression when a global score of 10 was used as the cut-off score (131). For this population, Kroenke et al. recommended cut-off scores of 5, 10, 15, and 20 for mild, moderate, moderately severe and severe depression.

Fann et al. (132) assessed the validity of the PHQ-9 for diagnosis of major depressive disorder following TBI using the Structured Clinical Interview for Diagnosis [SCID, (133)] as the gold standard for diagnostic comparison. The study population was limited to patients with a GCS score less than or equal to 12 (i.e., moderate to severe injury) or radiological evidence of acute brain abnormality. Fann et al. found that the PHQ-9 had a diagnostic specificity of $93 \%$ and a sensitivity of $89 \%$, a concurrence with the SCID that was anticipated since the nine items in the PHQ-9 cover the "A Criterion" symptoms of depression in the DSM-IV.

An important additional problem encountered in the assessment of depression in a post-TBI population was addressed by Cook et al. (134) using the PHQ-9. Namely, many of the symptoms of TBI and PCS (fatigue, poor concentration, disturbed sleep) are also symptoms of depression. These transdiagnostic symptoms could result in an over-estimate of depression following TBI. Stated operationally, should symptoms common to both TBI and major depressive disorder be dropped from a depression screening instrument or included with a correction factor when used in a post-TBI population? This question has been addressed by Cook et al. using a Differential Item Functioning analysis (135, 136) from Item Response Theory (137). They compared responses to PHQ-9 items obtained from a primary care patient population $(N=3000)$ and from patients presenting complicated mild to severe TBI $(N=365)$ and found that no PHQ-9 item demonstrated significant Differential Item Functioning attributable to TBI. Moreover, a sensitivity analysis did not detect an inflation of PHQ-9 scores due to the cumulative effects of negligible Differential Item Functioning. Cook et al. therefore recommended using all items of the PHQ-9 when assessing depression following TBI.

The Neurobehavioral Functioning Inventory [NFI, (138)] was developed for patients with TBI. Like the PHQ, it is not specific to depression. It assesses six different sets of symptoms: depression, somatic complaints, memory/attention, communication difficulties, aggression, and motor dysfunction. Administration requires approximately $30 \mathrm{~min}$. The depression scale is based on the DSM-IV criteria for depression. Seel and Kreutzer (120) compared the depression scale of the NFI against the Beck Depression Inventory [BDI $(139,140)]$ and the Minnesota Multiphasic Personality Inventory [MMPI-2 $(141,142)]$ in participants who had suffered TBIs with mean duration of unconsciousness of $4.0 \pm 11.5$ days and mean number of days of post-traumatic amnesia of $12 \pm 26.7$ days, one third of whom experienced amnesia for more than 7 days. Thus, most of the TBIs sustained by participants in this study would be classified as moderate to severe. Kreutzer et al. observed a high degree of correlation in the diagnosis of depression between the NFI and both the BDI $(r=0.765)$ and the MMPI-2 $(r=0.752)$.

Unlike the NFI and the PHQ, the BDI $(139,140)$ was developed specifically to assess depression. Administration requires 5-10 min. The maximum possible aggregate score is 63 . When validated with psychiatric populations, the BDI was found to have high test-retest reliability $[r=0.96$ (143)] and high internal consistency $[\alpha=0.92,(144)]$. Moreover, responses on items in the BDI have been found to correlate with those in the SCID at $r=0.83$ and in the Hamilton Psychiatric Rating Scale for Depression at $r=0.71(145,461)$. Importantly, the utility of the BDI in assessing depression following TBI has been studied by several investigators. Sliwinski et al. (146) compared the diagnostic efficacy of the 1987 version of the BDI (147) with the SCID (133) and the Institute of Rehabilitation Research Symptom Checklist [TIRR, (148)], the latter of which covers symptoms related to cognition, somatic complaints, communication problems, and behavioral problems in addition to those related to depression. They found a statistically significant but small correlation $(r=0.30)$ between a SCID diagnosis of depression and the total BDI score, whereas in contrast they found a higher and significantly larger $(r=0.67)$ correlation between the total BDI score and non-depressive symptoms on the TIRR. These differences, as Sliwinski et al. reasoned, suggest that transdiagnostic somatic symptoms common to both depression 
and TBI influence the BDI diagnosis. A Differential Item Functioning analysis was not performed. However, with specificities at 80 and $90 \%$, the respective sensitivities of the BDI were 36 and $20 \%$ for this population. This overall pattern of effects led Sliwinski et al. to conclude that "In fact, current findings call into question the validity of BDI as a tool for detecting clinical depression after TBI."

However, this conclusion was not supported by Green et al. (149) in a study of TBI patients discharged from an in-patient unit who completed the BDI as part of a 24 month follow-up assessment. These investigators were specifically interested in determining the degree to which the presence of somatic symptoms in TBI that are common to depression contribute to inflating the diagnosis of depression among TBI patients when Beck diagnostic criteria are used. A Principal Component Analysis identified three-factors that accounted for most of the variance. Those related, in order of variance explained, to negative cognition and affect, negative attitudes toward self, and somatic disturbances. More patients were classified as depressed using the cognitive/affective score only than using the total BDI score. This finding argues against the conclusion that somatic disturbance items in the Beck inventory lead to an overestimate of depression in a TBI population. Cronbach's alpha was 0.92 indicating excellent internal consistency (150). Green et al. concluded, "This study provides preliminary evidence suggesting that the BDI (Beck Depression Inventory) may be an effective screening tool for self-report depression in TBI."

In addition to Green et al. two other studies have implemented a factor analysis of the BDI in a TBI population. Christensen et al. (151) used the original BDI (147) and found a five-factor structure. Rowland et al. (152) used the BDI-II during the immediate post-injury period. In addition to using the current version of the BDI, this study included a mix of mild/moderate $(49 \%)$ and severe injury (51\%) patients. Rowland et al. identified a threefactor model that was not identical to the Green et al. factorization described above. The Rowland et al. factors are Negative Self Image (20\% of the variance) symptoms of Depression $(18 \%$ of the variance) and Vegetative Symptoms of Depression (12\% of the variance, see Table 7). The factor structure found in the TBI population was not the same as the two-factor structure, Cognitive and Somatic-Affective, found in psychiatric populations (140). They conclude that "it seems reasonable to conclude that these items (which includes a separate factor characterizing Vegetative Symptoms of Depression) are measuring something unique to the TBI sample."

Of fundamental interest to investigations of the influence of TBI on ERP measures of cognitive processing is the relationship between the severity of the injury and the severity of the concomitant depressive symptoms. Various classifications of the severity of depressive illness based on the aggregate score obtained with different instruments have been proposed. Beck et al. (153) have partitioned depressive disorder into the following levels of severity: none or minimal depression (aggregate score less than 10), mild to moderate depression (aggregate score 10-18), moderate to severe depression (aggregate score 19-29), and severe depression (aggregate score 30-63). The appropriateness of applying these cut-off criteria to a post-TBI population was examined systemically by Homaifar et al. (98). Using signal detection theory
Table 7 | Depression subscales in a TBI population based on the Beck depression inventory-II (152).

BDI item

BDI item number

\section{NEGATIVE SELF-EVALUATION}

Punishment feeling

Guilty feelings

5

Self-criticalness

Loss of pleasure

Self-dislike

Loss of interest

Past failure

\section{SYMPTOMS OF DEPRESSION}

Loss of energy

Concentration difficulty

Sadness

Irritability

Worthlessness

Crying

Indecisiveness

Tiredness or fatigue

Pessimism

Suicidal thoughts

\section{VEGETATIVE SYMPTOMS}

Changes in appetite

Loss of interest in sex

Agitation

Changes in sleep pattern

6

8

4

7

12

3

15

19

1

17

14

10

13

20

2

9

they constructed the receiver operating characteristic (ROC) for depression following TBI with the BDI-II as the discriminating metric and the SCID as the diagnostic standard. Optimal diagnostic efficiency ( $87 \%$ sensitivity and $79 \%$ specificity) was obtained with an aggregate Beck score of at least 19 following mild TBI and at least 35 following moderate or severe TBI.

On the basis of the patterns of results reviewed here, our recommendation is that depression following TBI be assessed using the BDI with the Homaifar et al. (98) cutoffs of 19 following mild TBI and 35 following moderate to severe TBI. Subscales based on the Rowland et al. factor analysis (Table 7) can be included in the report in order to explore relationships between different depression factors and post-injury alterations of ERPs.

\section{ASSESSMENT OF POST-TRAUMATIC STRESS DISORDER}

According to the DSM-IV, PTSD can occur in an individual who "has been exposed to a traumatic event in which both of the following were present: (1) The person experienced, witnessed, or was confronted with an event or events that involve actual or threatened death or serious injury, or a threat to the physical integrity of self or others, (2) The person's response involved intense fear, helplessness, or horror." Symptoms vary from patient to patient and can include recurrent and intrusive recollections of the event, recurrent dreams of the event and avoidance of stimuli associated with the event. Additional symptoms can include difficulty falling or staying asleep, irritability or outbursts of anger, difficulty concentrating, hypervigilance, and an exaggerated startle response. In 
the case of women the most frequent precipitating event is rape or physical assault whereas for most men it is a combat-related event (154).

The general observations made at the beginning of Section "Additional Assessments Recommended for Studies Investigating Traumatic Brain Injury and Specific Neuropsychiatric Disorders" concerning the assessment of psychiatric disorders following TBI apply with particular force when considering the assessment of PTSD. After reviewing the prior research on factor analysis of PTSD symptoms, Smith et al. (155) concluded, "There is thus reason to question whether PTSD is best considered to be a theoretically coherent psychological entity. Clearly, identical PTSD symptom counts can refer to different symptom pictures. It may not be in patients' best interests to assign them a diagnosis that lacks clear meaning." Nonetheless, the investigation of PTSD is now the focus of a major research effort.

The assessment recommendations presented in this paper are specifically directed to ERP studies in a TBI-positive population. Therefore, an operational question must be addressed: can PTSD occur as the result of a TBI? In 1996 Boake (160) wrote "Yet the preponderance of available evidence suggests that PTSD is not a major problem in the brain injured population. The traditional view of the relationship between brain injury and PTSD is that these disorders do not co-occur because they are incompatible." Similarly, Bontke (156) reported that "At this point I can only claim to have seen one patient out of 2000 in the last 9 years with the dual diagnosis of PTSD and a mild TBI." Sbordone and Liter (157) examined 28 patients with PCS and 42 with PTSD. The first author interviewed each patient individually for 2-3 $\mathrm{h}$ and asked them to describe their symptoms. In contrast to the patients diagnosed with PTSD, none of the mild TBI patients reported intrusive recollections of the traumatic event, nightmares. hypervigilance, phobic reactions, exaggerated startle reactions, or distress when asked to describe the traumatic event. Sbordone and Liter concluded that mild TBI and PTSD are incompatible.

This conclusion was challenged, however, by Bryant (158) and more recently in Bryant (159) who identified two critical methodological flaws in the Sbordone and Liter study: the interviewer was not blind to the status of each patient and standardized measures of PTSD were not used. Indeed, he directed attention to processes characteristic of PTSD following TBI including "implicit processing, biologically mediated fear conditioning and reconstruction of trauma events," and ended his review by concluding that TBI and PTSD can co-exist. Consistent with Bryant's (158) conclusion, PTSD has been reported in TBI populations (Table 8). Although it has been asserted that PTSD is highly improbable if not impossible in cases of brain injury when the patient does not have a memory of the injury event $(156,160)$, Joseph and Masterson (161) have argued that PTSD and TBI can co-occur either through a subconscious (i.e., implicit) level or through social reconstruction. Gil et al. (162) found that while explicit memory of the traumatizing event was a strong predictor of PTSD 6 months after a mild TBI, it was not an absolute requirement. Of the 55 participants with a memory of the traumatic event, $23 \%$ presented PTSD, while $6 \%$ of the patients who had no memory of the traumatic event met full diagnostic criteria for PTSD.
Table 8 | Incidence of PTSD in a TBI population.

\begin{tabular}{|c|c|}
\hline Source & $\begin{array}{l}\text { Reported incidence of PTSD in a } \\
\text { post-TBI population }\end{array}$ \\
\hline Grigsby and Kaye (388) & $36 \% N=107$ \\
\hline Rattok and Ross (389) & $20 \% N=40$ \\
\hline Ohry et al. (390) & $33 \% N=24$ \\
\hline Max et al. (391) & $4 \% N=46$ \\
\hline Hickling et al. (172) & $36 \% N=107$ \\
\hline Hibbard et al. (124) & $19 \% N=100$ \\
\hline Harvey and Bryant $(392,462)$ & $14 \% N=79$ \\
\hline Bryant et al. (393) & $27 \% N=96$ \\
\hline Mayou et al. (394) & $48 \% N=261$ \\
\hline Glaesser et al. (395) & $\begin{array}{l}27 \% \text { loc less than } 1 \mathrm{~h}, \mathrm{~N}=15,3 \% \text { loc } \\
\text { greater than } 12 \mathrm{~h} N=31\end{array}$ \\
\hline Gil et al. (162) & $14 \% N=120$ \\
\hline Sumpter and McMillan (175) & $\begin{array}{l}N=34,59 \% \text { via PDS, } 44 \% \text { via IES, } 18 \% \text { via } \\
\text { CAPS, } 3 \%(N=1) \text { via CAPS + Clinical } \\
\text { Judgment }\end{array}$ \\
\hline Hoge et al. (163) & $\begin{array}{l}43.9 \% \mathrm{TBI} \text { with loc, } N=124,27.3 \% \mathrm{TBI} \\
\text { with altered mental status, } N=260\end{array}$ \\
\hline Vanderploeg et al. (164) & $\begin{array}{l}\text { Vietnam era veterans, } 32.3 \% \text { at discharge } \\
N=155,46.0 \% \text { PTSD resolved }\end{array}$ \\
\hline Zatzick et al. (165) & $\begin{array}{l}22.7 \% \text { mild TBI, } N=406,18.8 \% \text { moderate } \\
\text { TBI, } N=358,16.8 \% \text { severe TBI, } N=592\end{array}$ \\
\hline Bryant et al. (396) & $12.7 \% N=377$ \\
\hline Wall (397) & Literature review 20 studies, $0.02-26 \%$ \\
\hline Taylor et al. (398) & $\begin{array}{l}73 \%, N=327,388 \text { Veterans using } \mathrm{VHA} \\
\text { services }\end{array}$ \\
\hline Bryan et al. (399) & $32.67 \% N=135$ \\
\hline MacGregor et al. (400) & $\begin{array}{l}26.2 \% \text { mTBI with LOC } N=103,24.0 \% \\
\text { mTBI w/o LOC } N=150\end{array}$ \\
\hline Bazarian et al. (401) & $17 \% N=52$ \\
\hline
\end{tabular}

The more recent literature (163-165) convincingly argues that TBI and PTSD can indeed be comorbid. The question of neurological mechanism has been addressed by Gil et al. (162) who suggested that "One possible mechanism by which these results could be explained is that emotionally charged traumatic memories are initially processed with brain circuits that bypass cortical structures and are mediated primarily through the amygdale, resulting in the formation of implicit (unconscious) memories (166-168). In addition, the stress-induced secretion of glucocorticosteroids, which have been shown to impair hippocampal functioning, may disrupt the formation of explicit memory (169)." Further understanding of the neurological basis of a relationship between PTSD and TBI has been found by MacDonald et al. (170). Using diffusion tensor imaging to examine blast-induced TBI patients, these investigators found abnormalities in cingulum bundles, in right orbitofrontal white matter and in the middle cerebellar peduncles. Asymmetrically altered integrity of the cingulum bundle is associated with PTSD (171) and alteration in the right orbitofrontal cortex has been observed longitudinally in cancer patients who present PTSD. Like Gil et al. Zatzick et al. (165) found that individuals who had suffered a mild to moderate 
Table 9 | Instruments used in the assessment of PTSD.

\begin{tabular}{|c|c|}
\hline Instrument & Reference \\
\hline Clinician administered PTSD scale & Blake et al. $(179,182,183)$ \\
\hline \multicolumn{2}{|l|}{ Subscales: } \\
\hline \multicolumn{2}{|l|}{ Re-experiencing (items 1-5) } \\
\hline \multicolumn{2}{|l|}{ Avoidance (items 6-12) } \\
\hline \multicolumn{2}{|l|}{ Hyperarousal (items 13-17) } \\
\hline Davidson trauma scale (DTS) & Davidson et al. $(402,403)$ \\
\hline \multirow[t]{2}{*}{ Impact of event scale } & Horowitz et al. (177), Weiss and \\
\hline & Marmar (404) \\
\hline M3 checklist & Gaynes et al. (405) \\
\hline $\begin{array}{l}\text { Penn inventory for posttraumatic } \\
\text { stress disorder }\end{array}$ & Hammarberg (406) \\
\hline $\begin{array}{l}\text { Posttraumatic stress disorder } \\
\text { interview-I }\end{array}$ & Watson et al. (407) \\
\hline Posttraumatic diagnostic scale & Foa et al. $(176,408,409)$ \\
\hline Primary care PTSD screen PC-PTSD & Prins et al. (410) \\
\hline $\begin{array}{l}\text { PTSD checklist PCL military, civilian } \\
\text { and specific incident additions }\end{array}$ & $\begin{array}{l}\text { Weathers et al. (187), Blanchard et } \\
\text { al. (190), Bliese et al. (411) }\end{array}$ \\
\hline PTSD inventory & Solomon et al. (412) \\
\hline $\begin{array}{l}\text { PTSD module of the composite } \\
\text { international diagnostic interview }\end{array}$ & Peters et al. (413) \\
\hline $\begin{array}{l}\text { Stanford acute stress reaction } \\
\text { questionnaire SASRO }\end{array}$ & Cardena et al. (414) \\
\hline Trauma screening questionnaire & Brewin et al. (415) \\
\hline $\begin{array}{l}\text { Trauma symptom inventory, three } \\
\text { validity scales (response level, } \\
\text { atypical response, inconsistent }\end{array}$ & Briere (416), Berah (417) \\
\hline Response), 10 clinical subscales & \\
\hline
\end{tabular}

TBI were more likely to experience PTSD than were those who experienced a severe TBI.

All participants in the TBI/PTSD incompatibility debate agree that the assessment of PTSD in a post-TBI population presents formidable challenges, and a large number of diagnostic instruments have been proposed to address these challenges (Table 9). Hickling et al. (172) found that patients with PTSD could be misdiagnosed with TBI, and McMillan (173) found that individuals with TBI could be misdiagnosed with PTSD. These misdiagnoses could have resulted from differences in the diagnostic procedures used. For example, Harvey et al. (174) found that the use of standardized self-report questionnaires (seven different instruments were used in the studies reviewed) resulted in a high incidence of PTSD diagnoses in a post-TBI population while clinical interviews resulted in a low incidence. Similar results were reported in a study by Sumpter and McMillan (175) of 34 patients with severe TBI (post-traumatic amnesia greater than 1 day) whose PTSD symptoms were assessed using two self-report questionnaires, the Post-Traumatic Diagnostic Scale (176) and the Impact of Events Scale ((177) with the (178) cut-off score of 25 as the criterion for PTSD), and a structured clinical interview, the Clinician Administered PTSD Scale (CAPS, (179)). They found that $59 \%$ of the participants met criterion for PTSD using the Post-Traumatic Diagnostic Scale and $49 \%$ of the participants met criterion for PTSD using the Impact of Events Scale. However, very different incidence rates were obtained with the Clinician Administered PTSD Scale (179). In the "with judgment" variant, a symptom is scored if it is present and the administering clinician concludes that the symptom is related to the traumatic event. In the 2005 Sumpter and McMillan study, $18 \%$ of the participants met the CAPS PTSD diagnostic criterion based on symptom presence. If the additional requirement of clinical attribution of a symptom to the traumatic event was introduced, $3 \%(N=1)$ of the sample met the diagnostic criterion. This should be compared with the $59 \%$ value obtained with the Post-Trauma Diagnostic Scale and the $49 \%$ obtained with the Impact of Event Scale with the same patient sample.

In a subsequent paper, Sumpter and McMillan (180) analyzed the sources of diagnostic discrepancy between self-report questionnaires and the clinician administered structured interview. They cited the following possible causes. (1) Post-injury cognitive impairments caused errors in understanding. (2) Recurrent efforts to reconstruct memories lost during peri-trauma amnesia were scored as intrusive thoughts. (3) "Upsetting thoughts" that scored on the PTSD Diagnostic Scale were due to frustrations with post-injury physical limitations and not due to re-experiencing. (4) "Detachment" which scored on the questionnaire was also due, in some instances, to disability-dependent social isolation and not to a psychological consequence of the injury event. Sumpter and McMillan explicitly stated that their results do not indicate that PTSD cannot occur after severe TBI. They also noted that the observed diagnostic discrepancy may not be replicated in a mild TBI population. The results demonstrating the limitations of self-report questionnaires for assessing PTSD after TBI that were reported by Sumpter and McMillan are consistent with the conclusions of Sbordone and Ruff (181) and the recommendation of Bryant (158) who concluded: "Accordingly assessment for PTSD following TBI should not rely excessively on the client's capacity to report relevant symptoms." In the Sumpter and McMillan study, the self-report questionnaires did not, however, produce false negative assessments. Sumpter and McMillan therefore suggest that these questionnaires can be used as a first screen for PTSD following brain injury which is followed by a more demanding clinician administered instrument, for example the CAPS.

The Clinician Administered PTSD Scale CAPS, Blake et al. (179, $182,183)$ is a structured interview containing 17 items scoring DSM criteria for PTSD. Frequency $(0=$ never, $1=$ once a week, $2=$ once or twice a week, $3=$ several times a week, $4=$ daily or almost every day) and intensity $(0=$ none, $1=$ mild, $2=$ moderate, $3=$ severe, $4=$ extreme) are scored for each item. Aggregate scores are produced by adding the frequency and intensity scores. Scores for a single item can therefore range from 0 to 8 , and the aggregate score for the entire assessment can range from 0 to 136 . Using signal detection theory Shalev et al. (184) determined that a CAPS score of 40 yielded $93 \%$ sensitivity and $80 \%$ specificity. The total score can be re-expressed as three subscales: re-experiencing (Items 1 to 5), Avoidance (Items 6-12), and Hyperarousal (Items 13-17). A factor analysis by King et al. (185) identified four correlated but distinct factors: re-experiencing, effortful avoidance, emotional numbing, and hyperarousal. Following Sumpter and McMillan (175), one can generate two CAPS scores, one without judgment (the symptom is present) and one with judgment 
(the symptom is present and is deemed to be a consequence of the traumatic incident). The instrument also provides five global scales: (1) Impact on Social Functioning, (2) Impact on Occupational Function, (3) Global Validity, (4) Global Severity, and (5) Global Improvement.

The National Center for PTSD (United States Department of Veterans Affairs) advises that "the CAPS was designed to be administered by clinicians and clinical researchers who have a working knowledge of PTSD, but can also be administered by appropriately trained paraprofessionals." The CAPS training CD-ROM can be ordered from the National Technical Information Service. The International Association of Trauma Professionals provides certification for administration, scoring, and interpretation of the CAPS. The CAPS-CA (186) is a version of CAPS that is appropriate for children and adolescents.

The PTSD Checklist [PCL, (187)] has three versions. The PCL$\mathrm{M}$ measures responses to stressful military experiences. The PCL-C is directed to civilians and assesses symptoms in relation to generic stressful occurrences, and the PCL-S is used in studies of symptoms relating to a specific stressful experience. There are minimal differences between the three versions. They all have 17 questions scored on a scale of $1=$ "Not at All" to $5=$ "Extremely." A higher score indicates a greater symptom burden. The questions are divided into three groups designated Group B, C, and D. Group B questions (Questions 1-5) assess intrusive thoughts, disturbing dreams, re-experiencing, and physical (autonomic) responses to memory of the stressful experience. Group C questions (Questions 6-12) score avoidance, memory deficits, psychological numbing, and social isolation. Group D questions (Questions 13-17) evaluate sleep, labile affect, and concentration difficulties. Patients will meet DSM-IV diagnostic criteria for PTSD if they have a moderate or severe response (scores 3-5) for at least one Group B question, three or more Group C questions and two or more Group D questions. The National Center for PTSD (188) proposes cut scores of 30-35 for the general population (civilian primary care, Department of Defense screening and general population screening), 36-44 for specialized medical clinics (TBI clinics, pain clinics, VA primary care) and 45-50 for VA or civilian specialty mental health clinics). Monson et al. (189) concluded that when used longitudinally a change of 5-10 points is reliable (that is, it is not due to chance), and a change of 10-20 points is clinically significant.

Several investigators have examined the psychometric properties of the PCL. Blanchard et al. (190) studied motor vehicle accident patients and sexual assault patients and used the CAPS diagnosis as the dispositive metric. They found that a PCL cutoff of 44 had a sensitivity of 0.94 and a specificity of 0.86 . Norris and Hamblen (191) studied Viet Nam era veterans. The internal consistency of the total score was 0.97 . The internal consistency of subscales ranged from 0.92 to 0.93 . The 2 -day test-retest reliability was 0.46 . The correlation with the Mississippi Scale of CombatRelated PTSD was 0.93. The correlation with the PK Scale of the MMPI (Minnesota Multiphasic Personality Inventory) was 0.77, and the correlation with the impact of Events Scale was 0.90. In a study in which a DSM-derived Structured Clinical Interview for Diagnosis was used as the defining metric, the PCL has a sensitivity of 0.82 and a specificity of 0.83 when a PCL score of 50 was used as the cut-off score.
Wilkins et al. (192) reviewed 72 studies using the PCL that were conducted between 1993 and 2010. In summary, they found that the PCL is psychometrically sound. They cite ease of administration as one of its strengths. Two weaknesses were identified. They suggested that the PCL may be above the reading level of some participants. Additionally, they found that the PCL may overestimate the prevalence of PTSD. This observation is consistent with the results of Ruggiero et al. (193). Ruggiero et al. used both the National Women's Study PTSD module (NWS-PTSD) and the PCL to assess 233 New York City area residents 4 months after the $9 / 11$ attacks. In this sample, the prevalence was $1.7 \%$ for the NWS-PTSD and $4.1 \%$ for the PCL.

Administration of the CAPS requires 45-60 min. For this reason, it is not recommended for an initial PTSD screening in studies where PTSD is not the primary focus of the investigation. Administration of the PTSD Checklist requires approximately $5 \mathrm{~min}$. We follow the proposal of McDonald and Calhoun (194) in recommending that the PCL be used as a screening test to be followed with a second-tier diagnostic evaluation. We recommend using the CAPS in this second-tier evaluation with the Shalev et al. cut-off score of 40 .

\section{ASSESSMENT OF ANXIETY}

We consider here anxiety disorders following TBI that do not meet PTSD diagnostic criteria. TBI is a significant risk factor for anxiety disorders. Epstein and Ursano (195) reviewed 11 studies with a total post-TBI clinical population of 1119 and reported an aggregate incidence of $29 \%$. As noted, however, by Hiott and Labbate (196) some of the studies summarized in Epstein and Ursano predate the publication of DSM-III criteria. Interpretation is, therefore, difficult. In a more recent review, Warden and Labbate (197) cited the following incidence of anxiety disorders following TBI: generalized anxiety disorder 8-24\%, panic disorder $2-7 \%$, obsessive-compulsive disorder $1-2 \%$, and specific phobias (especially driving) less than $25 \%$. For the specific diagnosis of generalized anxiety disorder following TBI (see Table 10), Hiott and Labbate reviewed four studies and found a cumulative incidence of $10.2 \%$ (26 of 254). This should be compared against the lifetime prevalence rate of generalized anxiety disorder in the general population of $5.1 \%$ reported by Kessler et al. (198) and approximately $6 \%$ reported by Ritter et al. (199). However, determination of incidence rates is complicated by symptom overlap between disorders and by comorbidities. Jorge et al. (104) found that two-thirds of the post-TBI patients in their sample presenting major depression also met the diagnostic criteria for generalized anxiety disorder.

Table 10 | Incidence of generalized anxiety disorder in a TBI population.

\begin{tabular}{ll}
\hline Source & $\begin{array}{l}\text { Reported incidence of generalized anxiety } \\
\text { disorder in a TBI population }\end{array}$
\end{tabular}

\begin{tabular}{ll}
\hline Jorge et al. (103) & $11 \% N=66$ \\
Fann et al. (377) & $24 \% N=50$ \\
van Reekum et al. (418) & $22 \% N=10$ \\
Hibbard et al. (124) & $9 \% N=100$ \\
Deb et al. (419) & $2.5 \% N=120$
\end{tabular}


Shear et al. (200) discuss several standardized instruments for assessing anxiety disorders. No single instrument has emerged as the preferred choice for studies of TBI-related anxiety disorders Because it has been used in a number of studies of anxiety following TBI (201-203) we recommend the Beck Anxiety Inventory $(204,458)$ for a rapid assessment of general anxiety and mixed anxiety disorders. Instruments for assessing specific anxiety disorders, such as panic disorder, social phobia, obsessive-compulsive disorder, and generalized anxiety disorder, are also described in Shear et al. (200).

\section{ASSESSMENT OF PSYCHOTIC DISORDERS}

Psychotic disorders can follow TBI (205-207), but there is considerable uncertainty about the frequency of post-injury psychosis. Davison and Bagley (208) [as cited by (209)] found the 10- to 20year incidence of psychosis following TBI to be two to three times higher than in the general population. Achte et al. (210) reviewed cases of 3000 combat veterans who had suffered moderate to severe brain injury and found that $750(25 \%)$ of these patients displayed psychotic symptoms. Paranoid schizophrenia and paranoid schizophreniform psychosis developed earlier (23\% within 1 year) than did delusional psychosis (4\%). Delusional psychosis lasted less than a year in $28 \%$ of the cases and more than 5 years in $40 \%$ of the cases. Thomsen (211) followed 40 TBI patients with severe blunt head trauma. Twenty percent $(N=8)$ developed psychotic disorders. Early onset of psychotic symptoms occurred in two patients ( 3 and 5 months post-injury), and six patients presented delayedonset psychosis (1-6 years post-injury). For comparison, Perälä et al. (212). reported lifetime prevalence in a general population to be $0.87 \%$ for schizophrenia, $0.32 \%$ for schizoaffective disorders, $0.07 \%$ for schizophreniform disorder, and $0.18 \%$ for delusional disorder.

The attribution of psychosis to brain injury is complicated not only by the delayed onset of psychotic symptoms (114-116), but also by the lack of uniformity in the occurrence of TBI in the population. Malaspina et al. (213) found that the "rate of TBI was significantly higher for those with a diagnosis of schizophrenia, bipolar disorder, and depression than for those with no mental illness." It therefore seems possible that in some instances brain injuries that evolved to psychosis were sustained by individuals who either had premorbid histories of psychotic disorders or were at increased risk of developing a psychosis prior to the injury. This later speculation is consistent with the finding of Sachdev et al. (116) who found that, along with the duration of LOC, a family history of psychotic illness was the best predictor of psychosis following TBI. An argument for a causative role of TBI in some instances of psychotic illness can nonetheless be made. Wilcox and Nasrallah (214) reviewed medical histories of 200 schizophrenic patients, 203 depressed patients, 122 manic patients, and 134 surgical controls. Histories were examined to determine if there was a history of head injury before the age of 10 (an age well before the appearance of psychotic symptoms) severe enough to require medical attention or a LOC due to head injury. Schizophrenics had a significantly greater frequency of TBI than did depressives, manics or surgical controls Wilcox and Nasrallah argued that because the head injuries occurred before the age of 10, deficits in premorbid functioning did not predispose schizophrenics to head injuries, suggesting that head injury may have a causative role in some presentations of schizophrenia. Arciniegas et al. (205) noted that the age of onset of psychosis following TBI does not follow the typical pattern of 18-25 years for males and 25-30 years for females [citing $(115,116,215)]$. Arciniegas et al. (205) also noted that at least in some instances, symptom types include comorbid seizure disorders and associated cognitive impairments which are not typical in a primary psychotic disorder. This further argues for a role of TBI in the etiology of post-injury psychosis in some patients, support for which is provided in a meta-analysis by Molloy et al. (216) who found a significant association between TBI and schizophrenia. Additionally, estimates they derived from family studies were higher than those from cohort case-control studies by a factor of almost two. Consequently Molloy et al. concluded "this meta-analysis supports an increased risk of schizophrenia following TBI with a larger effect in those with a genetic predisposition to psychosis."

Symptom-Checklist-90-R includes paranoid ideation and psychoticism subscales. For most ERP studies with TBI patients, this will be sufficient for studies that do not have post-TBI psychotic disorders as a primary focus. For research studies where psychotic disorders are a central concern, we recommend the clinician administered Scale for the Assessment of Positive Symptoms [SAPS, (217)] and the Scale for the Assessment of Negative Symptoms [SANS, (218)]. The SAPS has 30 items and four domains covering (1) hallucinations, (2) delusions, (3) bizarre behavior, and (4) positive formal thought disorders (incoherence, distractible speech, clanging). The SANS has 20 items covering five domains: (1) affective flattening or blunting, (2) alogia, (3) avolition-apathy, (4) anhedonia-asociality, and (5) attention. Participant burden is significant. Administration of each scale requires approximately $30 \mathrm{~min}$. It should be noted that clinician training is required in order to achieve reliable ratings.

\section{SLEEP DISORDERS}

In part because of the social acceptability of symptoms associated with sleep disorders, they are among the most frequently endorsed symptoms following TBI (219-221). However, evaluation of a causal role of TBI in disturbed sleep is difficult for several reasons. First, the sleep disorder may be pre-existing. Moreover, quantitative characterization of the epidemiology of sleep disorders in the general population, which provides an essential comparator to the TBI population, is complicated by a lack of uniformity in reporting criteria. For example, Hochstrasser (222) reported a prevalence of sleep disturbance in the general population of $26 \%$ with a $13 \%$ prevalence of moderate to severe disturbance. Ford and Kamerow (223) found that $10 \%$ of the general population endorses symptoms of insomnia, and Rosekind (224) reported 30\%. An additional factor complicates the evaluation of sleep disturbances following TBI. As we previously reviewed, depression is a common sequel to TBI, and as reviewed by Masoodi and Jiva (225), sleep disturbances are a frequent element in depressive illness. This TBIdepression-sleep disorder confound is documented in Fichtenberg et al. (226) who found a significant correlation between insomnia and depression, as documented by the BDI, in a TBI population. It is estimated that $50-80 \%$ of patients with a psychiatric disorder present sleep disturbances that can be attributed to the underlying 
Table 11 | Incidence of sleep disorders in a TBI population.

\begin{tabular}{|c|c|}
\hline Source & $\begin{array}{l}\text { Reported incidence of sleep disorders } \\
\text { in a TBI population }\end{array}$ \\
\hline Dikmen et al. (420) & $40 \% N=20$ \\
\hline Cohen et al. (421) & $\begin{array}{l}73 \% \text { recent injury, } N=22,52 \% \text {. Discharged } \\
\text { patients, } N=77\end{array}$ \\
\hline Beetar et al. (422) & $56 \% N=202$ \\
\hline Perlis et al. (423) & $65 \% N=39$ \\
\hline Clinchot et al. (424) & $50 \% N=130$ \\
\hline Fichtenberg et al. (425) & $30 \% N=50$ \\
\hline Ouellet et al. (426) & $29 \% N=452$ \\
\hline Korinthenberg et al. (427) & $10 \% N=98$ \\
\hline Parcell et al. (428) & $80 \% N=63$ \\
\hline Lundin et al. (429) & $49 \% N=122$ \\
\hline Castriotta et al. (430) & $46 \% N=87$ \\
\hline Makley et al. (431) & $68 \% N=31$ \\
\hline
\end{tabular}

psychiatric disorder. Further, the pattern of sleep disturbances following TBI is highly varied from patient to patient thereby complicating epidemiological study. In Table 11 we have listed the incidence of sleep disorders among TBI patients as reported across several studies.

Instruments for assessing sleep disorders have been reviewed by Benca and Lichstein (227) who began their review by observing that the definitive assessment of sleep disorders requires a polysomnographic study. With this understanding, we recommend the Pittsburgh Sleep Quality Index [PSQI, (228)]. It is the most comprehensive of the available instruments, and it has been validated with TBI patients. The internal consistency of the PSQI is good [Cronbach $\alpha>0.8 ;(228,230,231,459)]$. The test-retest reliability, as quantified by the Pearson linear correlation coefficient is 0.85 for the global score and $0.65-0.84$ for the component scores. The validity of the instrument was assessed by its ability to discriminate between different populations. In the Buysse et al. (228) study, the two groups were good and poor sleepers. Using a global score cutoff of five gave a sensitivity of $89.6 \%$ and a specificity of $86.5 \%$. Backhaus et al. (230) compared healthy controls and insomnia patients. Using the same cut-off score, they observed a sensitivity of $98.7 \%$ and a specificity of $84.4 \%$. Administration of the PSQI requires 5-10 min. It contains 19 self-rated multiple choice questions and four write-in questions (typical bedtime, typical wakeup time, sleep latency, sleep duration). An additional five multiple choice questions are to be answered by a bed partner or roommate. They are not used in scoring. The instrument generates scores for seven component scales. A global score greater than five is deemed to indicate significant dysfunction. There are no cut-off scores for component scales. The seven component scales are Subjective Sleep Quality, Sleep Latency, Sleep Duration, Habitual Sleep Efficiency, Sleep Disturbances, Use of Sleep Medications, and Daytime Dysfunction.

Fichtenberg et al. (232) conducted a validation study of the PSQI in a TBI population. Data taken from sleep diaries and interviews were used to classify 91 consecutive patients admitted to an outpatient neurorehabilitation program as insomnia or non-insomnia based on DSM-IV criteria. Patients taking sleep medications were excluded from the study. Using a PSQI global score of $>8$ as the cutoff, the sample was classified with $93 \%$ sensitivity and $100 \%$ specificity. Classification was also determined using the component scores. The criterion of sleep onset $>30 \mathrm{~min}$ more than twice a week gave an accurate classification for $92 \%$ of the sample. Sleep duration $<6.5 \mathrm{~h}$ more than twice a week had $82 \%$ accuracy, and sleep efficiency (the amount of time asleep divided by the amount of time in bed) $<85 \%$ more than twice a week gave an accurate classification in $74 \%$ of the cases. A further classification was constructed by requiring two or more of the component score criteria described above to be satisfied. This procedure had a sensitivity of $100 \%$ and a specificity of $91 \%$. For purposes of ERP studies it is typically not necessary to make a dichotomous insomnia/non-insomnia distinction. In studies where sleep quality is a measure of interest we recommend reporting both the global score and the seven component scores.

\section{ASSESSMENT OF SUICIDAL IDEATION}

Traumatic brain injury is a risk factor for suicide (233-236), suicide attempts $(237,238)$, and suicidal ideation $(106,239)$. The most exhaustive investigation to date of the relationship between TBI and suicide was conducted by Brenner et al. (240) who studied individuals receiving Veterans Health Administration services between 2001 and 2006. Patients with a history of TBI $(N=49,626)$ were compared with no history of brain injury $(N=389,053)$. Models were adjusted for demographic and psychiatric covariates. Veterans in the TBI-positive group were 1.55 times more likely to die by suicide than veterans in the TBI-negative group. The relationship between TBI and suicide is particularly pressing for the military because of the high incidence of TBI and suicide in the military population. Approximately $64 \%$ of OEF/OIF personnel wounded on active duty are wounded by blast events (241) indicating the presence of a large at-risk population in the military. The increased incidence of TBI in the military coincides with an increase in Army suicide rates from 9 per 100,000 in 2001 to 22 per 100,000 in 2009 (242). This should be compared with a global incidence of 16 per 100,000 per year (243).

Several instruments for assessing suicidal behavior and suicidal ideation are available (244). The Columbia Suicide History Form $(244,245)$ documents previous suicide attempts, and the Suicide Intent Scale (246) assesses the intensity of an attempter's wish to die at the time of the attempt. Neither scale is appropriate for evaluating suicidal ideation in individuals who do not have a history of attempted suicide. The risk of suicide following TBI has been assessed by Léon-Carrion et al. (247) using response Rorschach profiles evaluated with Exner's (248) scoring system to assess the risk of suicide, but this method requires expertise that is not typically available in an ERP laboratory. As an alternative, Tsaousides et al. (249) used the suicide related questions of the Beck Depression Inventory in their study of suicidal ideation following TBI. We suggest that either the BDI or the SCL-90-R, which asks about thoughts of ending life, is adequate for studies where suicide risk is not a major focus. For studies where suicidal ideation is a matter of specific interest, we join with Dennis et al. (250) in recommending the Beck Hopelessness Scale $(251,252)$ that was also used by Simpson and Tate (238) and Simpson et al. (253) in studies of suicide prevention after TBI. 
The Beck Hopelessness Scale (252) consists of 20 true/false questions and can be self-administered or administered verbally by a clinician. A global score from 0 to 20 is formed by summing individual items. Beck and Steer proposed the following classification: 0-3 minimal, 4-8 mild, 9-14 moderate, 15-20 severe. It has good internal consistency, Pearson $r=0.82-0.93$ for different populations and test-retest reliability at 1 week of $r=0.69$, and at 6 weeks of $r=0.66$ (252). Moreover, the validity of the measure was assessed by comparing the Beck Hopelessness Scale with measures of depression $(252,254)$. Nekanda-Trepka et al. (254) found that the Hopelessness Score was positively correlated with the aggregate BDI score $(r=0.47, p=0.001)$. In a prospective study of 1958 psychiatric outpatients, Beck et al. (255) found that individuals with a global score of greater than or equal to 9 were 11 times more likely to commit suicide than those with a lower score. This cut-off score identified 16 of the 17 individuals in the sample who committed suicide. It should be noted, however, that because the incidence of completed suicide is low, this criterion yields a high incidence of false positive evaluations, 59.0\%. Keller and Wolfersdorf (256) followed 61 depressed patients for 1 year. During this period there were eight suicide attempts and two completed suicides. A cut-off score of eight on the Hopelessness Scale successfully identified $90 \%$ of the suicidal actions. These investigators also found a high incidence of false positives.

\section{ASSESSMENT OF ALCOHOL ABUSE}

The association between alcohol and TBI is a complicated one because alcohol use is often a causative factor in civilian brain injury. Kraus et al. (257) found that $56 \%$ of adult civilians with a brain injury had a positive blood alcohol concentration at the time of injury, of whom $49 \%$ had a blood alcohol concentration in excess of the legal limit. Similarly, Sparedo and Gill (258) found that $67 \%$ of TBI patients tested positive for alcohol and $51 \%$ were intoxicated when the injury occurred. That these levels may be associated with pre-injury alcohol abuse is suggested by Kreutzer et al. (259) who reported a high incidence of heavy alcohol consumption both before and after injury. That a history of alcohol use or abuse is strongly associated with a higher risk of suffering a TBI is suggested by Hillbom and Holm (260) who found that the overall incidence of head injury in alcoholics is two to four times the incidence in the general population. Using the Quantity-Frequency-Variability Index $(261,262)$ to characterize alcohol consumption, Horner et al. (263) found that at 1 year post-injury $15.4 \%$ of the TBI sample were heavy drinkers and $14.3 \%$ were moderate drinkers. Bombardier et al. (264) found that drinking decreased following injury, but approximately $25 \%$ of their sample reported heavy drinking 1 year post-injury. Ponsford et al. (265) found that pre-injury TBI and appropriately matched control populations showed similar alcohol consumption. In the pre-injury TBI group, $31.4 \%$ used alcohol at a hazardous level, and $29.3 \%$ of the controls used alcohol at a hazardous level (In this study hazardous use was defined as a score greater or equal to eight on the Alcohol Use Disorder Identification Test. This instrument is discussed presently.). As did Bombardier et al. Ponsford et al. found that alcohol abuse declined post-injury, but it subsequently increased with $25.4 \%$ of the TBI group drinking at hazardous levels
2 years post-injury. In a 30-year follow-up study using DSM-IV criteria for alcohol dependence and alcohol abuse, Koponen et al. (266) found that $11.7 \%$ of their sample either abused alcohol or were alcohol dependent. This sample had a pre-injury prevalence of $8.3 \%$.

Alcohol use following head injury is higher than in the general population. In part this is to be expected since alcohol misuse may have been present prior to injury, but post-injury factors are also important. Reilly et al. (267) identified four psychosocial factors that increase the risk of alcohol abuse after TBI: (1) increased discretionary time and boredom, (2) increased enabling from family and friends, (3) uncertainty over the ability to return to work or to function effectively at work, and (4) physical limitations and post-traumatic mood change. Horner et al. (263) found six risk factors for heavy drinking following TBI: (1) gender, (2) young age, (3) history of abuse prior to TBI, (4) diagnosis of depression since TBI, (5) fair/moderate mental health, and (6) better physical functioning. Recidivism following completion of alcohol rehabilitation is high in the post-TBI population. Sparedo and Gill (258) found that 54\% of patients who completed alcohol rehabilitation returned to alcohol. Of the remaining $46 \%$, post-injury seizure disorders or placement into long-term supervised living were significant factors in maintaining abstinence.

Martino et al. (268) listed 14 instruments for assessing alcohol abuse and for planning and monitoring treatment for alcohol abuse. Of these, we recommend the Alcohol Use Disorders Identification Test [AUDIT (269)]. Martino et al. cited AUDIT's slightly better psychometric performance as quantified by internal consistency, test-retest reliability, and validity. In a review of 13 psychometric studies of AUDIT, Reinert and Allen (270) concluded that AUDIT is comparable and typically superior to other self-report screening measures. AUDIT measures a continuum of alcohol use and has proven to be of value in characterizing this continuum. It may therefore be useful in identifying clinically significant alcohol misuse at an early stage of drinking before it has reached the level of alcohol dependence.

AUDIT consists of 10 questions scored from $0=$ "never" to $4=$ "daily or almost daily." A global score is obtained by summing the scores of individual test items. Babor et al. (269) indicate that for men less than 65 years old, a score greater than or equal to eight indicates hazardous and harmful alcohol use. For men over 65 and all women, they recommend a cut-off score for hazardous use of seven. A score greater than or equal to 20 "clearly warrants further diagnostic evaluations for alcohol consumption." The instrument has a high internal consistency $(271,272)$. AUDIT is also consistent with other instruments that assess alcohol use. Bohn et al. (273) found a correlation between AUDIT and the Michigan Alcohol Screening Test [MAST, (274)] of $=0.88$. The correlation with the four question CAGE Questionnaire (275) is $r=0.78$ (272). The instrument has also been shown to be a valid indicator of alcohol impact on global life functioning. Claussen and Aasland (276) found that the probability of being unemployed over a 2 year period was 1.6 times higher for individuals with an AUDIT score greater than or equal to eight. Conigrave et al. (277) found that AUDIT scores predict future occurrences of physical disorders. The AUDIT score is not affected by question 
ordering or the wording of questions (278). Several groups have investigated the test-retest reliability of AUDIT reporting values of $r=0.92$ ((279), university students, 2 week interval), $r=0.81$ (280) (primary care patients, 6 week interval), and $r=0.64$ (281) (primary care patients selected for alcohol treatment, 2 week interval). Further results of validity and reliability testing of AUDIT are given in Reinert and Allen (270).

\section{SUBSTANCE ABUSE}

Most of the literature examining the relationship between substance abuse and TBI limits the discussion to alcohol. The literature that is available does, however, establish that as in the case of alcohol, the use of illicit drugs is a risk factor for sustaining TBI, and a history of pre-injury substance abuse is correlated with increased disability, delayed recovery, and poor outcome [reviewed in (282-285)]. Based on a review of the literature, Graham and Cardon reported that substance abuse rates decline following TBI, including mild TBI. Based on our non-systematic review of the literature, we concluded that the use of illicit drugs following TBI in individuals who did not have prior history of drug use is unusual.

We recommend the Drug Abuse Screening Test [DAST, (286)] for assessing drug abuse or dependence on psychoactive drugs other than alcohol. The DAST can be self-administered or administered in an interview by a clinician. It consists of a series of yes/no questions with zero being scored for no and one being scored for yes. A global score is constructed by summing the responses to individual items. There are two versions, 20 question and 28 questions. A global score greater or equal to five obtained with the 28 question version indicates that a drug disorder is probable. The instrument is consistent having a Cronbach $\alpha$ of 0.92 for individuals with a substance abuse disorder and of 0.94 for general psychiatric admissions (286). Using a DSM-III-R diagnosis by a psychiatrist as the reference standard, Gavin et al. (287) found that a cut-off score of 5 had a sensitivity of 0.96 and a specificity of 0.79 .

\section{COGNITIVE ASSESSMENTS EXECUTIVE FUNCTION}

Executive functions are broadly defined as the integrative and organizing functions of cognition. In the Cicerone et al. (288) characterization, executive functions can be categorized into four domains: executive cognitive functions (planning and organization), behavioral self-regulation functions (emotional processing, understanding the consequences of behavior), activation regulating functions (decreased initiation), and metacognitive processes (self-awareness). All or some of these functions can be impaired following brain injury. Malloy and Grace (289) reviewed five instruments for assessing executive function: the Behavior Rating Inventory of Executive function [BRIEF, (290)], the Dysexecutive Questionnaire [DEX, (291)], the Frontal Behavioral Inventory [FBI, (292)], the Frontal Systems Behavior Scale [FrSBe (293, 294)], and the Iowa Rating Scales of Personality Change [IRSPC, (295)]. Of these, Malloy and Grace note that the BRIEF and the FrSBe have good reliability and large scale norms. The BRIEF, however, is a measure for pediatric populations and normative data are only available for children up to 18 years old. The FrSBe has normative data for 18-95 years. A further argument for using the FrSBe in studies of TBI is provided by Reid-Arndt et al. (296) who found that while neuropsychological tests of executive function did not help predict post-injury community integration, the FrSBe did predict important functional outcomes. Additionally, the Apathy Subscale of the FrSBe (described below) was investigated by Lane-Brown and Tate (297) who found that it was a reliable and valid measure of apathy following TBI. Therefore, we recommend using the FrSBe in ERP studies of TBI where executive function is topic of interest.

The Frontal System Behavior Scale (293) is a 46 item questionnaire with each item score on a scale of 1, "Almost Never" to 5 "Almost Always." A high score indicates greater disability. It is composed of three subscales. Subscale A, 14 items, assesses apathy, and akinesia (anterior cingulate). Subscale D contains 15 items and evaluates disinhibition and emotional dysregulation (orbital frontal cortex). Scale E, 16 items, evaluates deficits in executive function (dorsolateral prefrontal cortex).

\section{COGNITIVE INSIGHT}

Insight is a word of many meanings. We have considered two distinct capabilities, cognitive insight (an assessment of the patient's self-understanding) and (ii) the ability to form novel insightdependent associations. Both can be significantly impaired following a TBI. At present there are no procedures for constructing premorbid estimates of these measures. In the absence of pre-injury measurement, their use will be limited to post-injury longitudinal assessments. Their utility in this regard should not, however, be under-estimated.

Several instruments for evaluating insight [see Ref. (229)] have been published. These are directed to evaluating insight in psychotic patients. The Beck Cognitive Insight Scale [BCIS, (229)] serves that function but is more broadly constructed and is applicable to other populations. It is therefore recommended for use in TBI studies. The instrument assesses self-reflectiveness about unusual experiences, the capacity to correct erroneous judgments and certainty about mistaken judgments. It is self-administered and contains 15 items that are scored on a four-point scale with $0=$ "Do Not Agree at All" to 3 = "Agree Completely." There are two subscales. The self-reflectiveness scale has nine items and evaluates objectivity, reflectiveness, and openness to feedback. The self-certainty subscale has six items and assesses certainty about beliefs and conclusions. A cognitive insight score is calculated by subtracting the aggregate self-certainty score from the aggregate self-reflectiveness score. Factor analysis indicated that the two subscales are minimally correlated. Internal consistency was indicated by $\alpha$ scores of 0.68 (self-reflectiveness) and 0.60 (self-certainty). Beck et al. acknowledge that these values are less than the 0.7 value recommended by Nunnally (298) but note that the prior literature $(299,300)$ indicates that these values are acceptable for research purposes. Construct validity for inpatients diagnosed with schizophrenia or schizoaffective disorders was indicated by comparisons with the Scale to Assess Unawareness of Mental Disorders (301). Construct validity was further supported by a study by Granholm et al. (302) who found that changes scores in positive and negative symptoms in response to treatment for schizophrenia were significantly correlated with changes scores on the BCIS. 


\section{INSIGHT FORMATION}

Typically, assessment following TBI is based on tasks that are simple, undemanding tasks that can be accomplished in the absence of intellectual insight. Life is not simple. It is not undemanding, and it frequently demands insight formation. It is possible that a test of higher cognitive processes can identify significant injury-derived deficits in individuals who present normal results in standard assessments. Tasks based on the discovery of compound remote associates provide a means of testing the capacity for insight. Schooler et al. (303) have published the following definition of an insight problem. It is a problem that

"(a) is well within the competence of the average subject; (b) has a high probability of leading to an impasse, that is, a state in which the subject does not know what to do next; and (c) has a high probability of rewarding sustained effort with an 'Aha' experience in which the impasse is suddenly broken and insight in to the solution is rapidly attained."

The remote associates test was introduced by Mednick (304) in studies of creativity. In the remote associates test, words from mutually distinct associative clusters are presented to the participant who must find a word that provides an associative mediating link between them. For example, the stimulus words rat, blue and cottage have the associative connection cheese. Success on this test has been shown to correlate with other tests of insight formation $(305,306)$. The test has also been used in investigations of psychopathology (307) (specifically subclinical predisposition to manic depression), in investigations of reactions to positive affect (308), and in research on self-esteem (309). The compound remote associate problem is a specific type of remote associate task (310). For example, in this task, three stem words (pine, crab, sauce) are presented simultaneously to the subject. The subject's task is to find a single-word that can be used to form a compound word or phrase with all three test words (apple to give pineapple, crab apple, and applesauce). The previous example from Mednick's remote associates test (rat, blue, cottage) would not satisfy the more restrictive criterion of a compound remote associate stimulus, but the stimulus triple board, blue, and cottage would meet the criterion. Bowden and Jung-Beeman (310) have constructed and tested 144 compound associate problems. Their documentation provides normative data regarding the percentage subjects solving the problem within a given time limit $(2,7,15$, or $30 \mathrm{~s})$ and the average time-to-solution of those trials where the problem was solved.

Bowden and Jung-Beeman (310) list the following advantages that compound remote associate problems have over what they term "classical insight problems."

"(1) They can be solved in a short time, so that many can be attempted in a single experimental session of $1 \mathrm{~h}$ or less. (2) They are simpler than classic insight problems, thus allowing better control of possible confounding variables. (3) They have single-word, unambiguous solutions, making scoring of responses easier. (4) They are physically compact, so that they can be presented in a small visual space or short time span.”
Table 12 | Instruments recommended for cognitive assessments.

\begin{tabular}{|c|c|c|}
\hline Domain assessed & Instrument & Reference \\
\hline Executive function & $\begin{array}{l}\text { Frontal systems } \\
\text { behavior scale (FrSBe) }\end{array}$ & $\begin{array}{l}\text { Grace and Malloy (293), } \\
\text { Stout et al. (294) }\end{array}$ \\
\hline Cognitive insight & $\begin{array}{l}\text { Beck cognitive insight } \\
\text { scale (BCIS) }\end{array}$ & Beck et al. (229) \\
\hline Insight formation & Remote associates test & $\begin{array}{l}\text { Bowden and } \\
\text { Jung-Beeman (310) }\end{array}$ \\
\hline
\end{tabular}

To this we would add that the test can be performed with a laptop computer. A sophisticated laboratory infrastructure is not required.

It should be noted that it is possible to incorporate a compound remote associate task in an experimental protocol that incorporates simultaneous neurophysiological measures $(311,312)$. Bowden and Jung-Beeman (313) and Jung-Beeman and Bowden (314) have used compound remote associates to investigate differential hemispheric contributions to problem solving and hemispheric contributions to the experience of a moment of insight when they are solved. The two phenomena, they argue, are distinct. In many cases, the subject solves the problem but does not have an experience of a punctate transition to the solution, what Bowden and Jung-Beeman refer to as the "Aha! experience." In a modification of the basic experimental procedure that includes electroencephalography and an fMRI study, the three stem words were presented to the left or to the right visual hemifield. Bowden and Jung-Beeman concluded that semantic activation of the right hemisphere may help solve insight problems (313), and that the right hemisphere maintains solution-related activation for yet to be solved problems (314). Bowden and Jung-Beeman (315) subsequently found that the insight experience correlates with solution activation in the right hemisphere (see Table 12).

\section{SOCIOLOGICAL ASSESSMENTS SOCIO-ECONOMIC STATUS}

As outlined in preceding sections some patients who sustain a TBI may be asymptomatic or minimally symptomatic immediately following injury but subsequently present neuropsychiatric disorders. The ability of ERPs to identify individuals at risk of delayed-onset psychiatric presentations is now being investigated. Given the heterogeneity of this clinical population, however, it is not suggested that ERPs alone will provide a uniformly successful indicator. ERP data must be combined with other physiological measures including serum biomarkers and imaging studies. Sociological factors, for example socio-economic status, SES, should also be considered. Research has established a correlation between PTSD and depression following injury or traumatic experiences with socio-economic status (316-320). Evidence indicates that both possible causal relationships can occur, that is psychiatric disorders result in lower socio-economic status, but conversely low socio-economic status is a risk factor for psychiatric disorders after a traumatic event. Socio-economic status may therefore be an important complement to physiological measures in efforts to identify individuals at risk of delayed-onset psychiatric disorders following TBI. Additionally, it is important to control for 
socio-economic status when constructing matching participant groups in clinical studies. This can be especially relevant for ERP studies as correlations between differences in SES and differences in ERPs have been observed (321-323).

The assessment of socio-economic status is, however, exceptionally difficult, Braverman et al. (324) summarized the situation admirably in the title of their JAMA review, "Socio-economic status in health research: one size does not fit all." While recognizing these difficulties, we recommend the Barratt Simplified Measure of Social Status [BSMSS, (325)] because of its simplicity and public domain availability. The aggregate score is computed from knowledge of the education and occupation of the participant, the participant's spouse/partner, and the participant's parents. Educational status is partitioned onto a seven-element scale, and occupations are classified into nine elements. The scale is derived from the widely used Hollingshead $(326,327)$ scale. Barrett made two significant modifications. First, the list of occupations reflects research updating occupational prestige ratings (328, 329). Second, the Barratt instrument incorporates scoring of parental and partner education and occupation. Adjustments are made in the scoring algorithm for participants who are not married/partnered and for participants who grew up in a single parent family. Parental scores are used for full time students.

The estimation of the socio-economic status of active duty military personnel is complicated. Past research which indicated that occupation is the best single indicator of SES (330) has no discriminatory power within this population since by definition they all have the same employer. In the case of military personnel, the procedure in Barratt for full time students should be used; namely the SES of the family of origin should be reported.

\section{SOCIAL SUPPORT}

Social support and patient perception of social support is a significant factor in the recovery from any illness or injury. A substantial body of literature indicates this is true of TBI. Perceived social support can be a significant predictor of neuropsychiatric disorders and post-injury community integration (331-333) (The relationship between social support and neuropsychiatric sequelae can, however, be complex. Leach et al. (334) found that effective use of problem solving and behavioral coping strategies by the family of a TBI patient correlated with reduced incidence of depressive illness, but perceived social support was not predictive of depression.).

The Multidimensional Scale of Perceived Social Support (335) measures subjective assessment of social support adequacy from three specific sources. Twelve items are scored on a scale from 1 (Very Strongly Disagree) to 7 (Very Strongly Agree). The instrument provides a total score and scores on three subscales (Significant Other, Family, Friends). In a study with undergraduates reliability was indicated by Cronbach alphas of 0.91 (Significant Other), 0.87 (Family), 0.85 (Friends), and 0.88 (Total Score). The test-retest reliability scores were 0.72 (Significant Other), 0.85 (Family), 0.75 (Friends), and 0.85 (Total Score). The construct validity was examined by comparisons with the Depression and the Anxiety subscores of the Hopkins Symptom Checklist [HSCL, a precursor of the SCL-90, (336)]. Zimet et al. hypothesized the perceived social support should be negatively related to depression and anxiety. Perceived support from family was inversely related to depression $(r=-0.24, p<0.01)$ and anxiety $(r=-0.18, p<0.01)$. Support from friends was inversely related to depression $(r=-0.24, p<0.01)$ as was support from significant others $(r=-0.13, p<0.05)$ and the aggregate score $(r=-0.25, p<0.01)$. These psychometric results were subsequently confirmed with other participant populations $(337,338)$.

\section{QUALITY OF LIFE}

Bullinger et al. (339) have correctly observed that the report of family members should not be used as a proxy measure of the patient's quality of life. When making this assessment, a distinction should be made between an assessment of the health-related quality of life and community integration. We consider here healthrelated quality of life. Community integration is considered in the next section.

Some investigators, for example Guilfoyle et al. (340) and Beseoglu et al. (341) have used the Short Form 36 (SF36) to assess health-related quality of life. While this measure is not specific to TBI, it is often an acceptable measure in TBI studies. A possible exception to this observation would be rehabilitation and treatment studies of TBI. In these studies a TBI-specific instrument is indicated. Several instruments for assessing health-related quality of life following TBI are available. They include the Function Independence Measure [FIM $(342,343)]$, the Function Independence Measure and Functional Assessment Measure [FIM + FAM $(344,345)]$, the Disability Rating Scale [DRS, (346)] and the Quality of Life After Brain Injury instrument [QOLIBRI (347-349)]. We recommend the QOLIBRI.

The QOLIBRI has 37 items scored on a five point scale. There are four "Satisfaction" subscales (Cognition, Self, Daily Life/Autonomy, and Social Relationships) and two "Bothered By" subscales (Emotions, Physical Problems). The subscales have high internal consistency (Cronbach alpha 0.75 to 0.89 ) and good test-retest reliability [interclass correlations from 0.78 to $0.85(347,348)]$. The TOTAL QOLIBRI has an internal consistency of alpha $=0.75$ and a test-retest reliability of $\mathrm{ICC}=0.95$ $(347,348)$. The instrument can be clinician administered or selfadministered. Administration requires approximately $10 \mathrm{~min}$ (see Table 13).

Table 13 | Instruments recommended for sociological assessments.

\begin{tabular}{lll}
\hline Domain assessed & Instrument & Reference' \\
\hline $\begin{array}{lll}\text { Socioeconomic } \\
\text { status }\end{array}$ & $\begin{array}{l}\text { Barratt simplified } \\
\text { measure of social } \\
\text { status (BSMSS) }\end{array}$ & Barratt (325) \\
Social support & $\begin{array}{l}\text { Multidimensional scale } \\
\text { of perceived social }\end{array}$ & Zimet et al. (335) \\
& $\begin{array}{l}\text { support } \\
\text { Quality of life after brain } \\
\text { related) }\end{array}$ & von Steinbüchel et al. \\
& injury (QOLIBRI) & (347, 348), Truelle et al. \\
Community & Community integration & Willer et al. (351, 352) \\
integration & $\begin{array}{l}\text { questionnaire } \\
\text { (health }\end{array}$ &
\end{tabular}




\section{COMMUNITY INTEGRATION}

The importance of community integration as an outcome measure for treatment of TBI has been considered by several authors [reviewed in (350)]. The Community Integration Questionnaire [CIQ, (351)] is self-administered, contains 15 items and has three subscales (Home Integration, Social Integration, and Productive Activities which characterizes travel, work, and training). Willer et al. (351) report good test-retest reliability and internal consistency. A subsequent study (352) established validity and showed good separation $(p<0.01)$ between TBI-positive and TBI-negative populations. The early applications of the CIQ were reported by Dijkers (353). Sander et al. (354) performed a factor analysis in a large population $(N=312)$. The threefactors identified by these calculations suggested modifications to the original questionnaire. Items on child care and shopping were deleted. The item "Who usually looks after your personal finances such as banking and paying bills?" was moved to the Home Integration subscale. The item "How often do you travel outside the house?" was moved to the Social Integration subscale.

Using the original scoring system, Zhang et al. (355) compared the CIQ against the Craig Handicap Assessment and Report Technique (356) and the Disability Rating Scale (346). They concluded that the CIQ was the most appropriate of these three instruments for characterizing post-rehabilitation community participation. Doninger et al. (357) studied the CIQ and in contrast with earlier investigators reported low reliability, poor measurement properties, and definitional problems. Reid-Arndt et al. (296) explicitly addressed the issues raised by Doninger et al. They wrote: "The validity of this measure has been suggested by several studies, including one evaluating a large sample of individuals with TBI (358) and another specifically assessing the measure's reliability and validity (352). On the other hand, the CIQ has also been the subject of some criticism. For example, rating scale analyses have resulted in low reliabilities suggestive of poor item coherence (357) and observations have been made that the CIQ fails to account for non-TBI factors that may influence scores such as pre-injury activity levels (342) and gender (359). Despite this, results from a comparison of several outcome measures suggested that of currently available instruments, the CIQ may be the most effective measure of rehabilitation outcomes following a TBI (355).”

Dijkers (360) expanded the CIQ to produce a 47 item CIQ-2 that was used in Whiteneck et al. (361) to produce the Participation Assessment with Recombined Tools-Objective, PART-O, instrument. This instrument was used by Brenner et al. (362) in a study of health and wellness interventions for individuals with moderate to severe TBI. Insofar as we can determine, this is the only study to date to use the PART-O.

In the absence of extensive experience with the PART-O, our present recommendation is to use the Community Integration Questionnaire. It should be administered in its original form, but both the original scoring and the revised Sander et al. scoring should be reported for both the total score and the three subscales. A reassessment of this recommendation should be made after additional experience with the PART-O is published.

\section{RESILIENCE}

Like all psychological constructs, resilience is difficult to define in a manner that readily provides in a definition that can be assessed by a psychological instrument. As emphasized by Meichenbaum (363), resilience is not the absence of symptoms, but rather refers to a pattern of adaptation in response to stress. Castro has presented a definition that has become standard in the US military. "Resilience comprises the sum total of the psychological processes that permit individuals to maintain or return to previous levels of well-being and functioning in response to adversity" [(364); see also (365)]. Given the difficulty in defining resilience, it is not surprising that a very large number of instruments have been constructed in an effort to provide a valid and reliable assessment instrument. Several are listed in Table 14.

Windle et al. (366) reviewed 15 instruments for assessing resilience including some of those listed in the table. Based on our review, we concur with Windle et al. that there is no gold standard for assessing resilience. Windle et al. concluded that the ConnorDavidson Resilience Scale, the Resilience Scale for Adults and the Brief Resilience Scale had the best psychometric properties. Of these we recommend the Connor-Davidson Resilience Scale.

The Connor-Davidson Resilience Scale assesses 17 domains with 25 questions that are scored on a five point scale. "Not true at

\section{Table 14 | Instruments used in the assessment of resilience and related constructs.}

Instrument Reference

Adolescent resilience scale

Antonovsky sense of coherence scale

Brief resilience scale

California healthy kids survey

resilience scale

Child and youth resilience measure

Connor-Davidson resilience scale, CD-RISC

Dispositional resilience scale

Ego resilience scale

Ego resiliency

Kobasa hardiness scale

Life orientation test - revised, LOT-R

Life satisfaction index A, LSI-A

Perceived stress scale

Psychological resilience

Resilience attitudes and skills profile

Resilience scale

Resilience scale for adults, RSA

Rosenberg self-esteem scale, RSES

Schute emotional intelligence scale

Stress vulnerability scale

Subjective well-being scale

Youth resiliency assessing

developmental strengths, YR:ADS
Oshio et al. (432)

Antonovsky (433)

Smith et al. (434)

Sun and Stewart (435)

Ungar et al. (436)

Connor and Davidson (367, 368)

Bartone (437)

Block and Kremen (438)

Klohnen (439)

Kobasa et al. (440)

Scheier et al. (441, 442)

Neugarten et al. (443)

Cohen and Williamson (444)

Windle et al. (445)

Hurtes and Allen (446)

Wagnild and Young (447)

Friborg et al. $(448,449)$

Rosenberg (450)

Schutte et al. (451)

Connor et al. (452)

Ryff (453)

Donnon and Hammond $(454,455)$ 
all" is scored as zero and "True nearly all the time" is scored as four. The maximum score is 100 , and a higher score indicates greater resilience. There are also 10 question and two question versions. We recommend the 25 question version. The scores in evaluation studies [reviewed in (367)] were for the US general population $80.4(12.8)$, primary care patients $71.8(18.4)$, generalized anxiety disorder 62.4(10.7), major depression 57.1(13.3), and two PTSD populations 47.8(19.5) and 52.8(20.4).

Connor and Davidson (368) performed a factor analysis and found five factors corresponding to persistence/tenacity, selfefficacy, emotional, and cognitive control when under pressure, adaptability/ability to bounce back, and control/meaning. Subsequent studies found that the factor structure varied with setting, and therefore Connor and Davidson (367) do not recommend separate scoring of factor subscales. The scale has excellent testretest reliability [(368), $r=0.87 ;(369), r=0.70]$. The 10 question version also has good test-retest properties [(370), $r=0.73$; (371), $r=0.90]$. An extensive literature establishing construct validity is reviewed in Connor and Davidson (367). This document also reviews studied reporting the Scale's applications in clinical studies and in studies with military populations.

\section{SUMMARY AND ADDITIONAL CONSIDERATIONS}

The assessments recommended for all ERP studies are summarized in Table 15. Each of the instruments listed in Table $\mathbf{1 6}$ is directed to a specific disorder and is appropriate in studies where the relationship between TBI and the comorbid psychiatric disorder is of specific interest. A number of issues should be noted. Several of the recommended instruments are proprietary, and investigators should obtain appropriate access before using them. It should be remembered that the psychometric validation of an instrument is specific to the form of its presentation. If, for example,

Table 15 | Instruments recommended for all studies of traumatic brain injury.

\begin{tabular}{|c|c|c|}
\hline Domain assessed & Instrument & Reference \\
\hline Combat exposure & $\begin{array}{l}\text { Combat exposure scale, or deployment risk and } \\
\text { resiliency inventory }\end{array}$ & $\begin{array}{l}\text { Lund et al. (10), Keane et al. (11), King et al. } \\
(12,13) \text {, Vogt et al. (15) }\end{array}$ \\
\hline Severity of injury at time of injury & $\begin{array}{l}\text { Mayo classification for traumatic brain injury severity } \\
\text { and/or VA/DoD classification of TBI severity }\end{array}$ & $\begin{array}{l}\text { Malec et al. (31), management of } \\
\text { concussion/mTBI working group. (17) }\end{array}$ \\
\hline Current post-concussion symptoms & $\begin{array}{l}\text { Rivermead post-concussion symptom questionnaire } \\
\text { aggregate score (RPQ16) subscales: RPQ3, RPQ13, } \\
\text { RPQ(Cognitive), RPQ(Emotional), RPQ(Somatic) }\end{array}$ & $\begin{array}{l}\text { King et al. (41), Eyres et al. (42), } \\
\text { Smith-Seemiller et al. (46), Potter et al. (47) }\end{array}$ \\
\hline Current post-concussion severity & $\begin{array}{l}\text { Rivermead post-concussion symptom questionnaire } \\
\text { aggregate score }\end{array}$ & Potter et al. (47) \\
\hline $\begin{array}{l}\text { Assessment of general health at the time of } \\
\text { the ERP study }\end{array}$ & Short form health survey, SF36 & $\begin{array}{l}\text { Ware and Sherbourne (54), McHorney et al. } \\
\text { (55), Turner-Bowker et al. (56) }\end{array}$ \\
\hline $\begin{array}{l}\text { Assessment of psychiatric symptoms at the } \\
\text { time of the ERP study }\end{array}$ & Symptom checklist-90-revised SCL-90-R & Derogatis et al. $(57,58)$ \\
\hline Estimation of premorbid intelligence & $\begin{array}{l}\text { American national adult reading test, Barona 1, } \\
\text { Barona } 2\end{array}$ & $\begin{array}{l}\text { Grober and Sliwinski (73), Barona et al. (76), } \\
\text { Barona and Chastain (79) }\end{array}$ \\
\hline Resilience & Connor-Davidson resilience scale, CD-RISC & Connor and Davidson $(367,368)$ \\
\hline
\end{tabular}

Table 16 | Additional instruments recommended for studies investigating traumatic brain injury and neuropsychiatric disorders.

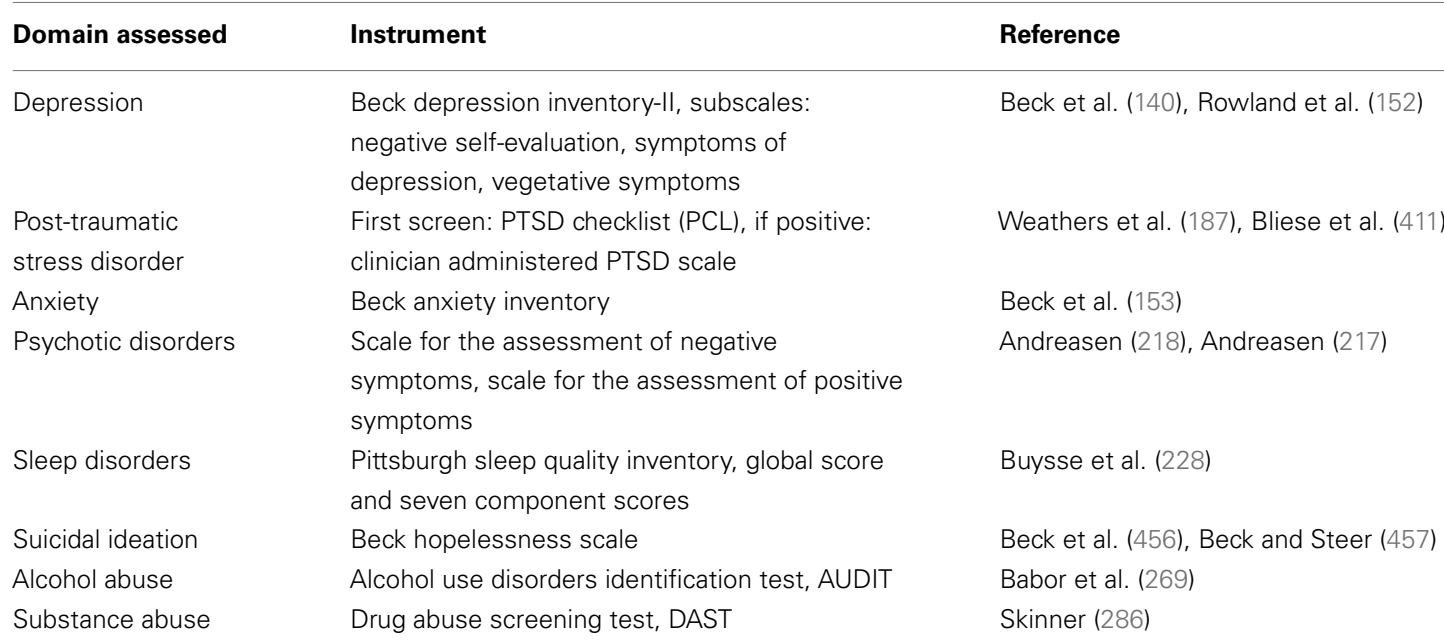


an instrument that was validated in a "paper-and-pencil" form is implemented on a computer, the previous validation studies are not, strictly speaking, applicable. Investigators will have to make a judgment as to the importance of prior validation before using an instrument. Validation concerns are particularly relevant to the acceptability of an outcome measure when studies are submitted to the Food and Drug Administration as the scientific basis for approval or clearance of an FDA regulated device or medication.

Some of the recommended instruments assess suicidal ideation, uncontrolled outbursts of temper, and thoughts of injuring others. Investigators have a responsibility to respond if a participant discloses thoughts of injury to self or others. The form of this response will vary according to the qualifications of the investigators and the location of the study. For example, support resources such as emergency psychiatric consultations that are available in a teaching hospital will not be available in academic departments and schools.

\section{REFERENCES}

1. McCarthy G, Donchin E. A metric for thought: a comparison of P300 latency and reaction time. Science (1981) 211:77-80. doi:10.1126/science.7444452

2. Bagiella E, Novack TA, Ansel B, Diaz-Arrastia R, Dikmen S, Hart $\mathrm{T}$, et al. Measuring outcome in traumatic brain injury trials: recommendations from the traumatic brain injury clinical trials network. J Head Trauma Rehabil (2010) 25(5):375-82. doi:10. 1097/HTR.0b013e3181d27fe3

3. Rapp PE, Curley KC. Is the diagnosis of "mild traumatic brain injury" a category mistake? J Trauma Acute Care Surg (2012) 73(2, Suppl 1):S13-23. doi:10. 1097/TA.0b013e318260604b

4. Mucci A, Volpe U, Merlotti E, Bucci P, Galderisi S. PharmacoEEG in psychiatry. Clin EEG Neurosci (2006) 37:81-98.

5. John ER, Prichep LS. The relevance of qEEG to the evaluation of behavioral disorders and pharmacological interactions. Clin EEG Neurosci (2006) 37:135-43.

6. Saletu B, Anderer P, Saletu-Zyhlarz GM. EEG topography and tomography (LORETA) in the classification and evaluation of the pharmacodynamics of psychotropic drugs. Clin EEG Neurosci (2006) 37:66-80.

7. Polich J, Criado JR. Neuropsychology and neuropharmacology of P3a and P3b. Int J Psychophysiol (2006) 60(2):172-85. doi:10.1016/j.ijpsycho.2005.12.012

8. Pogarell O, Mulert C, Hegerl U. Event related potentials and fMRI in neuropsychopharmacology. Clin EEG Neurosci (2006) 37:99-107.

9. Keane TM, Street AE, Stafford J. Assessment of military related
PTSD. In: Wilson JP, Keane TM, editors. Assessing Psychological Trauma and PTSD. New York, NY: Guilford Press (2004). p. 262-88.

10. Lund M, Foy D, Sipprelle C, Strachan A. The combat exposure scale: a systematic assessment of trauma in the Vietnam war. J Clin Psychol (1984) 40(6):1323-8. doi:10.1002/ 1097-4679(198411)40:6<1323::AI D-JCLP2270400607>3.0.CO;2-I

11. Keane TM, Fairbank JA, Caddell Mora CA. Clinical evaluation of a measure to assess combat exposure. Psychol Assess (1989) 1(1): 1.1 .53

12. King DW, King LA, Vogt DS, Manual for Deployment Risk and Resilience Inventory (DDRI). A Collection of Measure for Studying Deployment Related Experiences in Military Veterans. Boston, MA: National Center for PTSD, Department of Veterans Affairs (2003).

13. King L, King D, Vogt D, Knight J, Samper R. Deployment risk and resilience inventory: a collection of measures for studying deployment-related experiences of military personnel and veterans. Mil Psychol (2006) 18(2):89-120. doi:10.1207/s15327876mp1802_1

14. Fikretoglu D, Brunet A, Poundja J, Guay S, Pedlar D. Validation of the deployment risk and resilience inventory in FrenchCanadian Veterans: findings on the relation between deployment experiences and postdeployment health. Can J Psychiatry (2006) 51:755-63.

15. Vogt DS, Proctor SP, King DW, King LA, Vasterling JJ. JM, Zimering RT, Taylor KL, 53-5. doi:10.1037/1040-3590.

The specific legal requirements placed on investigators will vary. Typically, a response plan should be in place and approved by the investigators' Institutional Review Board (Human Subjects Protection Committee) before initiating the investigation.

\section{ACKNOWLEDGMENTS}

The opinions and assertions contained herein are the private opinions of the authors and are not to be construed as official or reflecting the views of the United States Department of Defense. Paul E. Rapp, David O. Keyser, Kevin M. Toruno, Christopher J. Cellucci, Dominic Nathan, and Brenna M. Rosenberg would like to acknowledge support from the Traumatic Injury Research Program of the Uniformed Services University of the Health Sciences, from the Defense Medical Research and Development Program and from the United States Marine Corps Systems Command.

Validation of scales from the deployment risk and resilience inventory in a sample of Operation Iraqi Freedom veterans. Assessment (2008) 15:391-403. doi:10.1177/1073191108316030

16. Arlinghaus KA, Shoaib AM, Price TRP. Neuropsychiatric assessment. In: Silver JM, McAllister TM, Yudofsky SC, editors. Textbook of Traumatic Brain Injury. Washington, DC: American Psychiatric Publishing, Inc (2005). p. 59-78.

17. Management of Concussion/mTBI Working Group. VA/DoD Clinical Practice Guideline for Management of Concussion/Mild Traumatic Brain Injury. Washington, DC: Veterans Administration - Department of Defense (2009). Available from: http://www.warrelatedillness.va. gov/WARRELATEDILLNESS/ provider/tbi/VADoD-CPGconcussion-mTBI.pdf

18. Greenwald BD, Burnett DM, Miller MA. Congenital and acquired brain injury. 1. Brain injury: epidemiology and pathophysiology. Arch Phys Med Rehabil (2003) 84(3 Suppl 1):S3-7. doi:10.1053/apmr.2003.50052

19. Rao V, Lyketsos C. Psychiatric aspects of traumatic brain injury. Psychiatr Clin North Am (2002) 25(1):43-69. doi:10.1016/S0193953X(03)00052-2

20. Cantu RC. Concussion classification: ongoing controversy. In: Slobunov S, Sabastianelli W, editors. Foundations of Sports-Related Brain Injuries. New York, NY: Springer (2006). p. 87-110.

21. Nelson WE, Jane JA, Gieck JH. Minor head injury in sports: a new system of classification and management. Phys Sportsmed (1984) 12(3):103-7.
22. Ommaya AK. Biomechanics of head injury: experimental aspects. In: Nahum AM, Melvin J, editors. Biomechanics of Trauma. Norwalk, CT: Appleton and Lange (1984). p. 245-69.

23. Cantu RC. Guidelines for return to contact sports after a cerebral concussion. Phys Sportsmed (1986) 14:76-9.

24. Cantu RC. Post traumatic (retrograde and anterograde) amnesia: pathophysiology and implications in grading and safe return to play. J Athl Train (2001) 36(3): 244-8.

25. Colorado Medical Society. Report of the Sports Medicine Committee. Guidelines for Management of Concussion in Sports. Denver, CO: Colorado Medical Society (1990).

26. Jordan BJ, Tsairis PT, Warren RF, editors. Head Injury in Sports: Sports Neurology (Vol. 227). Rockville, MD: Aspen Publications (1989).

27. Torg JS. Athletic Injuries to Head, Neck and Face. St. Louis, MO Mosby-Year Book (1991).

28. Roberts WO. Who plays? Who sits? Managing concussion on the sidelines. Phys Sportsmed (1992) 20:66-76.

29. Kelly JP, Rosenberg JM. The diagnosis and management of concussion in sports. Neurology (1997) 48:575-80. doi:10.1212/WNL.48.3.575

30. Anderson T, Heitger M, Macleod AD. Concussion and mild head injury. Pract Neurol (2006) 6:342-57. doi:10.1136/jnnp.2006. 106583

31. Malec JF, Brown AW, Leibson CL, Flaada JT, Mandrekar JN, Diehl $\mathrm{NN}$, et al. The Mayo classification system for traumatic brain injury. J Neurotrauma (2007) 24:141724. doi:10.1089/neu.2006.0245 
32. Gunstad J, Suhr JA. Perception of illness: nonspecificity of postconcussion syndrome symptom expectation. $J$ Int Neuropsychol Soc (2002) 8(1): 37-47. doi:10.1017/S135561770 2811043

33. World Health Organization. International Statistical Classification of Diseases and Related Health Problems. 10th ed. Geneva: World Health Organization (1992)

34. American Psychiatric Association. Diagnostic and Statistical Manual of Mental Disorders. DSM-IV Fourth Edition. Washington, DC: American Psychiatric Association (1994).

35. McCrea MA. Mild Traumatic Brain Injury and Postconcussion Syndrome: The New Evidence Base for Diagnosis and Treatment. New York: Oxford University Press (2007).

36. Boake C, McCauley SR, Levin HS, Contant CF, Song JX, Brown SA, et al. Limited agreement between criteria-based diagnoses of postconcussional syndrome. J Neuropsychiatry Clin Neurosci (2004) 16:4939. doi:10.1176/appi.neuro psych.16.4.493

37. Boake C, McCauley SR, Levin HS, Pedroza C, Contant CF, Song JX, et al. Diagnostic criteria for postconcussional syndrome after mild to moderate traumatic brain injury. J Neuropsychiatry Clin Neurosci (2005) 17:3506. doi:10.1176/appi.neuro psych.17.3.350

38. Iverson GL. Outcome from mild traumatic brain injury. Curr Opin Psychiatry (2005) 18(3):301-17. doi:10.1097/01.yco.0000165601. 29047.ae

39. Gouvier WD, Uddo-Crane M, Brown LM. Base rates of post-concussive symptoms. Arch Clin Neuropsychol (1988) 3(2):273-8. doi:10.1016/08876177(88)90019-4

40. Smith DH. Postconcussional symptoms not a syndrome. Psychosomatics (2006) 47(3):271-2. doi:10.1176/appi.psy.47.3.271

41. King NS, Crawford S, Wenden FJ, Moss NE, Wode DT. The Rivermead post concussion symptoms questionnaire: a measure of symptoms commonly experienced after head injury and its reliability. $J$ Neurol (1995) 242:587-92. doi:10.1007/BF00868811
42. Eyres S, Carey A, Gilworth G, Neumann V, Tennant A. Construct validity and reliability of the Rivermead post concussion symptoms questionnaire. Clin Rehabil (2005) 19:878-87. doi:10.1191/0269215505cr905oa

43. Andrich D. Rasch Models for Measurement. London: Sage (1988).

44. Crawford S, Wenden FJ, Wade DT. The Rivermead head injury follow up questionnaire: a study of a new rating scale and other measures to evaluate outcome after head injury. J Neurol Neurosurg Psychiatry (1996) 60:510-4. doi:10.1136/jnnp.60.5.510

45. Ryan LM, Warden DL. Post concussion syndrome. Int Rev Psychiatry (2003) 15:310-6. doi:10. 1080/09540260310001606692

46. Smith-Seemiller L, Fow NR, Kant R, Franzen MD. Presence of post-concussion syndrome symptoms in patients with chronic pain vs mild traumatic brain injury. Brain Injury (2003) 17(3):199-206. doi:10. 1080/0269905021000030823

47. Potter S, Leigh E, Wade D, Fleminger S. The Rivermead post concussion symptoms questionnaire: a confirmatory factor analysis. J Neurol (2006) 253(12):1603-14. doi:10.1007/s00415-006-0275-z

48. Ettenhofer ML, Barry DM. A comparison of long-term postconcussive symptoms between university students with and without a history of mild traumatic brain injury or orthopedic injury. J Int Neuropsychol Soc (2012):doi:10.1017/S135561771 1001895 Online prepublication,

49. Chan RCK. Base rate of postconcussive symptoms among normal people and its neuropsychological correlates. Clin Rehabil (2001) 15:266-73. doi: 10.1191/026921501675253420

50. Garratt AM, Schmidt L, Mackintosh A, Fitzpatrick R. Quality of life measurement: bibliographic study of patient assessed health outcome measures. $\mathrm{Br} \mathrm{Med}$ J (2002) 324(7351):1417-21. doi:10.1136/bmj.324.7351.1417

51. Garratt A. Patient reported outcome measures in trials. Br Med J (2009) 338:119-20. doi:10.1136/bmj.a2597

52. Contopoulos-Ioannidis DG, Karvouni A, Kouri I, Ioannidis PA. SF-36 outcomes in randomized trials: a systematic review. Br Med J (2008) 337:a3006.
53. Mokkind LB, Terwee CB, Knol DL, Stratford PW, Alonso J, Patrick DL, et al. Protocol of the COSMIN study: consensusbased standards for the selection of health measurement instruments. BMC Med Res Methodol (2006) 6:2. doi:10.1186/14712288-6-2

54. Ware JE, Sherbourne CD. The MOS 36-item short-form health survey (SF-36 ${ }^{\circledR}$ ): I. Conceptual framework and item selection. Med Care (1992) 30(6):473-83. doi:10.1097/00005650199206000-00002

55. McHorney CA, Ware JE, Raczek AE. The MOS 36-item shortform health survey (SF-36 $\left.{ }^{\circledR}\right)$ : II. Psychometric and clinical tests of validity in measuring physical and mental health constructs. Med Care (1993) 31(3):247-63. doi:10.1097/00005650199303000-00006

56. Turner-Bowker DM, Bartley PJ, Ware JE. SF-36 ${ }^{\circledR}$ Health Survey \& “SF" Bibliography: Third Edition (1988-2000). Lincoln, RI: QualityMetric Incorporation (2002).

57. Derogatis LR, Lipman RS, Covi L. The SCL-90: an outpatient psychiatric rating scale. Psychopharmacol Bull (1973) 9:13-28.

58. Derogatis LR. SCL-90-R Administration, Scoring and Procedures Manual. 3rd ed. Minneapolis: NSC Peason, Inc (1994).

59. Derogatis LR. Symptom checklist-90-revised (SCL90-R). Brief symptom inventory (BSI). 2nd ed. In: Rush AJ, First MB, Blacker D, editors. Handbook of Psychiatric Measures. Washington, DC: American Psychiatric Press (2008). p. 73-6.

60. Matarazzo JD. Psychological assessment versus psychological testing: validation from Binet to the school, clinic and courtroom. Am Psychol (1990) 45(9):999-1017. doi:10.1037/0003-066X.45.9.999

61. Lezak D, Howieson DB, Loring DW, Hannay HJ, Fischer JS. Neuropsychological Assessment. 4th ed. Oxford: Oxford University Press (2004).

62. Bazana PG, Stelmack M. Intelligence and information processing during an auditory discrimination task with backward masking: an event related potential analysis. $J$ Pers Soc Psychol (2002) 83(4): 998-1008. doi:10.1037/00223514.83.4.998
63. Zhang Q, Shi J, Luo Y, Zhao $\mathrm{D}$, Yang J. Intelligence and information processing during a visual search task in children: an event related potential study. Neuroreport (2006) 17:747-52. doi:10.1097/01.wnr.0000215774. 46108.60

64. DePascalis V, Varriale V, Matteoli A. Intelligence and P3 components of the event related potential elicited during an auditory discrimination task with masking. Intelligence (2008) 36(1):35-47. doi:10.1016/j.intell.2007.01.002

65. Franzen MD, Burgess EJ, SmithSeemiller L. Methods of estimating premorbid intelligence. Arch Clin Neuropsychol (1997) 12(8):711-38. doi:10.1016/ S0887-6177(97)00046-2

66. Lanham RA, Misukanis T. Estimating premorbid intelligence. determining change in cognition following brain injury. Brain Injury Source (1999) 3(3):42-3.

67. Kareken DA, Williams JM. Human judgment and estimation of premorbid intellectual function. Psychol Assess (1994) 6(2):83-91. doi:10.1037/1040-3590.6.2.83

68. Kareken DA. Judgment pitfalls in estimating premorbid intellectual function. Arch $\mathrm{Clin} \mathrm{Neu}$ ropsychol (1997) 12(8):701-9. doi:10.1093/arclin/12.8.701

69. Willshire D, Kinsella G, Prior M. Estimating WAIR-R IQ from the national adult reading test: a cross-validation. J Clin Exp Neuropsychol (1991) 13: 204-16. doi:10.1080/01688639 108401038

70. Ciplotti L, Warrington E. Neuropsychological assessment. J Neurol Neurosurg Psychiatry (1995) 58:655-64. doi:10.1136/jnnp.58.6.655

71. Nelson HE, McKenna P. The use of current reading ability in the assessment of dementia. Br J Soc Clin Psychol (1975) 14:259-67. doi:10.1111/j.20448260.1975.tb00178.x

72. Spreen O, Strauss E. A compendium of Neuropsychological Tests: Administration, Norms and Commentary. New York: Oxford University Press (1991).

73. Grober E, Sliwinski M. Development and validation of a model for estimating premorbid verbal intelligence in the elderly. $J$ Clin Exp Neuropsychol (1991) 13:933-49. doi:10.1080/01688639108405109 
74. Mortensen EL, Gade A, Reinisch JM. A critical note on Lezak's "best performance method" in clinical neuropsychology. $J$ Clin Exp Neuropsychol (1991) 13:361-71. doi:10.1080/01688639108401050

75. Wilson RS, Rosenbaum G, Brown G, Rourke D, Whitman D, Grisell J. An index of premorbid intelligence. $J$ Consult Clin Psychol (1978) 46(6):1554-5. doi:10.1037/0022006X.46.6.1554

76. Barona A, Reynolds CR, Chastain R. A demographically based index of premorbid intelligence for the WAIS-R. J Consult Clin Psychol (1984) 52(5): 885-7. doi:10.1037/0022006X.52.5.885

77. Eppinger MG, Craig PL, Adams RL, Parsons O. The WAIS-R index for estimating premorbid intelligence: cross validation and clinical utility. $J$ Consult Clin Psychol (1987) 55(1):86-90. doi:10.1037/0022-006X.55.1.86

78. Ryan JJ, Prifitera A. The WAIS-R index for estimating premorbid intelligence: accuracy of predicting short IQ. Int J Neuropsychol (1990) 12:20-3.

79. Barona A, Chastain RL. An improved estimate of premorbid IQ for blacks and whites on the WAIS-R. Int J Neuropsychol (1986) 8:167-73.

80. Basso MR, Bornstein RA, Roper BL, McCoy VL. Limited utility of premorbid intelligence estimators. A demonstration of regression to the mean. Clin Psychol (2000) 14:325-40.

81. Veiel HOF, Koopman RF. The bias in regression-based indices of premorbid IQ. Psychol Assess (2001) 13:356-68. doi:10.1037/1040-3590.13.3.356

82. Grove WM. Bias and error rates for premorbid IQ estimators: comment on Veiel and Koopman (2001). Psychol Assess (2001) 13(3):396-8. doi:10.1037/10403590.13.3.396

83. Veiel HOF, Koopman RF. Biased estimators, biased experts and the Ivory Tower: a reply to Grove. Psychol Assess (2001) 13(3):399-402. doi:10.1037/1040-3590.13.3.399

84. Crawford JR, Stewart LE, Parker DM, Besson JAO, Cochrane RHB. Estimation of premorbid intelligence: combining psychometric and demographic approaches improves predictive accuracy. Pers Individ Dif (1989)
10(7):793-6. doi:10.1016/01918869(89)90126-8

85. Crawford JR, Cochrane RHB, Besson JAO, Parker DM, Stewart LE. Premorbid IQ estimates obtained by combining NART and demographic variables: construct validity. Pers Individ Dif (1990) 11(2):209-10. doi:10.1016/01918869(90)90018-M

86. Vanderploeg RD, Schinka JA. Predicting WAIS-R IQ premorbid ability: combining subtest performance and demographic variable predictors. Arch Clin Neuropsychol (1995) 10(3):22539. doi:10.1093/arclin/10.3.225

87. Scott JG, Krull K, Williamson DJG, Adams RL, Iverson GL. Oklahoma premorbid intelligence estimation (OPIE) utilization in clinical samples. Clin Neuropsychol (1997) 11(2):146-54. doi:10.1080/13854049708407043

88. Axelrod BN, Vanderploeg RD, Schinka JA. Comparing methods for estimating premorbid intellectual functioning. Arch $\mathrm{Clin}$ Neuropsychol (1999) 14(4):3416. doi:10.1093/arclin/14.4.341

89. Axelrod BN, Vanderploeg RD, Rawlings DB, Dingell JD. WAIS-R prediction estimates in patients with traumatic brain injury. J Clin Exp Neuropsychol (1999) 21(3):368-74. doi:10.1076/jcen.21.3.368.916

90. Vanderploeg RD, Schinka JA, Axelrod BN. Estimation of WAIS-R premorbid intelligence: current ability and demographic data used in a best performance fashion. Psychol Assess (1996) 8:404-11. doi:10.1037/1040-3590.8.4.404

91. Krull K, Scott JG, Sherer M. Estimation of premorbid intelligence from combined performance and demographic variables. Clin Neuropsychol (1995) 9:83-7. doi:10.1080/13854049508402063

92. Williamson D, Krull KR, Scott JG. Revision and further validation of the Oklahoma premorbid intelligence estimate. Poster Session at the Sixteenth Annual Meeting of the National Academy of Neuropsychology. Orlando, FL (1996).

93. Riley GA, Simmonds LV. How robust is performance on the National adult reading test following traumatic brain injury? Br J Clin Psychol (2003) 42: 319-28. doi:10.1348/0144665 0360703410
94. Hoofien D, Vakil E, Gilboa A. Criterion validation of premorbid intelligence estimation in persons with traumatic brain injury: "Hold/Don't Hold" versus "best performance" procedures. J Clin Exp Neuropsychol (2000) 22(3):305-15. doi:10.1076/ 1380-3395(200006)22:3;1V;FT305

95. Green RE, Melo B, Christensen B, Ngo LA, Monette G, Bradbury C. Measuring premorbid IQ in traumatic brain injury: an examination of the validity of the Weshsler Test of Adult Reading (WTAR). J Clin Exp Neuropsychol (2008) 30(2):163-72. doi:10.1080/13803390701300524

96. Wechsler D. Wechsler Test of Adult Reading (WTAR). San Antonio, TX: The Psychological Corporation (2001).

97. Lowe DA, Rogers SA. Estimating premorbid intelligence among older adults: the utility of AMNART. $J$ Aging Res (2011) 2011: 428132. doi:10.4061/2011/428132

98. Homaifar BY, Brenner LA, Gutierrez PM, Harwood JF, Thompson C, Filey CM, et al. Sensitivity and specificity of the Beck depression inventory-II in persons with traumatic brain injury. Arch Phys Med Rehabil (2009) 90(4):652-6. doi:10.1016/j.apmr.2008.10.028

99. Smith CT, Oltmanns TF. Scientific advances in the diagnosis of psychopathology: introduction to the special section. Psychol Assess (2009) 21(3):241-2. doi:10.1037/a0016919

100. Widiger TA, Livesley WJ, Clark LA. An integrative dimensional classification of personality disorder. Psychol Assess (2009) 21:243-53. doi:10.1037/a0016606

101. Brown TA, Barlow DH. A proposal for a dimensional system based on the shared features of the DSM-IV anxiety and mood disorders. Implications for assessment and treatment. Psychol Assess (2009) 21:256-71. doi:10.1037/a0016608

102. Jorge RE, Robinson RG, Arndt SV, Forrester AW, Geisler F, Starkstein SE. Comparison between acute and delayed-onset depression following traumatic brain injury. J Neuropsychiatr Clin Neurosci (1993) 5:43-9.

103. Jorge RE, Robinson RG, Starkstein SE, Arndt SV. Depression and anxiety following traumatic brain injury. $J$ Neuropsychiatr Clin Neurosci (1993) 5:369-74.

104. Jorge RE, Robinson RG, Moser D, Tateno A, CrespoFacorro B, Arndt S. Major depression following traumatic brain injury. Arch Gen Psychiatry (2004) 61:42-50. doi:10.1001/archpsyc.61.1.42

105. Holsinger T, Steffens DC, Phillips C, Helms MJ, Harlik RJ, Breitner JC, et al. Head injury in early adulthood and the lifetime risk of depression. Arch Gen Psyciatry (2002) 59:17-22. doi:10.1001/archpsyc.59.1.17

106. Brenner LA, Homaifar BY, Adler LE, Wolfman JH, Kemp J. Suicidality and veterans with a history of traumatic brain injury: precipitating events, protective factors and prevention strategies. Rehabil Psychol (2009) 54(4):390-7. doi:10.1037/a0017802

107. Gray MJ, Bolton EE, Litz BT. A longitudinal analysis of PTSD symptom course: delayed-onset PTSD in Somalia peacekeepers. J Consult Clin Psychol (2004) 72(5):909-13. doi:10.1037/0022006X.72.5.909

108. Grieger TA, Cozza SJ, Ursano RJ, Hoge C, Martinez PE, Engel CC, et al. Posttraumatic stress disorder and depression in battle-injured soldiers. Am J Psychiatry (2006) 163:1777-83. doi:10.1176/appi.ajp.163.10.1777

109. Andrews B, Brewin CR, Philpott $\mathrm{R}$, Stewart L. Delayed-onset posttraumatic stress disorder: a systematic review of the evidence. Am J Psychiatry (2007) 164:1319-26. doi:10. 1176/appi.ajp.2007.06091491

110. Milliken CS, Auchterlonie JL, Hoge CW. Longitudinal assessment of mental health problems among active and reserve component soldiers returning from the Iraq war. JAMA (2007) 298(18):2141-8. doi:10.1001/jama.298.18.2141

111. Gerber DJ, Schraa JC. Mild traumatic brain injury: searching for the syndrome. J Head Trauma Rehabil (1995) 10(4):28-40. doi:10.1097/00001199199508000-00004

112. Bruce JM, Echemendia RJ. Delayed-onset deficits in verbal encoding strategies among patients with mild traumatic brain injury. Neuropsychyology (2003) 17:622-9. doi:10.1037/0894-4105.17.4.622

113. Lew HL, Poole JH, Alvarez S, Moore W. Soldiers with occult 
traumatic brain injury. Am J Phys Med Rehabil (2005) 84:393-8. doi:10.1097/01.phm.0000163703. 91647.a7

114. Fujii D, Ahmed I. Psychosis secondary to traumatic brain injury. Neuropsychiatr Neuropsychol Behav Neurol (1996) 9: 133-8.

115. Fujii D, Ahmed I. Risk factors in psychosis secondary to traumatic brain injury. $J$ Neuropsychiatr Clin Neurosci (2001) 13:61-9. doi:10. 1176/appi.neuropsych.13.1.61

116. Sachdev P, Smith PS, Cathcart S. Schizophrenia-like psychosis following traumatic brain injury: a chart-based descriptive and case-control study. Psychol Med (2001) 31:231-9. doi:10.1017/S0033291701003336

117. Lezak MD. The walking wounded of head injury: when subtle deficits can be disabling. Trends Rehabil (1988) 3(3):4-9.

118. Castrén E. Is mood chemistry? Nat Rev Neurosci (2005) 6:241-6. doi:10.1038/nrn1629

119. Kim E, Lauterbach EC, Reeve A, Arciniegas DB, Coburn KL, Mendez MF, et al. Neuropsychiatric complications of traumatic brain injury: a critical review of the literature (a report by the ANPA committee on research). J Neuropsychiatry Clin Neurosci (2007) 19(2):106-27. doi:10. 1176/appi.neuropsych.19.2.106

120. Seel RT, Kreutzer JS. Depression assessment after traumatic brain injury: an empirically based classification method. Arch Phys Med Rehabil (2003) 84(11):16218. doi:10.1053/S0003-9993(03) 00270-3

121. Iverson GL. Misdiagnosis of persistent postconcussion syndrome in patients with depression. Arch Clin Neuropsychyol (2006) 21:303-10. doi:10.1016/j.acn.2005.12.008

122. Bombardier $\mathrm{CH}$, Fann JR, Temkin NR, Esselman PC, Barber J, Dikmen SS. Rates of major depressive disorder and clinical outcomes following traumatic brain injury. J Am Med Assoc (2010) 303(19):1938-45. doi:10.1001/jama.2010.599

123. deGuise E, leBlanc J, Feyz M, Meyer K, Duplantie J, Thomas H, et al. Long-term outcome after severe traumatic brain injury: the McGill interdisciplinary prospective study. J Head Trauma Rehabil (2008) 23(5):294-303.
doi:10.1097/01.HTR.0000336842. 53338.f4

124. Hibbard MR, Uysal S, Kepler K, Bogdany J, Silver J. Axis I. psychopathology in individuals with traumatic brain injury. I Head Trauma Rehabil (1998) 13(4):24-39. doi:10.1097/ 00001199-199808000-00005

125. Moldover JE, Goldberg KB, Prout MJ. Depression after traumatic brain injury: a review of evidence for clinical heterogeneity. $\mathrm{Neu}$ ropsychol Rev (2004) 14:143-54. doi:10.1023/B:NERV.00000481 81.46159 .61

126. Wilk JE, Thomas JL, McGurk DM, Riviere LA, Castro CA, Hoge CW. Mild traumatic brain injury (concussion) during combat: lack of association of blast mechanism with persistent postconcussive symptoms. J Head Trauma Rehabil (2010) 25(1):1-6. doi:10.1097/ HTR.0b013e3181bd090f

127. Kruijshaar ME, Barendregt J, Vos T, de Graaf R, Spiker J, Andrews G. Lifetime prevalence estimates of major depression: an indirect estimation and a quantification of recall bias. Eur J Epidemiol (2005) 20(1):103-11. doi:10.1007/s10654-004-1009-0

128. Jorge RE, Robinson RG, Arndt WV. Are depressive symptoms specific for a depressed mood in traumatic brain injury? J Nerv Ment Dis (1993) 181:919. doi:10.1097/00005053-199302 000-00004

129. Robinson RG, Jorge R. Mood disorders. In: Silver JM, McAllister TW, Yudofsky SC, editors. Textbook of Traumatic Brain Injury. Washington, DC: American Psychiatric Publishing (2005). p. 201-12.

130. Spitzer RL, Kroenke D, Williams JBW, The Patient Health Questionnaire Primary Care Study Group. Validation and utility of a self-report version of PRIME-MD: the PHQ primary care study. J Am Med Assoc (1999) 282(18):1737-44. doi:10.1001/jama.282.18.1737

131. Kroenke K, Spitzer R, Williams JBW. The PHQ-9, validity of a brief depression severity measure. J Gen Intern Med (2001) 16:606-16. doi:10.1046/j.15251497.2001.016009606.x

132. Fann JR, Bombardier CH, Dikmen S, Esselman P, Warms CA, Pelzer E, et al. Validity of the patient health questionnaire- 9 in assessing depression following traumatic brain injury. $J$ Head Trauma Rehabil (2005) 20(6):501-11. doi:10.1097/ 00001199-200511000-00003

133. First MB, Spitzer RL, Williams JB. User's Guide for the Structured Clinical Interview for DSMIV Axis I Disorders (SCIDI): Clinical Version. Washington: American Psychiatric Publishing (1996).

134. Cook KF, Bombardier $\mathrm{CH}$, Bamer AM, Choi SW, Kroenke $\mathrm{K}$, Fann JR. Do somatic and cognitive symptoms of traumatic brain injury confound depression screening? Arch Phys Med Rehabil (2011) 92: 818-23. doi:10.1016/j.apmr. 2010.12.008

135. Jodoin MG, Gierl MJ. Evaluating type 1 error and power rates using an effect size measure with the logistic regression procedure for DIF detection. Appl Measurement Educ (2001) 14:329-49. doi:10. 1207/S15324818AME1404_2

136. Zumbo BD. Three generations of differential item functioning (DIF) analyses: considering where it has been, where it is now, and where it is going. Lang Assess Q (2007) 4:223-33.

137. Lord FM. Applications of Item Response Theory to Practical Testing Problems. Mahwah, NJ: Erlbaum (1980).

138. Kreutzer JS, Marwitz JH, Seel $R$, Serio CD. Validation of a neurobehavioral functioning inventory for adults with traumatic brain injury. Arch Phys Med Rehabil (1996) 77(2):11624. doi:10.1016/S0003-9993(96) 90155-0

139. Beck AT, Ward CH, Mendelson M, Mock J, Erbaugh J. An inventory of measuring depression. Arch Gen Psychiatry (1961) 4:53-63. doi:10.1001/archpsyc.1961.0171 0120031004

140. Beck AT, Steer RA, Brown GK. Beck Depression Inventory. II. Manual. San Antonio, TX: Psychological Corporation (1996).

141. Butcher JN, Dahlstrom WG, Graham JR, Tellegen A, Kaemmer B. Minnesota Multiphasic Personality Inventory-2 (MMPI2). Manual for Administration and Scoring. Minneapolis, MN: University of Minnesota Press (1989).

142. Butcher JN, Graham JR, Ben-Porath YS, Tellegen A, Dahlstrom WG, Kaemmer B.
Minnesota Multiphasic Personality Inventory-2 (MMPI-2). Manual for Administration and Scoring. Revised Edition. Minneapolis, MN: University of Minnesota Press (2001).

143. Sprinkle SD, Lurie D, Insko SL, Atkinson G, Jones JL, Logan AR, et al. Criterion validity, severity cut scores and test-retest reliability of the Beck depression inventory-II in a university counseling center sample. $J$ Couns Psychol (2002) 49:381-5. doi:10.1037/0022-0167.49.3.381

144. Steer RA, Kumar G, Ranieri WF, Beck AT. Use of the Beck depression inventory with adolescent psychiatric outpatients. J Psychopathol Behav Assess (1998) 20:127-37. doi:10.1023/A:1023091529735

145. Rosenthal M, Christensen BK, Ross TP. Depression following traumatic brain injury. Arch Phys Med Rehabil (1998) 79:90-103. doi:10.1016/S00039993(98)90215-5

146. Sliwinski M, Gordon WA, Bogdany J. The Beck depression inventory: is it a suitable measure of depression for individuals with traumatic brain injury? J Head Trauma Rehabil (1998) 13(4):40-6. doi:10.1097/00001199199808000-00004

147. Beck AT. Beck Depression Inventory Manual. San Antonio, TX: Psychological Corporation (1987).

148. Lehmkuhl D. The TIRR Symptom Checklist. Houston, TX: The Institute for Rehabilitation Research (1988).

149. Green A, Felmingham K, Baguley IJ, Slewa-Younan S, Simpson S. The clinical utility of the Beck depression inventory after traumatic brain injury. Brain Injury (2001) 15(12):1021-8. doi:10.1080/02699050110074187

150. Howell CD. Statistical Methods for Psychology. Florence, KY: Wadsworth Publishing Company (1997).

151. Christensen BK, Ross TP, Kotesek RS. Factor structure for the Beck Depression Inventory in a sample of persons with traumatic brain injury. (Abstract). J Int Neuropsychol Soc (1995) 1:121-86.

152. Rowland SM, Lam CS, Leahy B. Use of the Beck depression inventory-II (BDI-II) with persons with traumatic brain injury: analysis of factorial structure. Brain 
Injury (2005) 19(2):77-83. doi:10.1080/026990504100017 19988

153. Beck AT, Steer RA, Garbin MC. Psychometric Properties of the Beck depression inventory: twenty-five years of evaluation. Clin Psychol Rev (1988) 8(1):77-100. doi:10.1016/02727358(88)90050-5

154. Andreasen NC, Black DW. Introductory Textbook of Psychiatry. 2nd ed. Washington, DC: American Psychiatric Press (1995).

155. Smith GT, McCarthy DM, Zapolski TCB. On the value of homogeneous constructs for construct validation, theory testing and the description of psychopathology. Psychol Assess (2009) 21(3):27284. doi:10.1037/a0016699

156. Bontke CF. Do patients with mild brain injuries have posttraumatic stress disorder too? J Head Trauma Rehabil (1996) 11(1):95-102. doi:10.1097/00001199-

199602000-00011

157. Sbordone RJ, Liter JC. Mild traumatic brain injury does not produce posttraumatic stress disorder. Brain Injury (1995) 9:405-12. doi:10.3109/02699059509005780

158. Bryant RA. Posttraumatic stress disorder and traumatic brain injury: can they coexist? Clin Psychol Rev (2001) 21(6):93148. doi:10.1016/S0272-7358(00) 00074-X

159. Bryant R. Post-traumatic stress disorder vs traumatic brain injury. Dialogues Clin Neurosci (2011) 13(3):251-62.

160. Boake C. Do patients with mild brain injuries have posttraumatic stress disorder too? J Head Trauma Rehabil (1996) 11(1):98-100.

161. Joseph S, Masterson J. Posttraumatic stress disorder and traumatic brain injury: are they mutually exclusive? J Trauma Stress (1999) 12(3):437-53. doi:10.1023/A:1024762919372

162. Gil S, Caspi Y, Ben-Ari LZ, Koren D, Klein E. Does memory of a traumatic event increase the risk for posttraumatic stress disorder in patients with traumatic brain injury? A prospective study. Am J Psychiatry (2005) 162(5):963-9. doi:10.1176/appi.ajp.162.5.963

163. Hoge CW, McGurk D, Thomas JL, Cox AL, Engel CC, Castro CA. Mild traumatic brain injury in U.S. soldiers returning from Iraq. $N$ Engl
$J$ Med (2008) 358(5):453-63. doi:10.1056/NEJMoa072972

164. Vanderploeg RD, Belanger HG, Curtiss G. Mild traumatic brain injury and posttraumatic stress disorder and their associations with health symptoms. Arch Phys Med Rehabil (2009) 90(7):1084-93. doi:10.1016/j.apmr.2009.01.023

165. Zatzick DF, Rivara FP, Jurkovich GJ, Hoge CW, Wang J, Fan MY, et al. Multiside investigation of traumatic brain injuries, posttraumatic stress disorder and self-reported health and cognitive impairments. Arch Gen Psychiatry (2010) 67(12):1291-300. doi:10.1001/ archgenpsychiatry.2010.158

166. LeDoux JE. Emotion, memory and the brain. Sci Am (1994) 270:50-7. doi:10.1038/ scientificamerican0694-50

167. LeDoux JE. Fear and the brain. Where we have been and where are we going? Biol Psychiatry (1998) 44:1229-38. doi:10.1016/S00063223(98)00282-0

168. LeDoux JE, Cicchetti P, Xagoraris A, Romanski L. The lateral amygdaloid nucleus: sensory interface of the amygdala in fear conditioning. J Neurosci (1990) 10:1062-9.

169. Sapolsky RM, Uno H, Rebert CS, Finch CE. Hippocampal damage associated with prolonged glucocorticoid exposure in primates. $J$ Neurosci (1990) 10:2897-902.

170. MacDonald CL, Johnson AM, Cooper D, Nelson EC, Werner NJ, Shimony JS, et al. Detection of blast-related traumatic brain injury in US military personnel. $N$ Engl $J$ Med (2011) 364:2091-100. doi:10.1056/NEJMoa1008069

171. Kim SJ, Heong DU, Sim ME, Bae SC, Chung A, Kim MJ, et al. Asymmetrically altered integrity of cingulum bundle in posttraumatic stress disorder. $\mathrm{Neu}$ ropsychobiology (2006) 54:120-5. doi:10.1159/000098262

172. Hickling EJ, Gillen R, Blanchard EB, Buckley T, Taylor A. Traumatic brain injury and post traumatic stress disorder: a preliminary investigation of neuropsychological test results in PTSD secondary to motor vehicle accidents. Brain Injury (1998) 12:265-74. doi:10.1080/026990598122566

173. McMillan TM. Post-traumatic stress disorder following minor and severe closed head injury: 10 single cases. Brain Injury (1996) 40:749-58. doi:10.1080/026990596124016

174. Harvey AG, Brewin CR, Jones C, Kopelman MD. Coexistence of posttraumatic stress disorder and traumatic brain injury: towards a resolution of the paradox. J Int Neuropsychol Soc (2003) 9:663-76. doi:10. 1017/S1355617703940069

175. Sumpter RE, McMillan TM. Misdiagnosis of post traumatic stress disorder following severe traumatic brain injury. $\mathrm{Br}$ Psyhciatry (2005) 186:423-6. doi:10.1192/bjp.186.5.423

176. Foa EB, Cashman L, Jaycox L, Perry K. The validation of a selfreport measure of posttraumatic stress disorder: the posttraumatic diagnostic scale. Psychol Assess (1997) 9(4):445-51. doi:10. 1016/j.psychres.2007.09.005

177. Horowitz M, Wilner M, Alvarez W. Impact of event scale: a measure of subjective stress. Psychosom Med (1979) 41:209-18.

178. Corneil W, Beaton R, Murphy S, Johnson C, Pike K. Exposure to traumatic incidents and prevalence of post-traumatic stress symptomatology in urban firefighters in two countries. J Occup Health Psychol (1999) 4:131-41. doi:10.1037/1076-8998.4.2.131

179. Blake DD, Weathers FW, Nagy LM, Kaloupek DG, Gusman FD, Charney DS, et al. The development of a clinician administered PTSD scale. $J$ Trauma Stress (1995) 8(1):75-90. doi:10.1002/jts.2490080106

180. Sumpter RE, McMillan TM Errors in self-report of posttraumatic stress disorder and severe brain injury. Brain Injury (2006) 20(1):93-9. doi:10.1080/02699050500394090

181. Sbordone RJ, Ruff RM. Reexamination of the controversial coexistence of traumatic brain injury and posttraumatic stress disorder: misdiagnosis and self-report measures. Psychol Inj Law (2010) 3(1):63-76. doi:10.1007/s12207-010-9066-z

182. Blake DD, Weathers FW, Nagy LN, Kaloupek DG, Klauminzer G, Charney DS, et al. A clinician rating scale for assessing current and lifetime PTSD: the CAPS-1. Behav Ther (1990) 13:187-8.

183. Blake D, Weathers F, Nagy L, Kaloupek D, Klauminzer G, Charney D, et al. ClinicianAdministered PTSD Scale (CAPS)
Form 1. Current and Lifetime Diagnosis Version. West Haven, CT: National Center for Posttraumatic Stress Disorder (1990).

184. Shalev AY, Freedman S, Peri $T$, Brandes D, Sahar T. Predicting PTSD in trauma survivors: perspective evaluation of self-report and clinicianadministered instruments. $\mathrm{Br}$ Psychiatry (1997) 170:558-64. doi:10.1192/bjp.170.6.558

185. King NS, Crawford S, Wenden FJ, Caldwell FE, Wade DT. Early prediction of persiting post-concussion symptoms following mild and moderate head injuries. British $J$ Clin Psychol (1999) 38(1): 15-25. doi:10.1348/01446659 9162638

186. Newman E, Ribbe D. Psychometric review of the clinician administered PTSD scale for children. In: Stamm BH, editor. Measurement of Stress, Trauma and Adaptation. Lutherville, MD: Sidran Press (1996). p. 106-14.

187. Weathers F, Litz B, Huska JA, and Keane TM. PCL-C for DSM-IV (PTSD Checklist). National Center for PTSD. Boston: Behavioral Science Division (1994)

188. National Center for PTSD. Using the PTSD Checklist (PCL). Washington, DC: U.S. Department of Veteran Affairs (2012).

189. Monson CM, Gradus JL, YoungXu Y, Schurr PP, Price JL, Schumm JA. Change in posttraumatic stress disorder symptoms: do clinicians and patients agree? Psychol Assess (2008) 20(2):131-8. doi:10.1037/10403590.20.2.131

190. Blanchard EB, Jones-Alexander J, Buckley TC, Forneris CA. Psychometric properties of the PTSD checklist. Behav Res Ther (1996) 34(8):699-673. doi:10.1016/ 0005-7967(96)00033-2

191. Norris FH, Hamblen JL. Standardized self-report measures of civilian trauma and PTSD. 2nd ed. In: Wilson J, Keane T, editors. Assessing Psychological Trauma of PTSD: A Practitioner's Handbook. New York, NY: Guildford Press (2003). p. 63-192.

192. Wilkins KC, Lang AJ, Norman SB. Synthesis and psychometric properties of PTSD checklist (PCL) military, civilian and specific versions. Depress Anxiety (2011) 28(7):596-606 doi:10.1002/da.20837 
193. Ruggiero KJ, Rheingold AA, Resnick HS, Kilpatrick DG, Galea S. Comparison of two widely used PTSD screening instruments: implications for public mental health planning. $J$ Trauma Stress (2006) 19(5):699707. doi:10.1002/jts.20141

194. McDonald SD, Calhoun PS. The diagnostic accuracy of the PTSD checklist: a critical review. Clin Psychol Rev (2010) 30:976-87. doi:10.1016/j.cpr.2010.06.012

195. Epstein RS, Ursano RJ. Anxiety disorders. In: Silver JM, Yudofsky SC, Hales RE, editors. Neuropsychiatry of Traumatic Brain Injury. Washington, DC: American Psychiatric Press (1994). p. 285-311.

196. Hiott DW, Labbate L. Anxiety disorders associated with traumatic brain injury. NeuroRehabilitation (2002) 17:345-55.

197. Warden DL, Labbate LA. Posttraumatic stress disorder and other anxiety disorders. In: Silver JM, McAllister TW, Yudofsky SC, editors. Textbook of Traumatic Brain Injury. Washington, DC: American Psychiatric Press (2005). p. 231-43.

198. Kessler RC, McGonagle KA, Zhao S, Nelson CB, Hughes $\mathrm{M}$, Eshleman S, et al. Lifetime and 12-month prevalence of DSM-III-R psychiatric disorders in the United States. Results from the National Comorbidity Survey. Arch Gen Psychiatry (1994) 51:8-19. doi:10.1001/archpsyc.1994.0395 0010008002

199. Ritter MR, Balckmore MA, Heimberg RG. Generalized anxiety disorder. In: McKay D, Abramowitz JS, Taylor S, editors. Cognitive-Behavior Therapy for Refractory Cases: Turning Failure into Success. Washington, DC: American Psychological Association (2010). p. 111-37.

200. Shear MK, Brown C, Clark DB. Anxiety disorder measures. Second ed. In: Rush AJ, First MB, Blacker D, editors. Handbook of Psychiatric Measures. Washington, DC: American Psychiatric Publishing (2008). p. 529-58.

201. Bryant RA, Moulds MM, Guthrie R, Nixon RDV. Treating acute stress disorder following mild traumatic brain injury. Am J Psychiatry (2003) 160(3):585-7. doi:10.1176/appi.ajp.160.3.585

202. Cantor JB, Ashman TA, Schwartz ME, Gordon WA, Hibbard
MR, Brown M, et al. The role of self-discrepancy theory in understanding post-traumatic brain injury affective disorders: a pilot study. I Head Trauma Rehabil (2005) 20(6):527-43. doi:10.1097/00001199200511000-00005

203. Kit KA, Mateer CA, Graves RE. The influence of memory beliefs in individuals with traumatic brain injury. Rehabil Psychol (2007) 52(1):25-32. doi:10.1037/0090-5550.52.1.25

204. Leyfer OT, Ruberg JL, WoodruffBorden J. Examination of the utility of the Beck anxiety inventory and its factors as a screener for anxiety disorders. Anxiety Disorders (2006) 20:444-58. doi:10. 1016/j.janxdis.2005.05.004

205. Arciniegas DB, Harris SN, Brousseau KM. Psychosis following traumatic brain injury. Int Rev Psychiatry (2003) 15(4):328-40. doi:10. 1080/09540260310001606719

206. Zhang Q, Sachdev PS. Psychotic disorders and traumatic brain injury. Curr Psychiatry Rep (2003) 5(3):197-201. doi:10.1007/s11920-003-0042-0

207. Guerreiro DF, Navarro R, Silva M, Carhalho MJ, And Gois C. Psychosis secondary to traumatic brain injury. Brain Injury (2009) 23(4):358-61. doi:10.1080/02699050902800918

208. Davison K, Bagley CR. Schizophrenia-like psychoses associated with organic disorders of the central nervous system: a review of the literature. In: Harrington RN, editor. Current Problems in Neuropsychiatry, Schizophrenia, Epilepsy, and the Temporal Lobe. London: British Journal of Psychiatry (1969). p. 113-84.

209. Arciniegas DB, Beresford TP. Neuropsychiatry an Introductory Approach. Cambridge: Cambridge University Press (2001).

210. Achte K, Jarho L, Kyykka T, Vesterinen E. Paranoid disorders following war brain damage. Preliminary report. Psychopathology (1991) 24:309-15. doi:10.1159/000284731

211. Thomsen IV. Late outcome of very severe blunt head trauma: a $10-15$ year second follow-up. J Neurol Neurosurg Psychiatry (1984) 47(3):260-8. doi:10.1136/jnnp.47.3.260

212. Perälä J, Suvisaari J, Saarni SI, Kuoppasalmi K, Isometsä
E, Pirkola S, et al. Lifetime prevalence of psychotic and bipolar I disorders in a general population. Arch Gen Psychiatry (2007) 64(1):19-28. doi:10.1001/archpsyc.64.1.19

213. Malaspina D, Goetz RR, Friedman JH, Kaufman CA, Faraone SV, Tsuang M, et al. Traumatic brain injury and schizophrenia in members of schizophrenia and bipolar disorder pedigrees. Am J Psychiatry (2001) 158:440-6. doi:10.1176/appi.ajp.158.3.440

214. Wilcox JH, Nasrallah HA. Childhood head trauma and psychosis. Psychiatry Res (1987) 21(4):303-6. doi:10.1016/01651781(87)90013-8

215. Fujii D, Ahmed I. Characteristics of psychotic disorder due to traumatic brain injury: an analysis of case studies in the literature. J Neuropsychiatr Clin Neurosci (2002) 14:130-40. doi:10. 1176/appi.neuropsych.14.2.130

216. Molloy C, Conroy RM, Cotter DR, Cannon M. Is traumatic brain injury a risk factor for schizophrenia: a metaanalysis of case-controlled population-based studies. Schizophr Bull (2011) 37(6):1104-10. doi:10.1093/schbul/sbr091

217. Andreasen NC. Scale for the Assessment of Positive Symptoms. Iowa City, IA: University of Iowa (1984).

218. Andreasen NC. Scale for the Assessment of Negative Symptoms. Iowa City, IA: University of Iowa (1983).

219. Ouellet MC, Savard J, Morin $\mathrm{CN}$. Insomnia following traumatic brain injury: a review. Neurorehabil Neural Repair (2004) 18(4):187-98. doi:10.1177/1545968304271405

220. Orff HJ, Ayalon L, Drummond SPA. Traumatic brain injury and sleep disturbance: a review of current research. J Head Trauma Rehabil (2009) 24(3):155-65. doi:10.1097/HTR.0b013e3181a 0b281

221. Zeitzer JM, Friedman L, O'Hara R. Insomnia in the context of traumatic brain injury. $J$ Rehabil Res Dev (2009) 46(6):827-36. doi:10.1682/JRRD.2008.08.0099

222. Hochstrasser B. Epidemiology of sleep disorders. Therapeutische Umschau (1993) 50(10):679-83.

223. Ford DE, Kamerow DB. Epidemiologic study on sleep disturbances and psychiatric disorders. An opportunity for prevention. J Am Med
Assoc (1989) 262:1479-84. doi:10.1001/jama.262.11.1479

224. Rosekind MR. The epidemiology and occurrence of insomnia. Clin Psychiatry (1992) 53:S4-6.

225. Masoodi N, Jiva TM. Sleep disturbances associated with depression. Sleep Rev (2004) 2004:17-23.

226. Fichtenberg NL, Mills SR, Mann RN, Zafonte RD, Millard AE. Factors associated with insomnia among post-acute traumatic brain injury survivors. Brain Injury (2000) 14(7):659-67. doi:10.1080/02699050050044015

227. Benca R, Lichstein KL. Sleep disorders. Second ed. In: Rush AJ, First MB, Blacker D, editors. Handbook of Psychiatric Measures. Washington, DC: American Psychiatric Press (2008). p. 649-66.

228. Buysse DJ, Reynolds CF, Monk $\mathrm{TH}$, Berman SR, Kupfer DJ. The Pittsburgh sleep quality index: a new instrument for psychiatric practice and research. Psychiatry Res (1989) 28:193-213. doi:10.1016/01651781(89)90047-4

229. Beck AT, Baruch E, Balter JM, Steer AS, Warman DM. A new instrument for measuring insight: the Beck cognitive insight scale. Schizophr Res (2004) 68:319-29. doi:10.1016/S09209964(03)00189-0

230. Backhaus J, Junghanns $\mathrm{K}$ Broocks A, Riemann D, Hohagen F. Test-retest reliability and validity of the Pittsburgh sleep quality index in primary insomnia. $J$ Psychosom Res (2002) 53(3):73740. doi:10.1016/S0022-3999(02) 00330-6

231. Carpenter JS, Andrykowski MA. Psychometric evaluation of the Pittsburgh sleep quality index. J Psychosom Res (1998) 45:5-13. doi:10.1016/S00223999(97)00298-5

232. Fichtenberg NL, Putnam SH, Mann RN, Zafonte RD, Millard AE. Insomnia screening in postacute traumatic brain injury: utility and validity of the Pittsburgh sleep quality index. Am J Phys Med Rehabil (2001) 80(5):339-45. doi:10.1097/ 00002060-200105000-00003

233. Teasdale TW, Engberg AW. Suicide after traumatic brain injury: a population study. $J$ Neurol Neurosurg Psychiatry (2001) 71(4):436-40. doi:10.1136/jnnp.71.4.436 
234. Harrison-Felix CL, Whiteneck GG, Jha A, DeVivo MJ, Hammond FM, Hart DM. Mortality over four decades after traumatic brain injury rehabilitation: a retrospective cohort study. Arch Phys Med Rehabil (2009) 90(9): 1506-13. doi:10.1016/j.apmr. 2009.03.015

235. Mainio A, Kyllönen T, Viilo K, Hakko $H$, Särkioja T, Räsänen P. Traumatic brain injury, psychiatric disorders and suicide: a population-based study of suicide victims during the years 1988-2004 in Northern Finland. Brain Injury (2007) 21(8):851-5. doi:10.1080/02699050701504265

236. Martin J, GhahramanlouHolloway M, Lou K, Tucciarone P. A comparative review of US military and civilian suicide behavior: implications for OEF/OIF suicide prevention efforts. J Mental Health Counseling (2009) 31(2):101-18.

237. Silver JM, Kramer R, Greenwald $\mathrm{S}$, Weissman M. The association between head injuries and psychiatric disorders: findings from the New Haven NIMH Epidemiological Catchment area study. Brain Injury (2001) 15:935-45. doi:10.1080/02699050110065295

238. Simpson G, Tate R. Suicidality after traumatic brain injury: demographic, injury and clinical correlates. Psychol Med (2002) 32(4):687-97. doi:10.1017/S0033291702005561

239. Anstey K, Butterworth P, Jorm AF, Christensen H, Rodgers B, Windsor TD. A population survey found an association between self-reports of traumatic brain injury and increased psychiatric symptoms. J Clin Epidemiol (2004) 57(11): 1202-9. doi:10.1016/j.jclinepi. 2003.11.011

240. Brenner LA, Ignacio RV, Blow FC. Suicide and traumatic brain injury among individuals seeking Veterans Health administration services. J Head Trauma Rehabil (2011) 26(4):257-64. doi:10.1097/HTR.0b013e31821 fdb6e

241. Martin JS. A Cluster Analysis Typology of Suicide in the United States Air Force [Dissertation]. Bethesda, MD: Uniformed Services University of the Health Sciences (2011).

242. Black SA, Gallaway MS, Bell MR, Ritchie EC. Prevalence and risk factors associated with suicides of Army soldiers, 2001-2009.
Mil Psychol (2011) 23(4):433-51. doi:10.1037/h0094766

243. World Health Organization. Suicide prevention (SUPRE). Geneva. Available from: http://www.who.int/mental health/prevention/suicide/ suicideprevent/en.index.html (2011).

244. Oquendo MA, Giner L, Harkavy Friedman J, Tardiff KJ, Leon AC, Marzuk P. Suicide risk measures. Second ed. In: Rush AJ, First MB, Blacker D, editors. Handbook of Psychiatric Measures. Washington, DC: American Psychiatric Press (2008). p. 237-48.

245. Oquendo MA, Friend JM, Halberstam B, Brodsky BS, Burke AK, Grunebaum MF, et al. Association of comorbid posttraumatic stress disorder and major depression with greater risk for suicidal behavior. Am J Psychiatry (2003) 160(3):580-2. doi:10.1176/appi.ajp.160.3.580

246. Beck AT, Schuyler D, Herman I. Development of suicidal intent scales. In: Beck AT, Resnik HD, Lettieri DJ, editors. Prediction of Suicide. Philadelphia, PA: Charles Press (1974). p. $45-53$.

247. Léon-Carrion J, Serdio-Arias ML, Cabezas FM, DominguezRoldan JM, Dominguez-Morales $\mathrm{R}$, Barroso-y-Martin JM, et al. Neurobehavioral and cognitive profile of traumatic brain injury patients at risk for depression and suicide. Brain Injury (2001) 15(2):175-81. doi:10.1080/026990501458407

248. Exner JE. The Rorschach: A Comprehensive System. Volume 1. Basic Foundations. 2nd ed. New York: John Wiley and Sons (1986).

249. Tsaousides T, Cantor JB, Gordon WA. Suicidal ideation following traumatic brain injury: prevalence rates and the correlates in adults living in the community. J Head Trauma Rehabil (2011) 26(4):265-75. doi:10.1097/HTR. ob013e3182225271

250. Dennis JP, GhahramanlouHolloway M, Cox DW, Brown GK. A guide for the assessment and treatment of suicidal patients with traumatic brain injuries. J Head Trauma Rehabil (2011) 26(4):244-56. doi:10. 1097/HTR.0b013e3182225528

251. Beck AT, Weissman A, Lester D, Trexler L. Measurement of pessimism: the hopelessness case. J Consult Clin
Psychol (1974) 42(6):861-5. doi:10.1037/h0037562

252. Beck AT, Steer RA. Beck Hopelessness Scale Manual. San Antonio, TX: Harcourt Brace (1993).

253. Simpson GK, Tate RL, Whiting DL, Cotter RE. Suicide prevention after traumatic brain injury: a randomized controlled trial of a program for the psychological treatment of helplessness. J Head Trauma Rehabil (2011) 26(4):290-300. doi:10. 1097/HTR.0b013e3182225250

254. Nekanda-Trepka CJS, Bishop S, Blackburn IM. Hopelessness and depression. Br J Clin Psychol (1983) 22:49-60. doi:10.1111/j.20448260.1983.tb00578.x

255. Beck AT, Brown G, Berchick RJ, Stewart BL, Steer RA. Relationship between hopelessness and ultimate suicide: a replication with psychiatric outpatients. NULL (2006) 4(2):291-6.

256. Keller F, Wolfersdorf M. Hopelessness and the tendency to commit suicide in the course of depressive disorder. Crisis (1993) 14:173-7.

257. Kraus JF, Morgenstern H, Fife D, Conroy C, Nourjah P. Blood alcohol tests, prevalence of involvement and outcomes following brain injury. $A m J$ Public Health (1989) 79:294-9. doi:10.2105/AJPH.79.3.294

258. Sparedo F, Gill D. Effects of prior alcohol use on head injury recovery. $J$ Head Trauma Rehabil (1989) 4:75-82. doi:10.1097/00001199198903000-00010

259. Kreutzer JS, Marwitz JH, Witol AD. Interrelationships between crime, substance abuse and aggressive behaviors among persons with traumatic brain injury. Brain Injury (1995) 9:757-68. doi:10.3109/02699059509008232

260. Hillbom M, Holm L. Contribution of traumatic head injury to neuropsychological deficits in alcoholics. J Neurol Neurosurg Psychiatry (1986) 49:1348-53. doi:10.1136/jnnp.49.12.1348

261. Cahalan D, Cisin I. American drinking practices: summary of findings from a national probability sample. I. Extent of drinking by population subgroups. $Q$ J Stud Alcohol (1968) 29:130-51.

262. Cahalan D, Cisin I. American drinking practices: summary of findings from a national probability sample. II. Measurement of massed versus spaced drinking.
Q J Stud Alcohol (1968) 29: 642-56.

263. Horner MD, Ferguson P, Selassie AW, Labbate LA, Kniele K, Corrigan JD. Patterns of alcohol use 1 year after traumatic brain injury: a population-based epidemiological study. J Int Neuropsychol Soc (2005) 11(3):322-30. doi:10.1017/S135561770505037X

264. Bombardier CH, Temkin NR, Machamer J, Dikmen SS. The natural history of drinking and alcohol-related problems after traumatic brain injury. Arch Phys Med Rehabil (2003) 84(2):185-91. doi:10.1053/apmr.2003.50002

265. Ponsford J, Whelan-Goodinson R, Bahar-Fuchs A. Alcohol and drug use following traumatic brain injury: a prospective study. Brain Injury (2007) 21(13-14):1385-92. doi:10.1080/02699050701796960

266. Koponen S, Taiminen T, Portin $\mathrm{R}$, Himanen $\mathrm{L}$, Isoniemi $\mathrm{H}$, Heinonen $\mathrm{H}$, et al. Axis I and II psychiatric disorders after traumatic brain injury: a 30 year follow-up study. Am J Psychiatry (2002) 159: 1315-21.

doi:10.1176/appi.ajp.159.8.1315

267. Reilly EL, Kelly JT, Faillace LA. Role of alcohol use and abuse in trauma. Adv Psychosom Med (1986) 16:17-30.

268. Martino S, Poling J, Rounsaville BJ. Substance use disorders measures. In: Rush AJ, First MB, Blacker D, editors. Handbook of Psychiatric Measures. Washington, DC: American Psychiatric Press (2008). p. 437-70.

269. Babor TF, Higgins-Biddle JC, Saunders JB, Monterio MG. AUDIT. The Alcohol Use Disorders Identification Test. Guidelines for Use in Primary Care. 2nd Editon ed. Geneva: World Health Organization (2001). WHO Publication Number PSA/92.4.

270. Reinert DF, Allen JP. The alcohol use disorders identification test (AUDIT): a review of recent research. Alcohol Clin Exp Res (2002) 26:272-9. doi:10.1111/j.15300277.2002.tb02534.x

271. Fleming MF, Barry KL, MacDonald R. The alcohol use disorders identification test (AUDIT) in a college sample. Int $J$ Addict (1991) 26:1173-85.

272. Hays RD, Merz JF, Nichols R. Response burden, reliability, and validity of the CAGE. 
Short MAST, and AUDIT alcohol screening measures. Behav Res Methods Instrum Comput (1995) 27:277-80. doi:10.3758/BF03204745

273. Bohn MJ, Babor TF, Kranzler HR. The alcohol use disorders identification test (AUDIT): validation of a screening instrument for use in medical settings. J Stud Alcohol (1995) 56:423-32.

274. Selzer ML. The Michigan alcoholism screening test (MAST): the quest for a new diagnostic instrument. Am J Psychiatry (1971) 127:1653-8.

275. Ewing JA. Detecting alcoholism: the CAGE questionnaire. $J \mathrm{Am}$ Med Assoc (1984) 252:1905-7. doi:10.1001/jama.252.14.1905

276. Claussen B, Aasland OG. The alcohol use disorders identification test (AUDIT) in a routine health examination of long-term unemployed. Addiction (1993) 88:363-8. doi:10.1111/j.13600443.1993.tb00823.x

277. Conigrave KM, Saunders JB, Reznik RB. Predictive capacity of the AUDIT questionnaire for alcohol-related harm. Addiction (1995) 90:1479-85. doi:10.1111/j.13600443.1995.tb02810.x

278. Ivis FJ, Adlaf EM, Rehm J. Incorporating the AUDIT into a general population telephone survey: a methodological experiment. Drug Alcohol Depend (2000) 60:97-104. doi:10.1016/S03768716(00)80012-5

279. Lennings CJ. Evaluation of the Leeds dependence questionnaire. $J$ Child Adoles Subst Abuse (1999) 8(3):73-87. doi:10.1300/J029v08n03_05

280. Daeppen J, Yersin B, Landry U, Pecoud A, Decrey H. Reliability and validity of the alcohol use disorders identification test (AUDIT) imbedded within a general health risk screening questionnaire: results of a survey in 332 primary care patients. Alcohol Clin Exp Res (2000) 24:659-65. doi:10.1111/j.15300277.2000.tb02037.x

281. Maisto SA, Conigliaro J, McNeil M, Kraemer K, Kelley ME. An empirical investigation of the factor structure of the AUDIT. Psychol Assess (2000) 12(3):346-53. doi:10.1037/10403590.12.3.346

282. Corrigan JD. Substance abuse as a mediating factor in outcome from traumatic brain injury.
Arch Phys Med Rehabil (1995) 76(4):302-9. doi:10.1016/S00039993(95)80654-7

283. Taylor LA, Kreutzer JS, Demm SR, Meade MA. Traumatic brain injury and substance abuse: a review and analysis of the literature. Neuropsychol Rehabil (2003) 12(1/2): 165-88. doi:10.1080/096020102 44000336

284. Parry-Jones BL, Vaughan FL, Cox WM. Traumatic brain injury and substance misuse: a systematic review of prevalence and outcomes research (1994-2004). Neuropsychol Rehabil (2006) 16(5):537-60. doi:10.1080/09602010500231875

285. Graham DP, Cardon AL. An update on substance use and treatment following traumatic brain injury. Ann N Y Acad Sci (2008) 1141(1):148-62. doi:10.1196/annals.1441.029

286. Skinner HA. The drug abuse screening test. Addict Behav (1982) 7(4):363-71. doi:10.1016/0306-4603(82) 90005-3

287. Gavin DR, Ross HE, Skinner HA. Diagnostic validity of the drug abuse screening test in the assessment of DSM-III drug disorders. Br J Addict (1989) 84:301-7. doi:10.1111/j.13600443.1989.tb03463.x

288. Cicerone K, Levin J, Malec J, Stuss D, Whyte J. Cognitive rehabilitation interventions for executive function: moving from bench to bedside in patients with traumatic brain injury. J Cogn Neurosci (2006) 18: 1212-22.

doi:10.1162/jocn.2006.18.7.1212

289. Malloy P, Grace J. A review of rating scales for measuring behavior changes due to frontal system damage. Cogn Behav Neurol (2005) 18:18-27. doi:10.1097/01.wnn.0000152232. 47901.88

290. Gioia GA, Isquith PK, Guy SC, Kenworthy L. Behavior rating inventory of executive function. Child Neuropsychol (2000) 6(3):235-8. doi:10.1076/chin.6.3.235.3152

291. Burgess PW, Alderman N, Evans J, Emslie H, Wilson BA. The ecological validity of tests of executive function. $J$ Int $\mathrm{Neu}$ ropsychol Soc (1998) 4:547-58. doi:10.1017/S1355617798466037

292. Kertesz A, Davidson W, Fox H. Frontal behavioral inventory: diagnostic criteria for frontal lobe dementia. Can J Neurol Sci (1997) 24:29-36.

293. Grace J, Malloy PF. Frontal Systems Behavior Scale (FrSBe): Professional Manual. Lutz, FL: Psychological Assessment Resources (2001).

294. Stout JC, Ready RE, Grace J, Malloy PF, Paulsen JS. Factor analysis of the frontal systems behavior scale (FrSBe). Assessment (2003) 10:79-85. doi:10.1177/1073191102250339

295. Barrash J, Tranel D, Anderson SW. Acquired personality disturbances associated with bilateral damage to the ventromedial prefrontal region. Dev Neuropsychol (2000) 18:355-81. doi:10.1207/S1532694205Barrash

296. Reid-Arndt SA, Nehl C, Hinkebein J. The frontal systems behaviour scale (FrSBe) as a predictor of community integration following brain injury. Brain Injury (2007) 21(13-14):1361-9. doi:10.1080/02699050701785062

297. Lane-Brown AT, Tate RL. Measuring apathy after traumatic brain injury: psychometric properties of the apathy evaluation scale and the frontal systems behavior scale. Brain Injury (2009) 23(13-14):999-1007. doi:10.3109/02699050903379347

298. Nunnally JC. Psychometric Theory. Second ed. New York, NY: McGraw Hill (1978)

299. Cortina JM. What is coefficient alpha? An examination of theory and applications. J Appl Psychol (1993) 78:98-104.

300. Holden RR, Fekken GC, Cotton DHG. Assessing psychopathology using structured test-item response latencies. Psychol Assess (1991) 3:111-8. doi:10.1037/1040-3590.3.1.111

301. Amador XF, Flaum M, Andreasen NC, Strauss DH, Yale SA, Clark $\mathrm{SC}$, et al. Awareness of illness in schizophrenia and schizoaffective and mood disorders. Arch Gen Psychiatry (1994) 51(10):826-36. doi:10.1001/ archpsyc.1994.03950100074007

302. Granholm E, McQuaid JR, McClure FS, Pedrelli P, Beck AT. A randomized controlled trial of cognitive behavioral therapy for older patients with schizophrenia: improved insight is associated with symptom change. $17^{\text {th }}$ Annual Society for Research in Psychopathology Convention. San Francisco, CA: (2002) (as cited in Beck et al. 2004).
303. Schooler JW, Ohlsson S, Brooks $\mathrm{K}$. Thoughts beyond words: when language overshadows insight. J Exp Psychol Gen (1993) 122:166-83. doi:10.1037/00963445.122.2.166

304. Mednick SA. The associative basis of the creative process. Psychol Rev (1962) 69:220-32. doi:10.1037/h0048850

305. Dominowski RL, Dallob P. Insight and problem solving. In: Sternberg RJ, Davidson JE, editors. The Nature of Insight. Cambridge, MA: MIT Press (1995). p. 33-62.

306. Schooler JW, Melcher J. The ineffability of insight. In: Smith SM, Ward TB, Finke RA, editors. The Creative Cognition Approach. Cambridge, MA: MIT Press (1995). p. 249-68.

307. Fodor EM. Subclinical inclination toward manic-depression and creative performance on the remote associates test. Pers Individ Dif (1999) 27:1273-83. doi:10.1016/S01918869(99)00076-8

308. Mikulincer M, Shetti E. Adult attachment style and cognitive reactions to positive affect: a test of mental categorization and creative problem solving Motiv Emot (2000) 24:149-74 doi:10.1023/A:1005606611412

309. Vohs KD, Heatherton TF. Self-esteem and threats to self: implications for self-construals and interpersonal perceptions. J Pers Soc Psychol (2001) 81:1103-18. doi:10.1037/00223514.81.6.1103

310. Bowden EM, Jung-Beeman M. Normative data for $144 \mathrm{com}$ pound remote associate problems. Behav Res Methods Instrum Comput (2003) 35:634-9. doi:10.3758/BF03195543

311. Kounios J, Frymaire JL, Bowden EM, Fleck JI, Subramaniam $\mathrm{K}$, Parrish TB, et al. The prepared mind. Neural activity prior to problem presentation predicts subsequent solution by sudden insight. Psychol Sci (2006) 17(10):88290. doi:10.1111/j.1467-9280. 2006.01798.x

312. Kounios J, Beeman M. The Aha! moment: the cognitive neuroscience of insight. Curr Dir Psychol Sci (2009) 18(4):210-6. doi:10.1111/j.14678721.2009.01638.x

313. Bowden EM, Jung-Beeman M. Getting the right idea: semantic activation in the 
right hemisphere may help solve insight problems. Psychol Sci (1998) 9:435-40. doi:10.1111/1467-9280.00082

314. Jung-Beeman MJ, Bowden EM. The right hemisphere maintains solution-related activation for yet-to-be-solved problems. Mem Cogn (2000) 28:1231-41. doi:10.3758/BF03211823

315. Bowden EM, Jung-Beeman M. Aha! Insight experience correlates with solution activation in the right hemisphere. Psychon Bull Rev (2003) 10(3):730-7. doi:10.3758/BF03196539

316. Epstein RS, Fullerton CS, Ursano RJ. Posttraumatic stress disorder following an air disaster: a prospective study. Am J Psychiatry (1998) 155:934-8.

317. Beckham JC, Moore SD, Feldman ME, Hertzberg MA, Kirby AC, Firbank JS. Health status, somatization and severity of posttraumatic stress disorder in Vietnam combat veterans with posttraumatic stress disorder. Am J Psychiatry (1998) 155(11):1565-9.

318. Cardenas J, Williasm K, Wilson JP. PTSD, major depressive symptoms and substance abuse following September 11, 2001 in a Midwestern university population. Int J Emerg Ment Health (2003) 5:15-28.

319. Johnson SD, North CS, Smith EM. Psychiatric disorders among victims of a courthouse shooting spree: a three-year followup study. Community Ment Health J (2002) 38:181-97. doi:10.1023/A:1015269521969

320. Galea S, Nandi A, Vlahov D. The epidemiology of post-traumatic stress disorder after disasters. Epidemiol Rev (2005) 27(1):7891. doi:10.1093/epirev/mxi003

321. D’Angiulli A, Herdman A, Stapells D, Hertzman C. Children's event-related potentials of auditory selective attention vary with their socioeconomic status. Neuropsychology (2008) 22(3):293-300. doi:10.1037/0894-4105.22.3.293

322. D’Angiulli A, Weinberg J, Grunau R, Hertzman C, Grebenkov P. Towards a cognitive science of social inequality: children's attention-related ERPs and salivary cortisol vary with their socioeconomic status. Proceedings of the 30th Cognitive Science Society Annual Meeting. Wheat Ridge, CO: Cognitive Science Society, Inc (2008). p. 211-6.
323. Hackman DA, Farah MJ. Socioeconomic status and the developing brain. Trends Cogn Sci (2008) 13(2):65-73. doi:10.5363/tits.13.65

324. Braverman PA, Cubbin C, Egerter S, Chideya S, Marchi KS, Metzler M, et al. Socioeconomic status in health research: one size does not fit all. JAMA (2005) 294:2879-88. doi:10.1001/jama.294.22.2879

325. Barratt W. The Barratt Simplified Measure of Social Status (BSMSS) measuring SES. Indiana State University (2009).

326. Hollingshead AB. Two Factor Model of Social Position. New Haven, CT: Yale University (1957)

327. Hollingshead AB. Four Factor Index of Social Status. New Haven, CT: Yale University (1975).

328. Davis J, Smith T, Hodge R, Nakao K, Treas J. Occupational Prestige Ratings from the $1989 \mathrm{Gen}$ eral Social Survey. Ann Arbor, MI: Inter-University consortium for Political and Social research (1991).

329. Nakao K, Treas J. Updating occupational prestige and socioeconomic scores: how the new measures measure up. Sociol Methodol (1994) 24:1-72. doi:10.2307/270978

330. Powers MG. Measures of socioeconomic status: an introduction. In: Powers MG, editor. Measures of Socioeconomic Status. Boulder, CO: Westview (1981). p. 1-28.

331. Rapp DL. Brain Injury Casebook: Methods for Re-Integration to Home, School and Community. Springfield, IL: Thomas (1987)

332. Tomberg T, Toomela T, Enok $\mathrm{M}$, Tikk A. Changes in coping strategies, social support, optimism and health-related quality of life following traumatic brain injury: a longitudinal study. Brain Injury (2007) 21(5):479-88. doi:10.1080/02699050701311737

333. Izaute M, Durozard C, Aldigier E, Teissedre F, Perreve A, Gerbaud L. Perceived social support and locus of control after a traumatic brain injury (TBI). Brain Injury (2008) 22(10): 758-64. doi:10.1080/02699050 802366002

334. Leach LR, Frank RG, Bouman DE, Farmer J. Family functioning social support and depression after traumatic brain injury. Brain
Injury (1994) 8(7):599-606. doi:10.3109/02699059409151012

335. Zimet GD, Dahlem NW Zimet SG, Farley GK. The Multidimensional scale of perceived social support. J Pers Assess (1988) 52:30-41. doi:10.1207/s15327752jpa5201_2

336. Derogatis LR, Lipman RS, Rickel K, Uhlenhuth EH, Covi L. The Hopkins symptom checklist (HSCL): a self-report symptom inventory. Behav Sci (1974) 19:115. doi:10.1002/bs.3830190102

337. Zimet GD, Powell SS, Farley GK, Werkman S, Berkoff KA. Psychometric characteristics of the multidimensional scale of perceived social support. $J$ Pers Assess (1990) 55:610-7. doi:10.1207/s15327752jpa5503 \&4_17

338. Cantry-Mitchell J, Zimet GD. Psychometric properties of the multidimensional scale of perceived social support in urban adolescents. Am J Community Psychol (2000) 28:391400.

339. Bullinger M, Azouvi P, Brooks N, Basso A, Christensen AL, Gobiet $\mathrm{W}$, et al. Quality of life in patients with traumatic brain injury basic issues, assessment and recommendations. Restor Neurol Neurosci (2002) 20(3-4):111-24.

340. Guilfoyle MR, Seeley HM, Corteen E, Harkin C, Richards H, Menon DK, et al. Assessing quality of life after traumatic brain injury: examination of the short form 36 health survey. J Neurotrauma (2010) 27(12):2173-81. doi:10.1089/neu.2010.1353

341. Beseoglu K, Roussaint N, Steiger H-J, Hänggi D. Quality of life and socio-professional reintegration after mild traumatic brain injury. Br J Neurosurg (2012) 27(2): 202-6. doi:10.3109/02688697. 2012.717984

342. Hall KM, Johnston MV. Outcomes evaluation in TBI rehabilitation: part II. measurement tools for a nationwide data system. Arch Phys Med Rehabil (1994) 75(Suppl):SCI10-8.

343. Hall KM, Mann N, High WM, Wright J, Kreutzer JS, Wood D. Functional measures after traumatic brain injury: ceiling effects of FIM, FIM+FAM and CIQ. J Head Trauma Rehabil (1996) 11(5):27-39. doi:10.1097/00001199 199610000-00004

344. Dahmer ER, Shilling MA, Hamilton B, Bontke C, Englander J, Kreutzer JS, et al. A model systems database for traumatic brain injury. J Head Traume Rehabil (1993) 8(2):12-25. doi:10.1097/00001199-

199308020-00004

345. Wright, J. The functional assessment measure. The Center for Outcome Assessment in Brain Injury. (2000). Bethesda, MD. Available from: http: //www.tbims.org/combi/FAM (accessed 26 December 2012).

346. Rappaport M, Hall KM, Hopkins HK, Belleza T, Cope DN. Disability rating scale for severe head traumas: coma to community. Arch Phys Med Rehabil (1982) 63:118-23.

347. von Steinbüchel N, Wilson $\mathrm{L}$, Gibbons H, Hawthrone G, Höfer S, Schmidt S, et al. Quality of life after brain injury (QOLIBRI): scale validity and correlates of quality of life. $J$ Neurotrauma (2010) 27:115765. doi:10.1089/neu.2009.1077

348. von Steinbüchel N, Wilson L, Gibbons H, Hawthrone G, Höfer S, Schmidt S, et al. Quality of life after brain injury (QOLIBRI): scale development and metric properties. J Neurotrauma (2010) 27(7): 1167-85. doi:10.1089/neu.2009. 1076

349. Truelle JL, Koskinen S, Hawthorne G, Sarajuuri J, Formisano R, von Wild K, et al. Quality of life after traumatic brain injury: the clinical use of the QOLIBRI, a novel diseasespecific instrument. Brain Injury (2010) 24(11):1272-91. doi:10. 3109/02699052.2010.506865

350. Cicerone KD. Participation as an outcome of traumatic brain injury rehabilitation. J Head Trauma Rehabil (2004) 19(6):494-501. doi:10.1097/00001199200411000-00006

351. Willer B, Rosenthal M, Kreutzer JS, Gordon WA, Rempel R. Assessment of community integration following rehabilitation for traumatic brain injury. $J$ Head Trauma Rehabil (1993) 8(2):75-87. doi:10.1097/000011 99-199308020-00009

352. Willer B, Ottenbacher KJ, Coad ML. The community integration questionnaire: a comparative examination. Am J Phys Med Rehabil (1994) 73:103-11. doi:10.1097/00002060199404000-00006

353. Dijkers M. Measuring longterm outcomes of traumatic 
brain injury: a review of community integration questionnaire studies. J Head Trauma Rehabil (1997) 12(6):74-91. doi:10.1097/00001199199712000-00007

354. Sander AM, Seel RT, Kreutzer JS, Hall KM, High WM, Rosenthal M. Agreement between persons with traumatic brain injury and their relatives regarding psychosocial outcome using the community integration questionnaire. Arch Phys Med Rehabil (1997) 78(4):353-7. doi:10.1016/S00039993(97)90225-2

355. Zhang L, Abren BC, Gonzales V, Scale G, Masel B, Ottenbacher KJ. Comparison of the community integration questionnaire, the Craig handicap assessment and reporting technique and the disability rating scale in traumatic brain injury. I Head Trauma Rehabil (2002) 17:497-509. doi:10.1097/00001199200212000-00002

356. Whiteneck GG, Charlifue SW, Gerhart KA, Overholser JD, Richardson GN. Quantifying handicap: a new measure of longterm rehabilitation outcomes. Arch Phys Med Rehabil (1992) 73:519-26.

357. Doninger NA, Heinemann AW, Bode RK, Sokol K, Corrigan JD, Moore D. Predicting community integration following traumatic brain injury with health and cognitive status issues. Rehabil Psychol (2003) 48: 67-76. doi:10.1037/00905550.48.2.67

358. Sander AM, Fuchs KL, High WM, Hall KM, Kreutzer JS, Rosenthal M. The community integration questionnaire revisited: an assessment of factor structure and validity. Arch Phys Med Rehabil (1999) 80(10):1303-8. doi:10.1016/S0003-9993(99) 90034-5

359. Nabors NA, Freymouth A. Renorming the community integration questionnaire: influence of gender. Poster Presented at the Annual Meeting of the International Neuropsychological Society. Denver, CO (2000).

360. Johnston MV, Goverover Y, Dijkers M. Community activities and individuals' satisfaction with them: quality of life in the first year after traumatic brain injury. Arch Phys Med Rehabil (2005) 86: 735-45. doi:10.1016/j.apmr. 2004.10.031
361. Whiteneck GG, Dijkers MP, Heinemann AW, Bogner JA, Bushnik T, Cicerone KD, et al. Development of the participation assessment with recombined tools for use after traumatic brain injury. Arch Phys Med Rehabil (2011) 92(4): 542-51. doi:10.1016/j.apmr. 2010.08.002

362. Brenner LA, Braden CA, Bates M, Chase T, Hancock C, Harrison-Felix C, et al. A health and wellness intervention for those with moderate to severe traumatic brain injury: a randomized controlled trial. J Head Trauma Rehabil (2012) 27(6):E57-68. doi:10. 1097/HTR.0b013e318273414c

363. Meichenbaum D. Resiliency building as a means to prevent PTSD and related adjustment problems in military personnel. In: Moore B, Penk W, editors. Treating PTSD in Military Personnel: A Clinical Handbook. New York, NY: Guilford Press (2011). p. 325-44.

364. Castro, CA. Technical Panel 13. Symposium of the Annual Meeting of the International Military Testing Association on Military Resiliency. Perspectives from an International Technical Panel. Amsterdam (2008).

365. Castro CA, Adler AB. Military mental health training: building resilience. In: Southwick SM, Litz BT, Charney D, Friedman MJ, editors. Resilience and Mental Health. Cambridge: Cambridge University Press (2011). p. 323-39.

366. Windle G, Bennett KM, Noyes J. A methodological review of resilience measurement scales. Health Qual Life Outcomes (2011) 9:8. doi:10.1186/1477-7525-9-8

367. Connor KM, and Davidson JRT. Overview: Connor-Davidson Resilience Scale. Available from: www.cd-risc.com. (2012).

368. Connor KM, Davidson JRT. Development of a new resilience scale: the Connor-Davidson resilience scale (CD-RISC). Depress Anxiety (2003) 18:76-82. doi:10.1002/da.10113

369. Baek HS, Lee KU, Joo EJ, Lee MY, Choi KS. Reliability and validity of the Korean version of the Connor-Davidson Resilience Scale (K-CD-RISC). Psychiatric Investigation (2010) 7: 109-15. doi:10.4306/pi.2010.7. 2.109
370. Notario-Pacheco B, SoleraMartinez M, Serrano-Parra $\mathrm{MD}$, Bartolome-Gutierrez R, Garcia-Campayo J, MartinezVizcaino V. Reliability and validity of the Spanish version of the 10-itemConnor-Davidson Resilience Scale (10-item CDRISC) in young adults. Health Qual Life Outcomes (2011) 9:63. doi:10.1186/1477-7525-9-63

371. Wang L, Shi Z, Zhang Y, Zhang Z. Psychometric porpoerties of the 10-item ConnorDavidson Resilience Scale in Chinese earthquake victims. Psychiatry Clin Neurosci (2010) 64:499-504. doi:10.1111/j.14401819.2010.02130.x

372. Brooks N, Campsie L, Symington C, Beattie A, McKinlay W. The five year outcome of severe blunt head injury: a relative's view. J Neurol Neurosurg Psychiatry (1986) 49(7):764-70. doi:10.1136/jnnp.49.7.764

373. Varney M, Martzke J, Roberts R. Major depression in patients with closed head injury. $\mathrm{Neu}$ ropsychology (1987) 1:7-9. doi:10.1037/h0091773

374. Schoenhuber R, Gentilini M. Anxiety and depression after mild head injury: a case control study. J Neurol Neurosurg Psychiatry (1988) 51(5):722-4. doi:10.1136/jnnp.51.5.722

375. Alexander MP. Neuropsychiatric correlates of persistent postconcussive syndrome. I Head Trauma Rehabil (1992) 7(2):609. doi:10.1097/00001199199206000-00009

376. Ettlin TM, Kischka U, Reichmann S, Radii EW, Heim S, Wengen $\mathrm{D}$, et al. Cerebral symptoms after whiplash injury of the neck: a prospective clinical and neuropsychological study of whiplash injury. J Neurol Neurosurg Psychiatry (1992) 55:943-8. doi:10.1136/jnnp.55.10.943

377. Fann JR, Katon WJ, Uomoto JM, Esselman PC. Psychiatric disorders and functional disability in out-patients with traumatic brain injuries. Am J Psychiatry (1995) 152(10):1493-9.

378. Parker RS, Rosenblum A. IQ loss and emotional dysfunctions after mild head injury incurred in a motor vehicle accident. J Clin Psychol (1996) 52:32-43. doi:10.1002/(SICI)10974679(199601)52:1<32::AIDJCLP5>3.0.CO;2-Y

379. Salazar AM, Warden DL, Schwab $\mathrm{K}$, Spector J, Braverman S,
Walter J, et al. Cognitive rehabilitation for traumatic brain injury. A randomized trial. JAMA (2000) 283(23):3075-81. doi:10.1001/jama.283.23.3075

380. Kreutzer JS, Seel RT, Gourley E. The prevalence and symptom rates of depression after traumatic brain injury: a comprehensive examination. Brain Inj (2001) 15(7):563-76. doi:10.1080/02699050116884

381. Jorge R, Robinson RG. Mood disorders following traumatic brain injury. Int Rev Psychiatry (2003) 15:317-27. doi:10. 1080/09540260310001606700

382. Seel RT, Kreutzer JS, Rosenthal M, Hammond FM, Corrigan JD, Black K. Depression after traumatic brain injury: a National Institute on disability and rehabilitation research model systems multicenter investigation. Arch Phys Med Rehabil (2003) 84(2):177-84. doi:10.1053/apmr.2003.50106

383. Rapoport MJ, McCullagh S, Streiner D, Feinstein A. The clinical significance of major depression following mild traumatic brain injury. Psychosomatics (2003) 44:31-7. doi:10.1176/appi.psy.44.1.31

384. Ashman TA, Spielman SA, Hibbard MR, Silver JM, Chandna T, Gordon WA. Psychiatric challenges in the first 6 years after traumatic brain injury: cross-sequential analyses of Axis I disorders. Arch Phys Med Rehabil (2004) 85(Supplement 2):S36-42. doi:10.1016/j.apmr.2003.08.117

385. Dikmen SS, Bombardier CH, Machamer JE, Fann JR, Temkin NR. Natural history of depression in traumatic brain injury. Arch Phys Med Rehabil (2004) 85(9):1457-64. doi:10.1016/j.apmr.2003.12.041

386. O'Donnell ML, Creamer M, Pattison P, Atkin C. Psychiatric morbidity following injury. Am J Psychiatry (2004) 161(3):507-14. doi:10.1176/appi.ajp.161.3.507

387. Rapoport MJ, McCullagh S, Shammi P, Feinstein A. Cognitive impairment associated with major depression following mild and moderate traumatic brain injury. J Neuropsychiatry Clin Neurosci (2005) 17:61-5. doi:10. 1176/appi.neuropsych.17.1.61

388. Grigsby J, Kaye K. Incidence and correlates of depersonalization following head trauma. Brain Injury (1993) 7: 
507-13. doi:10.3109/0269905 9309008178

389. Rattok J, Ross B. Cognitive rehabilitation. In: Silver JM, Yudofsky SC, Hales RE, editors. Neuropsychiatry of Traumatic Brain Injury. Washington, DC: American Psychiatric Press (1994). p. 703-29.

390. Ohry A, Rattok J, Solomon Z. Post-traumatic stress disorder in brain injury patients. Brain Injury (1996) 10(9):687-95. doi:10.1080/026990596124106

391. Max JE, Castillo CS, Robin DA, Lindgren SD, Smith WL, Sato $\mathrm{Y}$, et al. Posttraumatic stress symptomatology after childhood traumatic brain injury. J Nerv Ment Dis (1998) 186:589-96. doi:10.1097/00005053199810000-00001

392. Harvey AG, Bryant RA. Predictors of acute stress following mild traumatic brain injury. Brain Injury (1998) 12(2):147-54. doi:10.1080/026990598122773

393. Bryant RA, Marosszeky JE, Crooks J, Gurka JA. Posttraumatic stress disorder after severe traumatic brain injury. $A m$ J Psychiatry (2000) 157(4): 629-31.

doi:10.1176/appi.ajp.157.4.629

394. Mayou R, Black J, Bryant B. Unconsciousness, amnesia and psychiatric symptoms following road traffic accident injury. $\mathrm{Br}$ J Psychiatry (2000) 177:540-5. doi:10.1192/bjp.177.6.540

395. Glaesser J, Neuner F, Lütgehetmann R, Schmidt R, Elbert T. Posttraumatic stress disorder in patients with traumatic brain injury. BMC Psychiatry (2004) 4:5. doi:10.1186/1471-244X-4-5

396. Bryant RA, O’Donnell ML, Creamer M, McFarlane AC, Clark CR, Silove D. The psychiatric sequelae of traumatic injury. Am J Psychiatry (2010) 167(3):312-20. doi:10. 1176/appi.ajp.2009.09050617

397. Wall PL. Posttraumatic stress disorder and traumatic brain injury in current military populations: a critical analysis. J Am Psychiatr Nurses Assoc (2012) 18(5):278-98. doi:10.1177/1078390312460578

398. Taylor BC, Hagel EM, Carlson KF, Cifu DX, Cutting A, Bidelspach DE, et al. Prevalence and costs of co-occurring traumatic brain injury with and without psychiatric disturbance and pain among Afghanistan and Iraq war veteran VA users. Med
Care (2012) 50(4):342-6. doi:10. 1097/MLR.0b013e318245a558

399. Bryan CJ, Clemans TA, Hernandez AM, Rudd MD. Loss of consciousness, depression, posttraumatic stress disorder, and suicide risk among deployed military personnel with mild traumatic brain injury. J Head Trauma Rehabil (2013) 28(1):13-20. doi:10. 1097/HTR.0b013e31826c73cc

400. MacGregor AJ, Dougherty AL, Tang JJ, Galarneau MR. Postconcussive symptom reporting among US combat veterans with mild traumatic brain injury from Operation Iraqi Freedom. J Head Trauma Rehabil (2013) 28(1):59-67. doi:10. 1097/HTR.0b013e3182596382

401. Bazarian JJ, Donnelly K, Peterson DR, Warner GC, Zhu T, Zhong J. The relation between posttraumatic stress disorder and mild traumatic brain injury acquired during Operations Enduring Freedom and Iraqi Freedom. J Head Trauma Rehabil (2013) 28(1):1-12. doi:10. 1097/HTR.0b013e318256d3d3

402. Davidson JRT, Book SW, Colket JT, Tupler LA, Roth S, David D, et al. Assessment of a new self-rating scale for post-traumatic stress disorder. Psychol Med (1997) 27:153-60. doi:10.1017/S0033291796004229

403. Davidson JR, Tharwani HM, Connor KM. Davidson trauma scale (DTS): normative scores in the general population and effect sizes in placebo-controlled SSRI trials. Depress Anxiety (2002) 15:75-8. doi:10.1002/da.10021

404. Weiss D, Marmar C. The impact of event scale - revised. In: Wilson J, Keane T, editors. Assessing Psychological Trauma and PTSD. New York: Guildford (1997).

405. Gaynes BN, DeVeaugh-Geiss J, Weir S, Gu H, MacPherson C, Schulberg HC, et al. Feasibility and diagnostic validity of the M-3 checklist: a brief, selfrated screen for depressive, bipolar, anxiety and post-traumatic stress disorders in primary care. Ann Fam Med (2010) 8:160-9. doi:10.1370/afm.1092

406. Hammarberg M. Penn inventory for post-traumatic stress disorder: psychometric properties. Psychol Assess (1993) 4(1):67-76. doi:10.1037/1040-3590.4.1.67

407. Watson CG, Juba MP, Manifold V, Kucala T, Anderson PED. The PTSD interview: rationale, description, reliability and concurrent validity of a DSM-III technique. J Clin Psychol (1991) 47:179-88. doi:10.1002/10974679(199103)47:2<179::AIDJCLP2270470202>3.0.CO;2-P

408. Foa EB, Riggs DS, Dancu CV, Rothbaum BO. Reliability and validity of a brief instrument for assessing posttraumatic stress disorder. J Trauma Stress (1993) 6:459-73. doi:10.1002/jts.2490060405

409. Foa EB. Posttraumatic Stress Diagnostic Scale Manual. Minneapolis, MN: NCS Pearson (1995).

410. Prins A, Ouimette P, Kimerling R, Cameron RP, Hugelshofer DS, Shaw-Hegwer J, et al. The primary care PTSD screen (PC-PTSD): development and operating characteristics. Primary Care Psychiatry (2003) 9:9-14. doi:10. $1185 / 135525703125002360$ (Corrigendum 9, 151).

411. Bliese PD, Wright KM, Adler $\mathrm{AB}$, Cabrera O, Castrol CA, Hoge CW. Validating the primary care posttraumatic stress disorder screen and the posttraumatic stress disorder checklist with soldiers returning from combat. J Consult Clin Psychol (2008) 7:272-81. doi:10.1037/0022-006X.76.2.272

412. Solomon Z, Bebenishty R, Neria Y, Abramowitz M, Ginzburg K, Ohry A. Assessment of PTSD: validation of the revised PTSD inventory. Isr J Psychiatry (1993) 30:110-5.

413. Peters L, Andrews G, Cottler LB, Chatterji S, Janca A, Smeets R. The composite international diagnostic interview post-traumatic stress disorder module: preliminary data. Int $J$ Methods Psychiatr Res (1996) 6:167-74. doi:10.1002/(SICI)1234988X(199610)6:3<167::AIDMPR159>3.3.CO;2-Z

414. Cardena EC, Koopman C, Classen C, Waeide LC, Spiegel D. Psychometric properties of the Stanford acute stress reaction questionnaire. (SASRQ): a valid and reliable measure of acute stress. J Trauma Stress (2000) 13(4):719-34. doi:10.1023/A:1007822603186

415. Brewin CR, Rose S, Andrews B, Green J, Tata P, McEvedy C, et al. Brief screening instrument for posttraumatic stress disorder. $\mathrm{Br}$ J Psychiatry (2002) 181:158-62.
416. Briere J. Psychological Assessment of Adult Posttraumatic States. Washington, DC: American Psychological Press (2004).

417. Berah E. Test review: the trauma symptom inventory. Psychiatr Psychol Law (1997) 4:93-4 doi:10.1080/13218719709524901

418. van Reekum R, Bolago I, Finlayson MA, Garner S, Links PS. Psychiatric disorders after traumatic brain injury. Brain Injury (1996) 10:319-27. doi:10.1080/026990596124340

419. Deb S, Lyons I, Koutzoukis C, Ali I, McCarthy G. Rate of psychiatric illness one year after traumatic brain injury. Am J Psychiatry (1999) 156:374-8.

420. Dikmen S, McLean A, Temkin N. Neuropsychological and psychosocial consequences of minor head injury. $J$ Neurol Neurosurg Psychiatry (1986) 49: 1227-32. doi:10.1136/jnnp.49. 11.1227

421. Cohen M, Oksenberg A, Snir D, Stern MJ, Grosswasser Z. Temporally related changes of sleep complaints in traumatic brain injury patients. J Neurol Neurosurg Psychiatry (1992) 55:313-5. doi:10.1136/jnnp.55.4.313

422. Beetar JR, Guilmette TJ, Sparadeo FR. Sleep and pain complaints in symptomatic traumatic brain injury and neurologic populations. Arch Phys Med Rehabil (1996) 77(12):1298$302 . \quad$ doi:10.1016/S00039993(96)90196-3

423. Perlis ML, Artiola L, Giles DE. Sleep complaints in chronic postconcussion syndrome. Percept Mot Skills (1997) 84:595-9. doi:10.2466/pms.1997.84.2.595

424. Clinchot DM, Bogner J, Mysiw WJ, Fugate L, Corrigan J. Defining sleep disturbances after brain injury. Am J Phys Med Rehabil (1998) 77(4):291-5. doi:10.1097/00002060199807000-00006

425. Fichtenberg N, Zafonte RD, Putnam S, Mann NR, Millard AE. Insomnia in a post-acute brain injury sample. Brain Injury (2002) 16(3):197-206. doi:10.1080/02699050110103940

426. Ouellet MC, Beauleu-Bonneau S, Morin CM. Insomnia in patients with traumatic brain injury: frequency, characteristics and risk factors. J Head Trauma Rehabil (2006) 21(3):199-212. doi:10.1097/00001199200605000-00001 
427. Korinthenberg R, Schreck J, Weser J, Lehmkuhl G. Posttraumatic syndrome after minor head injury cannot be predicted by neurological investigations. Brain Dev (2004) 26:113-7. doi:10.1016/S03877604(03)00110-4

428. Parcell DL, Ponsford JL, Rajaratnam SM, Redman JR. Self-reported changes to nighttime sleep after traumatic brain injury. Arch Phys Med Rehabil (2006) 87(2):278-85. doi:10.1016/j.apmr.2005.10.024

429. Lundin A, de Bussard C, Edman G, Borg J. Symptoms and disability until three months after mild TBI. Brain Injury (2006) 20(8):799-806. doi:10.1080/02699050600744327

430. Castriotta RJ, Wilde MC, Lai JM, Atanasov S, Masel BE, Kuna ST. Prevalence and consequences of sleep disorders in traumatic brain injury. J Clin Sleep Med (2007) 3(4):349-56.

431. Makley MJ, English JB, Drubach DA, Kreuz AJ, Celnick PA, Tarwater PM. Prevalence of sleep disturbance in closed head injury patients on a rehabilitation unit. Neurorehabil Neural Repair (2008) 22(4):341-7. doi:10.1177/1545968308315598

432. Oshio A, Kaneko H, Nagamine S, Nakaya M. Construct validity of the adolescent resilience scale. Psychol Rep (2003) 93:1217-22. doi:10.2466/pr0.2003.93.3f.1217

433. Antonovsky A. The structure and properties of the sense of coherence scale. Soc Sci Med (1993) 36(6):725-33. doi:10.1016/02779536(93)90033-Z

434. Smith BW, Dalen J, Wiggins K, Tooley E, Christopher P, Bernard J. The brief resilience scale assessing the ability to bounce back. Int J Behav Med (2008) 15:194-200. doi:10.1080/10705500802222972

435. Sun J, Stewart D. Development of population-based resilience measures in the primary school setting. Health Educ (2007) 7(6):575-99. doi:10.1108/09654280710827957

436. Ungar $\mathrm{M}$, Liebenberg $\mathrm{K}$, Boothroyd R, Kwong WM, Lee TY, Leblanc J, et al. The study of youth resiliency across cultures: lessons from a pilot study of measurement development. Res Hum Dev (2008) 5(3):166-80. doi:10.1080/15427600802274019

437. Bartone PK. Test-retest reliability of the dispositional resilience scale-15, a brief hardiness scale. Psychol Rep (2007) 101:943-4. doi:10.2466/pro.101.3.943-944

438. Block J, Kremen AM. IQ and ego resiliency: conceptual and empirical connections and separateness. J Pers Soc Psychol (1996) 70:349-61. doi:10.1037/0022-3514.70.2.349

439. Klohnen EC. Conceptual analysis and measurement of the construct of ego-resiliency. $J$ Personal Soc Psychiatry (1996) 70(5):1067-79. doi:10.1037/0022-3514.70. 5.1067

440. Kobasa SC, Maddi SR, Kahn S. Hardiness and health: a prospective study. $J$ Pers Soc Psychol (1982) 42:168-77. doi:10.1037/0022-3514.42.1.168

441. Scheier MF, Carver CS. Optimism, coping and health: assessment and implications of generalized outcome expectancies. Health Psychol (1985) 4: 219-47. doi:10.1037/0278-6133. 4.3.219

442. Scheier MF, Carver CS, Bridges MW. Distinguishing optimism from neuroticism (and trait anxiety, self-mastery and self-esteem): a re-evaluation of the life orientation test. $J$ Pers Soc Psychol (1994) 67:1063-78. doi:10.1037/00223514.67.6.1063

443. Neugarten BL, Havighurst RJ, Tobin S. The measurement of life satisfaction. $J$ Gerontol (1961) 16:134-43. doi:10.1093/geronj/16.2.134

444. Cohen S, Williamson G. Perceived stress in a probability sample of the United States. In: Spacapan S, Oskamp S, editors. The Social Psychology of Health. The Claremont Symposium on Applied Social Psychology. Newbury Park, CA: Sage (1988). p. 31-67.

445. Windle G, Markland DA, Woods B. Examination of a theoretical model of psychological resilience in older age. Aging Mental health (2008) 12(3): 285-92. doi:10.1080/136078608 02120763

446. Hurtes KP, Allen LR. Measuring resiliency in youth: the resiliency attitudes and skills profile. Ther Recreation J (2001) 35(4): $333-47$.

447. Wagnild GM, Young HM. Development and psychometric evaluation of the resilience scale. $J$ Nurs Meas (1993) 1(2):165-78.
448. Friborg O, Hjemdal O, Rosenvinge $\mathrm{JH}$, Marinussen M. A new rating scale of adult resilience: what are the central protective resources behind healthy adjustment? Int J Methods Psychiatr Res (2003) 12:65-76. doi:10.1002/mpr.143

449. Friborg O, Barlaug D, Martinussen $\mathrm{M}$, Rosenvinge $\mathrm{JH}$, Hjemdal O. Resilience in relation to personality and intelligence. Int $J$ Methods Psychiatr Res (2005) 14(1):29-42. doi:10.1002/mpr.15

450. Rosenberg M. Society and the Adolescent Self-Image. Princeton, NJ: Princeton University Press (1965).

451. Schutte NS, Malouff JM, Hall LE, Haggerty DJ, Cooper JT, Golden CJ, et al. Development and validation of a measure of emotional intelligence. Pers Individ Dif (1998) 25:167-77. doi:10.1016/S01918869(98)00001-4

452. Connor KM, Vaishnavi S, Davidson JRT, Sheehan DV, Sheehan KH. Perceived stress in anxiety disorders and the general population: a study of the Sheehan stress vulnerability scale. Psychiatry Res (2007) 151(3): 249-54. doi:10.1016/j.psychres. 2006.11.008

453. Ryff CD. Psychological well-being in adult life. Curr Dir Psychol Sci (1995) 4:99-104. doi:10.1111/14678721.ep10772395

454. Donnon T, Hammond W, Charles G. Youth resiliency: assessing students' capacity for success at school. Teach Learn (2003) 1(2):23-8.

455. Donnon T, Hammond W. A psychometric assessment of the self reported youth resiliency assessing developmental strengths questionnaire. Psychol Rep (2007) 100:963-78. doi:10.2466/pr0.100.3.963-978

456. Beck AT, Weissman A, Lester D, Trexler L. Measurement of pessimism: the hopelessness case. J Cons Clin Psychol (1974b) 42(6):861-5.

457. Beck AT, Steer RA. Manual for beck hopelessness scale. San Antonio, TX: Psychological Corporation (1988).

458. Beck AT, Epstein N, Brown G, Steer RA. An inventory for measuring clinical anxiety: psychometric properties. J Consult Clin Psychol (1988) 56:
893-7. doi:10.1037/0022-006X. 56.6.893

459. Beck SL, Schwartz AL, Dudley W, Barsevick A. Psychometric evaluation of the Pittsburgh sleep quality index in cancer patients. J Pain Symptom Manage (2004) 27:140-8. doi:10. 1016/j.jpainsymman.2003.12.002

460. Crawford JR, Allan KM. Estimating premorbid IQ with demographic variables: regression equation derived from a UK sample. Clin Neuropsychol (1997) 11:192-7. doi:10.1080/13854049708407050

461. Hamilton MA. A rating scale for depression. J Neurol Neurosurg Psychiatry (1960) 23:56-62. doi:10.1136/jnnp.23.1.56

462. Harvey AG, Bryant RA. Acute stress disorder following mild traumatic brain injury. $J$ Nerv Ment Dis (1998) 186:333-7. doi:10.1097/00005053199806000-00002

463. Jorge RE, Robinson RG, Arndt SV, Starkstein SE, Forrester AW, Geisler F. Depression following traumatic brain injury: a 1 year longitudinal study. J Affect Disord (1993) 27:233-43. doi:10.1016/01650327(93)90047-N

Conflict of Interest Statement: The authors declare that the research was conducted in the absence of any commercial or financial relationships that could be construed as a potential conflict of interest.

Received: 07 May 2013; accepted: 26 June 2013; published online: 22 July 2013. Citation: Rapp PE, Rosenberg BM, Keyser DO, Nathan D, Toruno KM, Cellucci CJ, Albano AM, Wylie SA, Gibson D, Gilpin AMK and Bashore TR (2013) Patient characterization protocols for psychophysiological studies of traumatic brain injury and post-TBI psychiatric disorders. Front. Neurol. 4:91. doi: 10.3389/fneur.2013.00091

This article was submitted to Frontiers in Neurotrauma, a specialty of Frontiers in Neurology.

Copyright (0) 2013 Rapp, Rosenberg, Keyser, Nathan, Toruno, Cellucci, Albano, Wylie, Gibson, Gilpin and Bashore. This is an open-access article distributed under the terms of the Creative Commons Attribution License, which permits use, distribution and reproduction in other forums, provided the original authors and source are credited and subject to any copyright notices concerning any third-party graphics etc. 